\title{
Examination of the expression of the heat shock protein gene, hsp110, in Xenopus laevis cultured cells and embryos
}

\author{
by \\ Julie Gauley \\ A thesis \\ presented to the University of Waterloo \\ in fulfillment of the \\ thesis requirement for the degree of \\ Doctor of Philosophy \\ in \\ Biology
}

Waterloo, Ontario, Canada, 2008

(C) Julie Gauley 2008 


\section{AUTHOR'S DECLARATION}

I hereby declare that I am the sole author of this thesis. This is a true copy of the thesis, including any required final revisions, as accepted by my examiners.

I understand that my thesis may be made electronically available to the public. 


\begin{abstract}
Prokaryotic and eukaryotic organisms respond to various stressors with the production of heat shock proteins (HSPs). HSP110 is a large molecular mass HSP that is constitutively expressed in most adult mammalian tissues. In the present study, we have examined for the first time the expression of the hsp110 gene in Xenopus laevis cultured cells and embryos. The Xenopus hsp110 cDNA encodes an 854 amino acid protein, which shares 74\% identity with mice and humans. In Xenopus A6 kidney epithelial cells hsp 110 mRNA was detected constitutively and was heat inducible. Enhanced $h s p 110$ mRNA levels were detected within $1 \mathrm{~h}$, and remained elevated for at least $6 \mathrm{~h}$. A similar accumulation of $h s p 70$ mRNA was observed, but only in response to stress. Treatment of A6 cells with sodium arsenite and cadmium chloride also induced $h s p 110$ and $h s p 70$ mRNA accumulation. However, while ethanol treatment resulted in the accumulation of $h s p 70$ mRNA no effect was seen for $h s p 110$. Similarly, HSP110 and HSP70 protein increased after a $2 \mathrm{~h}$ heat shock and $12 \mathrm{~h}$ sodium arsenite treatment. The elevation in HSP110 and HSP70 protein in response to heat was detectable for up to 6 h. Recent studies with mice suggest an important role for HSP110 during development. Analysis of Xenopus embryos revealed that $h s p 110$ mRNA was present in unfertilized eggs, indicating that it is a maternal mRNA, unlike the $h s p 70$ message which was only detectable in response to heat shock. Heat shock-induced $h s p 110$ mRNA accumulation was developmentally regulated, similar to $h s p 70$, since it was not detectable until after the midblastula stage of development. Enhanced hsp110 mRNA accumulation was evident with heat shock at the blastula stage, and levels continued to increase reaching a maximum at the late tailbud stage. Message for the small heat shock protein, $h s p 27$, was not detectable until the early tailbud stage, indicating that this $h s p$ was not present maternally and was developmentally regulated. In situ hybridization analysis revealed that hsp $110 \mathrm{mRNA}$ was present in control embryos in the lens placode, spinal cord and somites, but increased upon heat shock in the anterior and posterior region, the lens placode, as well as in the somites and spinal cord. A similar
\end{abstract}


distribution was observed for the hsp27 message, although it was not detectable until the early tailbud stage in control or heat-shocked embryos. The intracellular localization of HSP110 protein in response to stress was also investigated. HSP110 was detected predominantly in the cytoplasm in either a diffuse pattern or in long spindle-shaped fibres. Additionally, HSP110 was present in the nucleus. In heat shocked Xenopus A6 cells, HSP110 localized in distinct patterns surrounding the nucleus and was enhanced in the nucleus after prolonged heat stress. Sodium arsenite-treated cells displayed a similar pattern in which HSP110 localized on opposite ends of the nucleus. In contrast, in response to stress HSP30 was homogeneously distributed in the cytoplasm, moving into the nucleus only upon intense stress. This study presents, for the first time, a characterization of HSP110 in Xenopus laevis, adding to the growing knowledge of HSPs in this important model organism. 


\section{Acknowledgements}

As can be imagined, a great many people have contributed in their own way to the ultimate completion of this thesis. I most certainly did not accomplish this entirely on my own. I have several people to thank, too many to list here, but I will of course mention a few.

First, I must thank my advisor, Dr. John Heikkila. A doctorate is a very long road to travel, and I often required his help with navigation. John has been incredibly supportive every step of the way. He has a keen talent for developing confident and independent scientists. His direction was subtle, his style his own, and his support unwavering. John has been a wonderful supervisor and I take away some great experiences from his lab. Second, I must thank my committee. I am very lucky to have had the opportunity to work with such a wonderful group of scientists, with whom I have thoroughly enjoyed interacting over the years.

Third, I must thank Heikkila lab survivors, past and present. With no word of a lie, I have established my closest friendships during my time here at the University of Waterloo, and I have made some of the best friends of my life in the lab. Angelo Kaldis (HEY!) and Daniel Ovakim (Seealll!!) - seriously, who could ask for better friends? Anne Mulligan Tuttle, Amanda Hamilton, and Laurie Manwell - those girls helped me through some of the toughest years, what a crew we were! I have learned so much from all of them, about how to be a good scientist, how to be a good person and how to be a good friend. And who could forget the 'J' lab? Ahhh, John's lab of Julie, Janine, Jessica, and Jordan - good times! I have been so lucky to have such awesome labmates - for real! 
Who could forget all of the other wonderful characters I met along the way. Mark Lampi, Steve Wiseman and Jeff Semple - we spent many a year at UW together (some might say too many...), but the years pass surprisingly quickly when you have such fantastic friends to spend them with. The 'energetic' Jan Thomas - a PhD and full-time job with energy to spare, she is truly a wonder! And who could forget Daniel Picard and Stewart Boden, two of my favorite peeps ever, nothing but trouble those two! Julie and Matt Scorah, two of my closest friends, wonderful people with an impressive tolerance for venting (and fondue).

Not surprisingly, I have saved the best for last; my family. My parents have been unbelievably supportive and understanding through the duration of my graduate studies. I always knew I could go home and be taken care of, pampered, and loved, any time I needed it. A better family there could not be. And last, but totally not least, my husband, Luke Coleman. We were lucky (or unlucky) enough to endure our PhD's together. Luke is a brilliant academic with impressive enthusiasm for his research, which I find absolutely admirable. He has believed in me when I thought I could not continue; he somehow sees things in me that I can not. He gives me the strength and confidence and motivation to want to be a better scientist, and a better person.

I am very lucky to leave the University of Waterloo as a better person than when I arrived. I have only to thank all of the wonderful people that I have encountered along the way. I take with me very fond memories, and many wonderful friends. 


\section{Table of Contents}

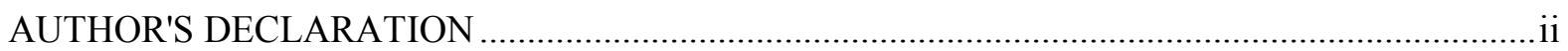

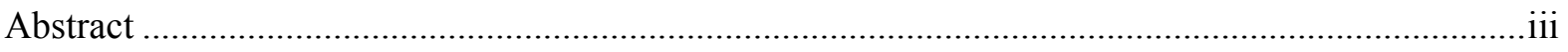

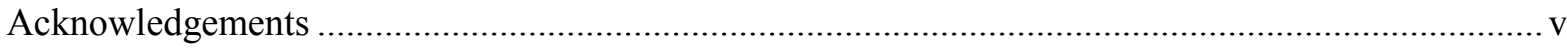

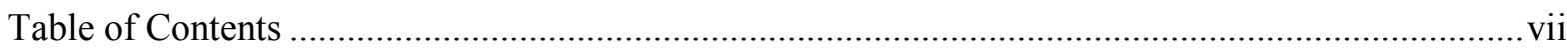

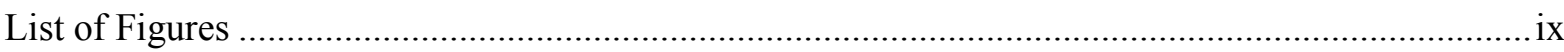

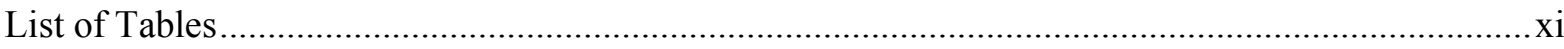

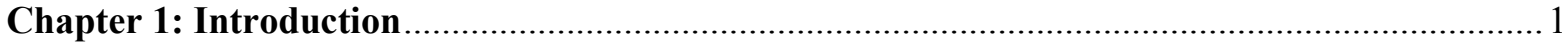

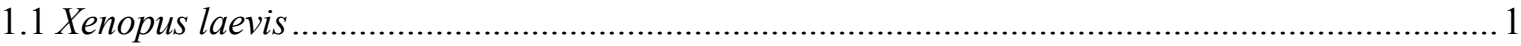

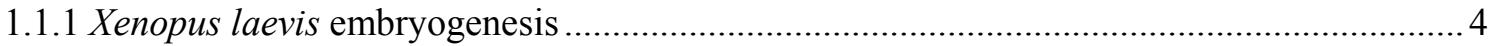

1.1.2 Xenopus laevis gene expression during embryogenesis .................................................. 8

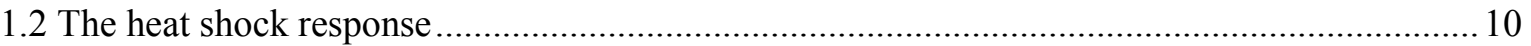

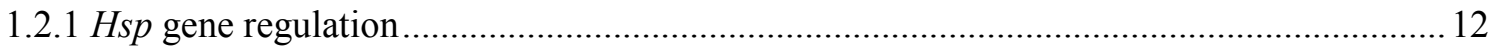

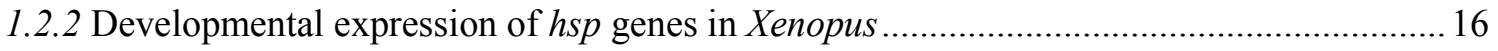

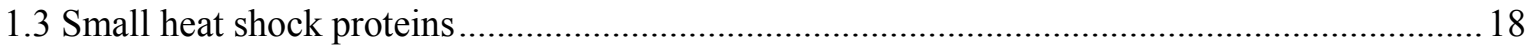

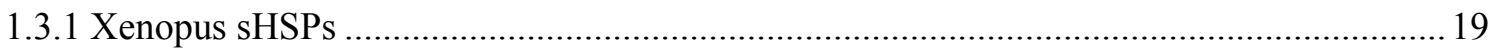

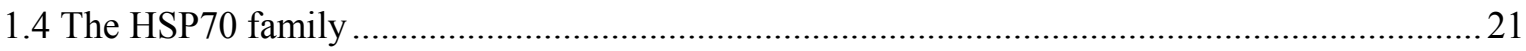

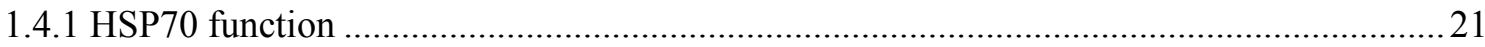

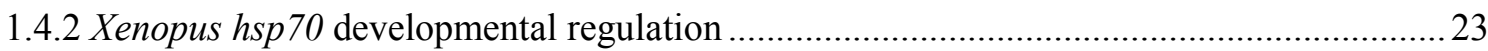

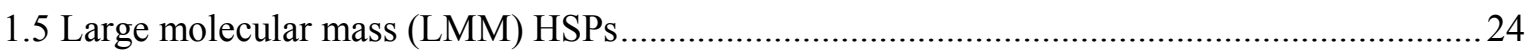

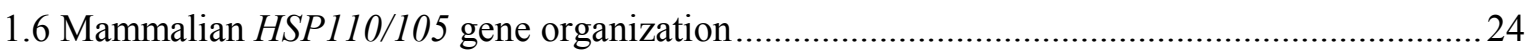

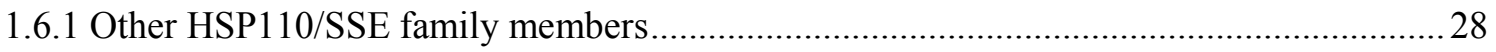

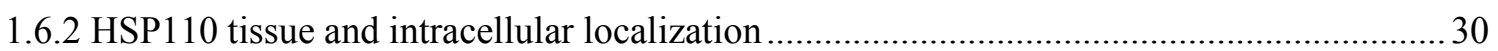

1.6.3 HSP110/105 developmental regulation and involvement in apoptosis .............................. 32

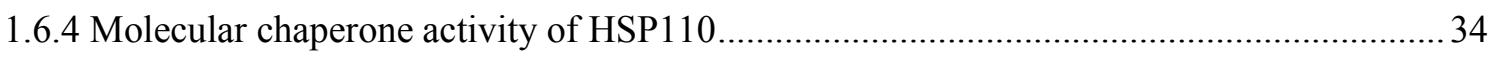

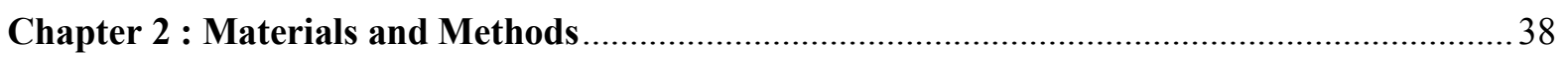

2.1 Maintenance of Xenopus laevis A6 cells and embryos ...................................................... 38

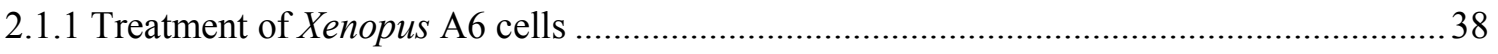

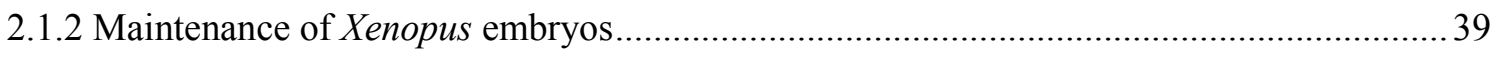

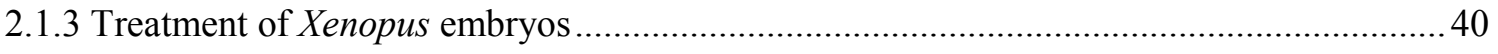

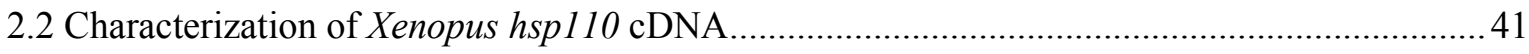

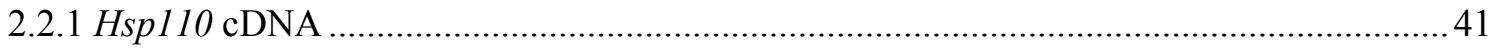

vii 


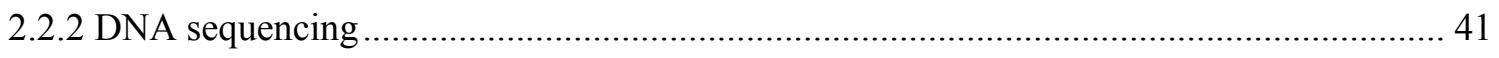

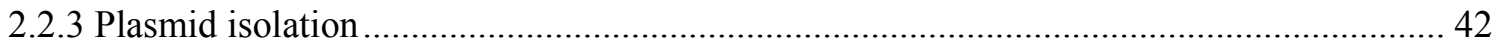

2.2.4 Rapid amplification of cDNA ends (RACE)-polymerase chain reaction (PCR) ................ 44

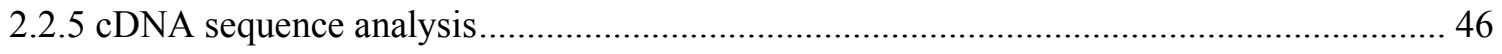

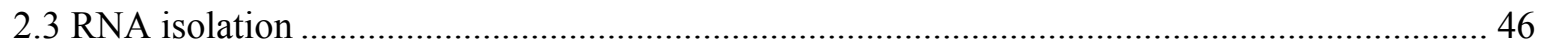

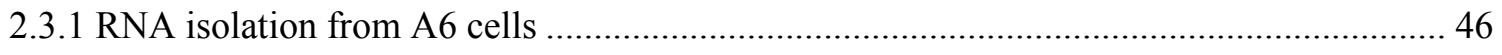

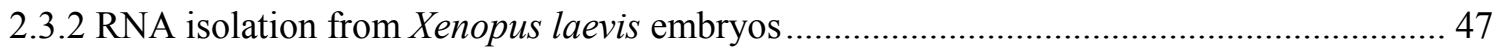

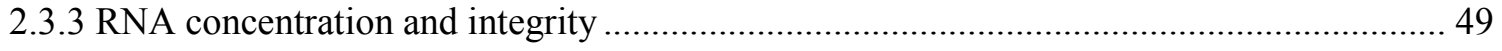

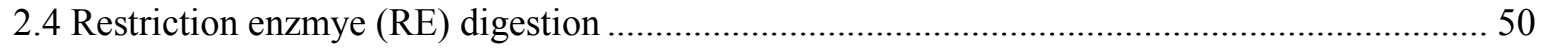

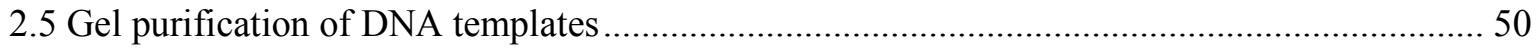

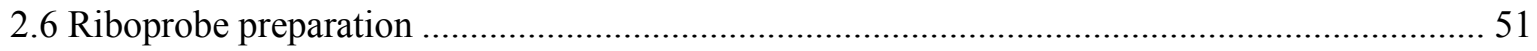

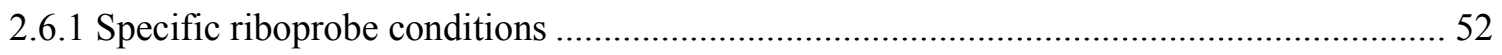

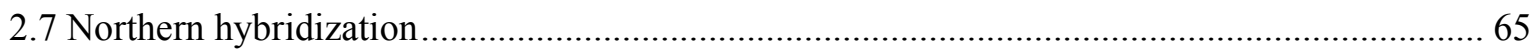

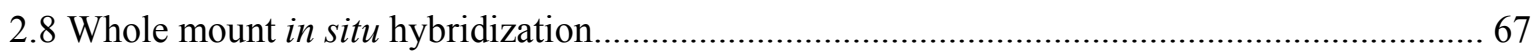

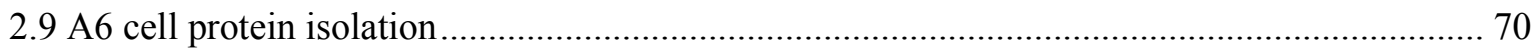

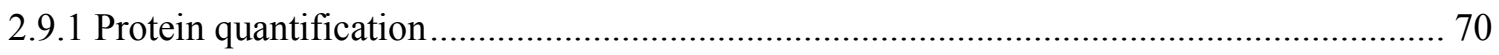

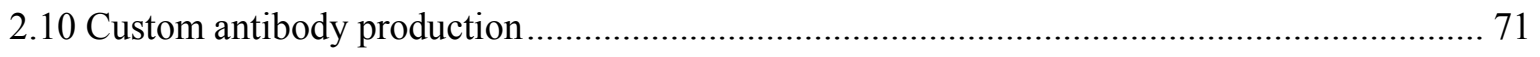

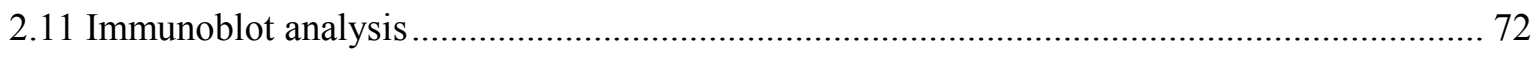

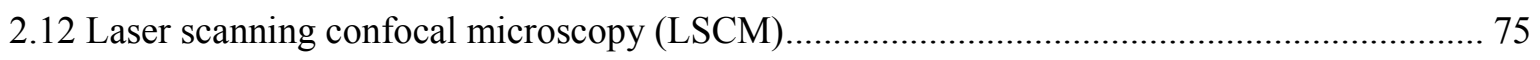

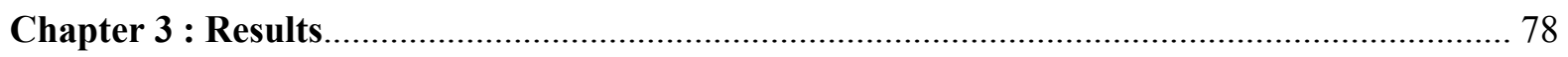

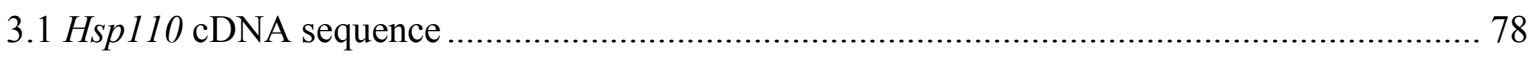

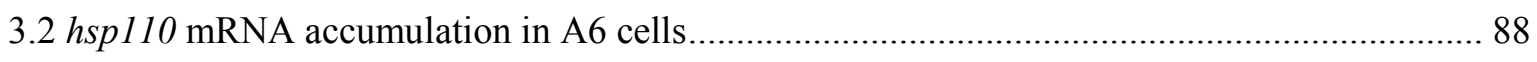

3.3 Hsp1 10 mRNA accumulation in Xenopus embryos.......................................................... 100

3.4 Production of anti-Xenopus HSP70 and HSP110 custom polyclonal antibodies.................... 110

3.5 HSP110 protein accumulation in Xenopus A6 cells .......................................................... 115

3.6 Intracellular accumulation of HSP110 and HSP30 in Xenopus A6 cells .............................. 127

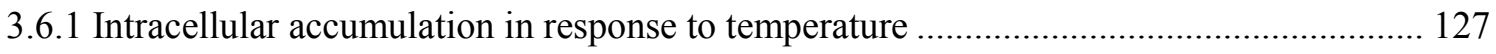

3.6.2 Intracellular accumulation in response to sodium arsenite ......................................... 132

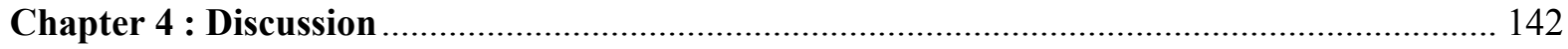

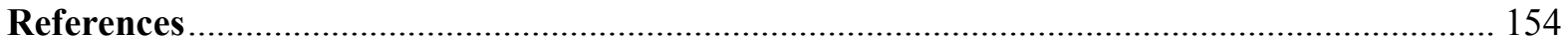




\section{List of Figures}

Figure 1. An overview of the early developmental stages of Xenopus laevis. ..................................... 6

Figure 2. Current model for regulation of $h s p$ gene transcription by HSF1 ..................................... 13

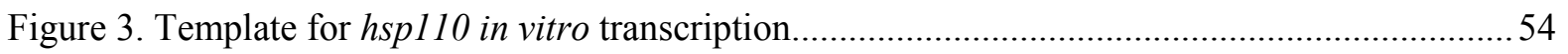

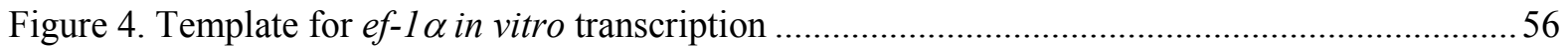

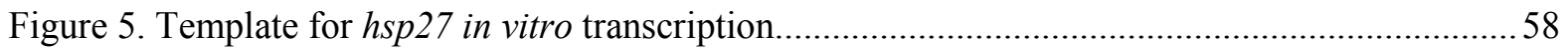

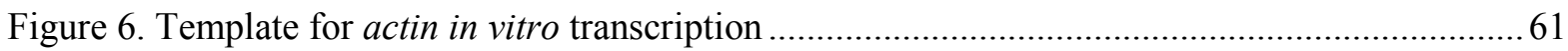

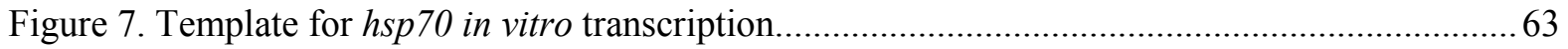

Figure 8. Nucleotide sequence and predicted amino acid sequence of the complete Xenopus laevis

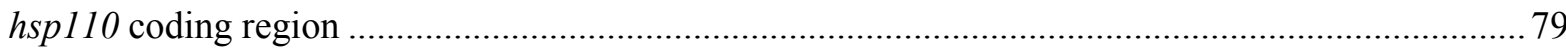

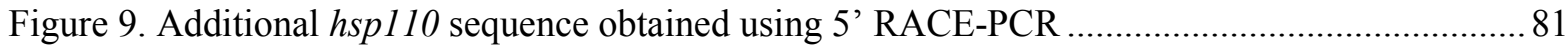

Figure 10. Amino acid sequence comparison of Xenopus laevis HSP110 predicted amino acid

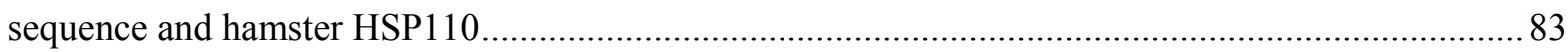

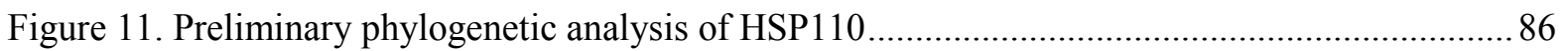

Figure 12. The effect of temperature on $h s p 110$ and $h s p 70$ mRNA accumulation in A6 cells............ 89

Figure 13. The temporal pattern of hsp110, hsp70 and actin mRNA accumulation in A6 cells subjected to continuous heat shock

Figure 14. The temporal pattern of hsp110, hsp70 and actin mRNA accumulation in A6 cells subjected to continuous heat shock

Figure 15. The effect of selected non-heat shock stressors on $h s p 110$ and $h s p 70$ mRNA accumulation

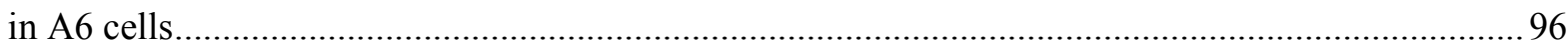

Figure 16. The effect of sodium arsenite on hsp 110, hsp70 and actin mRNA accumulation in A6 cells .98

Figure 17. hsp110 mRNA is present as a maternal message ......................................................... 101

Figure 18. hsp mRNA accumulation during early development .................................................... 103

Figure 19. Pattern of hsp110 mRNA accumulation during development ........................................ 106

Figure 20. Spatial pattern of $h s p 70$ mRNA accumulation during development............................... 108

Figure 21. Spatial pattern of hsp27 mRNA accumulation during development............................... 111

Figure 22. HSP110 protein accumulation in A6 cells measured with a commercially available antibody

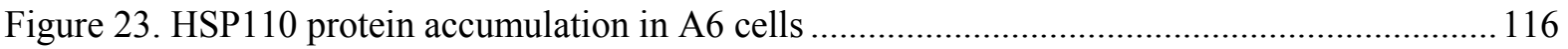

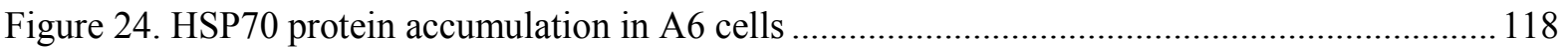


Figure 25. Protein accumulation in response to elevated temperature in A6 cells

Figure 26. Temporal response of heat shock proteins to elevated temperatures in A6 cells

Figure 27. Protein accumulation in response to selected sodium arsenite concentrations in A6 cells 125 Figure 28. Cellular localization of HSP110 and HSP30 proteins in A6 cells in response to elevated temperatures

Figure 29. Cellular localization of HSP110 and HSP30 protein in A6 cells in response to extended temperature elevation at $33^{\circ} \mathrm{C}$

Figure 30. Cellular localization of HSP110 and HSP30 protein in A6 cells in response to extended temperature elevation at $35^{\circ} \mathrm{C}$

Figure 31. Cellular localization of HSP110 and HSP30 proteins in A6 cells in response to sodium arsenite

Figure 32. Cellular localization of HSP110 protein in A6 cells in response to extended sodium arsenite exposure at $10 \mu \mathrm{M}$

Figure 33. Cellular localization of HSP110 protein in A6 cells in response to extended sodium arsenite exposure at $50 \mu \mathrm{M}$ 


\section{List of Tables}

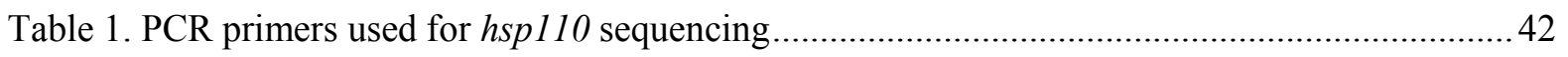

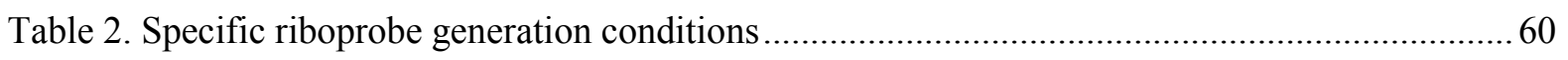

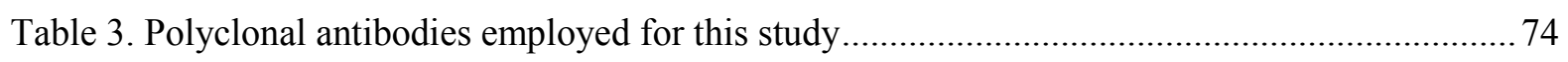

Table 4. Comparison of the amino acid sequence of Xenopus HSP110 with members of the

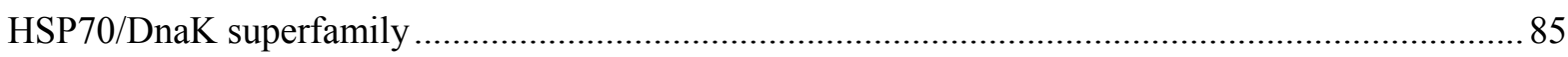





\section{Chapter 1: Introduction}

The biochemical processes that sustain higher organisms are, in general, temperature dependent (Katschinski, 2004). Responses to temperature variation are diverse; ranging from behavioural to molecular modifications. One mechanism used by the cell to maintain homeostasis, when faced with the devastating effects of stress, is the heat shock response. The heat shock response is a transient response which is triggered by a variety of stressful stimuli, ultimately providing protection for vital cellular proteins against damage inflicted by stress (Katschinski, 2004). Specifically, organisms respond to temperature stress with the rapid induction of heat shock protein (HSP) synthesis (Lindquist and Craig, 1988). The HSPs

are highly conserved, existing in almost all organisms. Furthermore, it has been suggested that the heat shock response is the most highly conserved genetic system known (Lindquist and Craig, 1988). However, while several aspects of the heat shock response are universal, certain features may vary between organisms. Briefly, HSPs function to protect cellular proteins against irreversible damage, such as aggregation and denaturation induced by stress. Upon return to normal conditions, denatured proteins are refolded to their native state by members of the HSP superfamily or degraded. The focus of this thesis will be one HSP in particular, HSP110, and its involvement in the heat shock response of Xenopus laevis.

\subsection{Xenopus laevis}

Xenopus laevis laevis (Daudin) is one of the most widely used non-mammalian laboratory research animals. Xenopus has long been a useful amphibian model organism for development, and its cell and molecular biology have also been extensively examined. There 
are 7 species within the Xenopus genus, and 7 subspecies of Xenopus laevis. The South African clawed frog is indigenous to temperate Southern and Western Africa. These animals are entirely aquatic, spending little if any time on land (Deuchar, 1975). Xenopus generally prefer stagnant pools of water and gulp air for respiration. In such an environment, prone to drastic temperature changes, Xenopus would be exposed to a broad temperature range, rendering Xenopus an interesting organism for heat shock research. In fact, the majority of heat shock research in amphibians has involved Xenopus, and as such the cell and molecular nature of its heat shock response has been well-characterized.

Xenopus laevis is a common model organism for early vertebrate development. Several features render Xenopus useful for this purpose; ease of laboratory maintenance, the production of a very large number of eggs, large egg size, the ability to induce egg production repeatedly, rapid development of embryos, external fertilization (enabling in vitro fertilization), embryo growth at room temperature, and also the availability of an extensive amount of literature (Deuchar, 1975; Sive et al., 2000). The ability to stimulate egg induction hormonally, and fertilize eggs in vitro, provides a great deal of control to the researcher, making Xenopus a convenient model organism. The large egg size yields a copious amount of protein and nucleic acids for analysis, allows visual observation of developmental progression, and facilitates microinjection. In addition, the wealth of literature available regarding Xenopus embryogenesis provides researchers with a solid framework upon which to build. Although Xenopus laevis are tetraploid organisms, they have served very well as model amphibian organisms in both cellular and genetic studies (Graf and Kobel, 1991). 
Several important discoveries in cellular and molecular biology have been made using the Xenopus laevis model system. For example, maturation promoting factor, was discovered by Masui and Markert (1971), using Xenopus laevis oocytes. This cytoplasmic factor was discovered to direct the induction of meiosis following hormone exposure. Ultimately, this initial finding in Xenopus facilitated the understanding of the overall eukaryotic cell cycle apparatus. Another Xenopus contribution was the discovery of the Spemann organizer by Spemann and Mangold, significantly increasing our knowledge of the control of vertebrate development (Gilbert, 1994). The concept of nuclear transfer was popularized with Xenopus embryos, and in specifically, this pioneering work demonstrated that transfer of the dorsal organizer region resulted in ectopic neural induction. In addition, the work of Gurdon using Xenopus has made substantial contribution to the literature (Gilbert, 1994). For example, research on the direction of development by differentiated nuclei, as well as the use of Xenopus oocytes to express exogenous proteins have led to many other discoveries. In summary, many very important milestone experiments have utilized the model organism Xenopus laevis and they remain equally important today.

Finally, Xenopus continuous cell lines are useful tools for in vitro molecular analyses. While not as popular as mammalian cell lines, several Xenopus cell lines have been established: A6, B3.2, KR, XF, XL2, XL110, XL-177 and XTC-2 (Smith and Tata, 1991), among several others. The most popular Xenopus cell line used today is the A6 somatic cell line, which was used in this study. This cell line was initiated in 1965 (Rafferty), by a primary culture derived from normal adult male kidney cells. 


\subsubsection{Xenopus laevis embryogenesis}

Xenopus males and females are sexually mature by 10 to 12 months of age, at which point females produce oocytes capable of being fertilized. In the laboratory Xenopus females can produce eggs for fertilization approximately every 3 months, but they naturally mate in the spring. The numerous oocytes present in the ovaries of an adult female are at varying stages of maturity, since Xenopus oogenesis is asynchronous. Eggs must first be released from the ovary to prepare the vitelline membrane for sperm penetration. During oocyte maturation, precursors of RNA, DNA and protein, enzymes, energy stores, tRNA, mRNA and other factors accumulate (Gilbert, 1994). Together, these components allow the egg to survive initial developmental stages, during which the embryonic genome remains quiescent.

Early development of Xenopus is initiated and directed by the egg. Prior to fertilization eggs display an animal-vegetal polarity, whereby the pigmented animal half is darker than the unpigmented vegetal half (Keller, 1991). Fertilization allows the less dense pigmented half to move to the top of the embryo, and the cortex rotates, establishing the dorsal axis opposite the sperm entry point (stage 1; Figure 1). The first embryonic cleavage is initiated approximately 100 minutes after fertilization (stage 2), and rapid, synchronous cleavage continues throughout early development. To achieve such rapid cell division, the cell cycle is shortened to allow only DNA synthesis and mitosis (Newport and Kirchner, 1982a). Any protein produced during this time is translated from maternally inherited mRNA. It is not until stage 8.5 , the midblastula transition (MBT) that transcription can occur in the newly activated embryonic genome. At this point in development, the cell cycle lengthens, cells 
acquire motility and cell division becomes asynchronous (Brown and Littna, 1964; Newport and Kirchner, 1982b).

Following MBT, the embryos proceed to blastula (stage 9), at which point the blastocoel forms, and the embryo prepares for gastrulation. In blastula embryos, the primary germ layers of ectoderm, mesoderm and endoderm form, which will eventually give rise to all organs and tissues (Nieuwkoop and Faber, 1994). The initiation of gastrulation (stage 10) occurs at the dorsal marginal zone, triggering a complex program forming the basic embryo body plan. Extensive cellular rearrangement within the embryo accompanies the gastrula stage, shifting endoderm inside, and resulting in the formation of the archenteron, or primitive gut. The ectoderm remains on the surface, and the mesoderm lies between. Interaction between the mesoderm and overlaying ectoderm triggers organogenesis. Ultimately, the mesoderm gives rise to muscle, heart, bone, cartilage and the urogenital system. Endoderm becomes the digestive and respiratory lining. Ectoderm forms the brain, spinal cord, neural crest cells and skin (Keller, 1991). 
Figure 1. An overview of the early developmental stages of Xenopus laevis. (Modified from Nieuwkoop and Faber, 1994). 


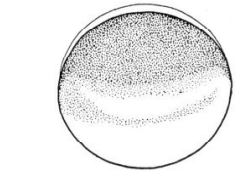

Fertilized Egg

(stage 1)

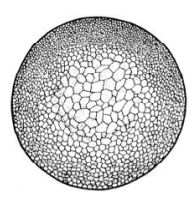

Blastula

(stage 9)

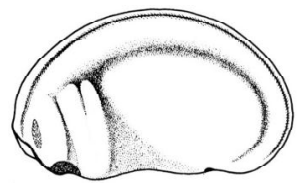

Early tailbud

(stage 23)

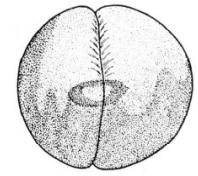

Early Cleavage

(stage 2)

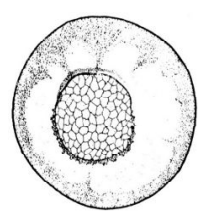

Gastrula

(stage 11)

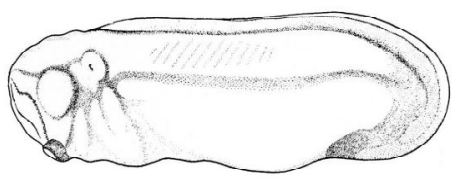

Mid tailbud

(stage 27)

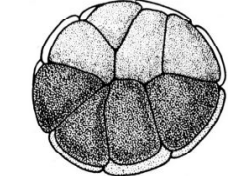

Late Cleavage (stage 5)

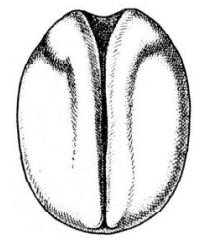

Neurula

(stage 17)

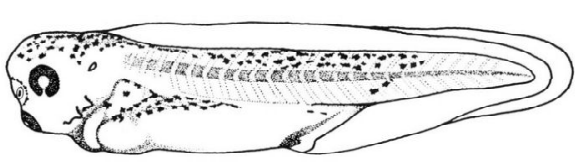

Late tailbud

(stage 35) 
Soon after gastrulation, neurulation (stage 19) occurs, at which point the chordamesoderm underlying the ectoderm signals neural tube formation and closure from the neural plate. The neural plate edges form the neural folds and neural crest (Baker and Bronner-Fraser, 1997). The ectodermally derived neural plate becomes more dominant on the dorsal side, where neural crest cells originate, and eventually give rise to neurons and glial cells of the nervous system (Nieuwkoop and Faber, 1994). Toward the end of the neurula stage, somites form from remaining mesoderm. The somites, located laterally on each side of the notochord, are distinct, but transient structures giving rise to vertebrae, ribs, dermis and skeletal muscle (Gilbert, 1994).

Once past the neurula stage, the embryos progress through the tailbud stages (early - stage 23, mid - stage 27, and late - stage 35). During this time the organs form, and commence function. The first of which is the cement gland, a temporary mucus-producing organ, which facilitates attachment of developing embryos to solid supports. During the tailbud stages the embryos hatch, becoming mobile, and quickly become full-fledged free-living tadpoles (stages 42-50).

\subsubsection{Xenopus laevis gene expression during embryogenesis}

Embryogenesis is a critical process for all organisms, comprising a tightly regulated series of events which are regulated by proteins. During Xenopus embryogenesis, there occurs a significant and abrupt transition in macromolecular synthesis, with no apparent accompanying morphological consequence, which is known as the midblastula transition. MBT is characterized by the initiation of transcription by RNA polymerase, a decline in the 
rate of the cell cycle, asynchronous divisions, and cell motility (Newport and Kirschner, 1982a). These events activate the previously quiescent zygotic genome. Until MBT, the embryo is sustained and controlled by components present in the oocyte prior to fertilization. This developmental event is not unique to Xenopus as it has been described in Drosophila (Edgar et al., 1986), zebrafish and mouse (Davidson, 1986), albeit with different timing.

The mechanism responsible for the repression of transcription of embryonic genes in preMBT embryos remains unclear, although several theories have been proposed. Newport and Kirschner (1982a) suggested that a general maternal repressor, eventually titrated out with regards to increasing levels of DNA, was responsible. Alternatively, experimental manipulation demonstrated that transcription was possible in pre-MBT embryos, and a hypothesis involving a repressively high mitotic rate was proposed (Kimelman et al., 1987; Shiokawa, 1991). A later theory put forward by Hair et al. (1998) proposed that the unusually high ratio of histones to DNA in the early embryo was inhibitory, ultimately competing with basal transcription machinery. The concentration of factors originally present in the oocyte does not vary during embryogenesis, however, the stoichiometric ratio of DNA to nuclear protein does change, from 1:1 to 30 000:1 by the gastrula stage. Taken together, the authors suggested that chromatin structure, DNA accessibility and transcription complex-chromatin interactions are all important factors in early embryonic transcriptional regulation (Hair et al., 1998). In summary, while strong evidence for potential mechanisms governing early gene repression in the Xenopus embryo grows, it is clear that the story is not yet complete. 


\subsection{The heat shock response}

The heat shock response encompasses a number of processes including $h s p$ gene activation, accumulation of HSPs and the acquisition of thermotolerance. This response was initially observed as a localized distortion or puffing of salivary glands in Drosophila (Ritossa, 1962). This observation was eventually attributed to heat shock-induced $h s p$ gene transcription (Nover, 1991; Morimoto et al., 1994b; Morimoto, 1998). The magnitude of the heat shock response of cells depends on a number of variables including the final heat shock temperature, the rate of temperature elevation, and the length of heat exposure. Early events of the heat shock response include $h s p$ gene activation and cell cycle block. Later heat shock events include mRNA degradation, HSP accumulation, repression of HSP synthesis and induced thermotolerance (Nover, 1991; Parsell and Lindquist, 1993).

Although HSPs were aptly named after their discovery in response to heat shock, they were later shown to respond to other factors including chemical exposure and other environmental changes. As such, HSPs are often referred to generally as 'stress proteins'. Stress can be broadly defined as a disruption of equilibrium, and physiologically, a disruption to homeostasis. A stress may occur at many levels, from the cell to the whole organism. Chemical and environmental stressors include sodium arsenite, hydrogen peroxide, heavy metals (e.g. cadmium, copper, mercury and zinc), ethanol, hypoxia/anoxia and pH (Bernstam and Nriagu, 2000). Additional stressors include unfolded/abnormal proteins, amino acid analogues, gene expression inhibitors, steroid hormones (estrogen), viruses, teratogens, and ultraviolet irradiation (Nover, 1991). Many of the aforementioned stressors can act in concert yielding synergistic effects. For example, Xenopus A6 cells exposed to a moderate heat 
shock while being incubated with sodium arsenite exhibit increased levels of $h s p$ genes (Heikkila et al., 1987).

Additional experimentation revealed that HSPs are fundamentally involved in cellular activity, and are found in a wide variety of organisms from bacteria to man (Morimoto et al., 1994b). Some HSPs are expressed constitutively, indicating roles in normal cell function. In fact, HSPs are vital for cellular survival, regardless of stress. Under normothermic conditions, HSPs function as molecular chaperones in protein transport, translation of proteins and protein folding (Katschinski, 2004). In stressful situations they inhibit the irreversible aggregation of denatured protein and aid in its refolding (Gething and Sambrook, 1992). Eukaryotic HSPs are present in all major subcellular compartments including the cytoplasm, nucleus, mitochondria and endoplasmic reticulum (Nover, 1991). The endoplasmic reticulum (ER) contains a unique set of molecular chaperones known as glucose regulated protein (GRP) or immunoglobulin binding protein (BiP). These proteins were initially discovered in cells subjected to glucose starvation. GRPs are closely related to HSPs in structure and function, but are induced primarily by treatments that cause an unfolded protein response (UPR) in the ER (Easton et al., 2000).

HSPs comprise several families related by sequence, which are classified by molecular size (kDa). They include: the small heat shock proteins (sHSPs) (10-30 kDa), the HSP40 family, the HSP60 family, the HSP70 family, the HSP90 family and the HSP110/SSE family (Parsell and Lindquist, 1993). Until recently, very little research has been carried out with the HSP110/SSE family, which will be the focus of this thesis. 


\subsubsection{Hsp gene regulation}

Hsp gene expression is regulated at several levels; mRNA synthesis, mRNA stability and translation efficiency (Katschinski, 2004). The synthesis of hsp mRNA is regulated by transcription factors known as heat shock factors (HSFs) that are activated in response to stress. Although some organisms possess only one HSF (yeast and Drosophila), higher eukaryotes possess multiple HSFs (Morimoto et al., 1994a; Cotto and Morimoto, 1999). The HSF gene family includes HSF1, HSF2, HSF3 and HSF4 which are activated under different conditions. HSF1, the vertebrate homolog to the HSF found in yeast and Drosophila, is activated by heat shock and other stressors. Alternatively, HSF2 does not demonstrate stressinducible heat shock transcription, but rather is activated during embryogenesis, spermatogenesis and erythroid differentiation (Morimoto et al., 1994a). HSF3, an avianspecific HSF, responds to severe and persistent stress (Pirkkala et al., 2001). Finally, HSF4, unlike the other HSFs, constitutively binds to DNA, and has been suggested to be a negative regulator of the heat shock response (Nakai et al., 1997).

In metazoans, HSF is constitutively expressed and is present in the cell as an inactive monomer with a very weak affinity for DNA (Fernandes et al., 1994; Cotto and Morimoto, 1999). Although a detailed mechanism for HSF activation remains unclear, Bharadwaj et al. (1999) proposed that HSP90 and p23 may function as a semi-permanent core heterocomplex maintaining HSF1 monomers inactive but competent for rapid trimerization (Figure 2). Stress causes monomeric HSF to trimerize, which greatly increases its DNA-binding affinity (Westwood et al., 1991). The active HSF homotrimer now recognizes and binds to $c$ is-acting 
Figure 2. Current model for regulation of $h s p$ gene transcription by HSF1

(1) Cytoplasmic complex of HSF1 and HSP90; (2) HSF1 translocates to the nucleus; (3)

HSF1 intranuclear activation and $h s p$ gene transcription regulation; (4) HSF1/HSP90/p23

intranuclear complex; (5) HSF1 returns to the cytoplasm. (Modified from Sõti et al., 2005) 


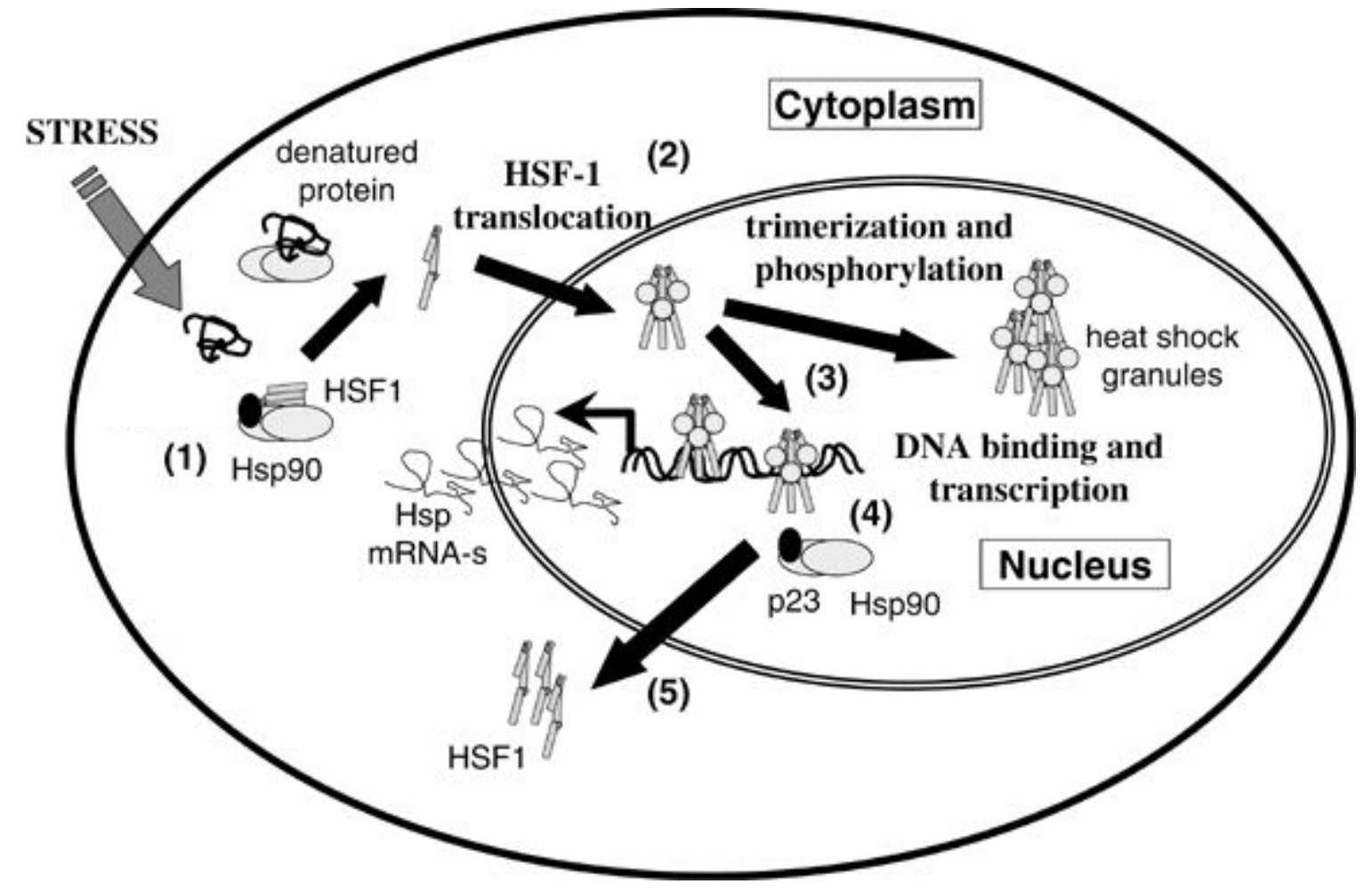


upstream DNA sequence elements, known as heat shock elements (HSEs) (Morimoto et al., 1994a).

The HSE is a highly conserved domain, consisting of [nGAAn] inverted repeats, present in the 5' upstream region of hsp genes (Fernandes et al., 1994). Hsp genes contain at least one upstream HSE, and the binding of HSF to HSE regulates transcription of the downstream $h s p$ gene. An HSE is present in all heat shock promoters, mediating the response to heat shock as well as other stressors, including agents that alter protein conformation (Mosser et al., 1990), and other chemicals such as sodium arsenite (Mosser et al., 1988). The ability of such diverse stimuli to trigger the activation of HSF suggests a common feature shared by all. The common denominator shared by 'stressful conditions' is the potential for protein unfolding (Voellmy, 2004). The presence of stress-induced unfolded protein elsewhere in the cell competes for members of the multichaperone complex that represses HSF1, resulting in free HSF1 monomers. The monomers, no longer negatively regulated, rapidly trimerize and become transcriptionally competent (Voellmy, 2004).

The regulation of $h s p$ gene transcription in Xenopus is controlled by HSF1 (Stump et al., 1995) and HSF2 (Hilgarth et al., 2004). Stump et al. (1995) isolated the Xenopus HSF1 cDNA and reported that it shared a high level of similarity with human HSF1. Furthermore, Xenopus HSF1 accumulated in the nucleus and activated transcription of the $h s p 70$ gene in response to heat shock. Xenopus HSF2 was recently identified and characterized by Hilgarth et al. (2004), and was also found to share strong similarity to its homolog in other organisms. Data from this study suggested the existence of at least 2 other HSFs in Xenopus, but these remain to be investigated. 


\subsubsection{Developmental expression of hsp genes in Xenopus}

The expression of hsp genes during Xenopus development has been relatively well characterized (Heikkila et al., 1997; Heikkila, 2003; Heikkila, 2004). In general, several Xenopus hsp mRNAs are present throughout early embryogenesis and are heat-inducible following MBT, while others are not stress-inducible until later stages (Heikkila et al., 1997). The patterns of expression of representative Xenopus hsp genes (hsp30, hsc70, hsp 70, BiP, hsp47, and hsp90) during development have been summarized below.

The Xenopus hsp30 gene family displays a unique developmental pattern of expression compared to other $h s p$ genes, such as $h s p 70$ and $h s p 90$. While the known members of the Xenopus $h s p 30$ gene family include $h s p 30 A-E$, $h s p 30 B$ and $E$ are likely pseudogenes (Bienz, 1984a; Krone et al., 1992). Constitutive expression of the hsp30 gene family has not been detected during early Xenopus development except for the cement gland in early tailbud embryos (Lang et al., 1999). Heat shock-induced accumulation of hsp30 mRNA was first detected at the late neurula/early tailbud stage of development. This was in contrast to other hsp genes including $h s p 70$ which was heat-inducible immediately after the MBT (Krone and Heikkila, 1988; Lang et al., 1999). A more detailed analysis revealed that although $h s p 30 A$ and $h s p 30 C$ were first heat-inducible at the late neurula/early tailbud stage, $h s p 30 D$ was not heat-inducible until the midtailbud stage, one day later in development (Ohan and Heikkila, 1995). A recent study from our laboratory suggested that the state of chromatin conformation may play a role in the developmental regulation of $h s p 30$ gene expression (Ovakim and Heikkila, 2003). For example, treatment of Xenopus embryos with histone deacetylase inhibitors, which loosen the structure of repressed chromatin domains, resulted in heat- 
inducible $h s p 30$ gene expression at the gastrula stage rather than late neurula/early tailbud. Finally, whole mount in situ hybridization revealed that heat shock-induced accumulation of hsp30 mRNA was enriched in selected tissues of tailbud embryos (Lang et al., 1999; Ovakim and Heikkila, 2003). However, the mechanism responsible for this enrichment is not known.

The Xenopus $h s p 70$ gene family consists of the stress-inducible $h s p 70$, the constitutively expressed $h s c 70$ and the ER family member, $B i P$. In a study of $h s c 70$ mRNA accumulation in Xenopus embryos, Lang et al. (2000) observed that this message was present in unfertilized eggs, indicative of its maternal origin. $H s c 70$ mRNA was detected at all stages of development with increasing relative levels at neurula and late tailbud stages. Unlike other hsps, hsc70 mRNA was not heat-inducible at any stage of development (Ali et al., 1996a). In contrast, $h s p 70$ mRNA was not detected constitutively at any stage of development, but was heat-inducible at all stages after MBT (Bienz, 1984a; Krone and Heikkila, 1988). Finally, $B i P$ mRNA accumulation was detected at relatively constant levels from unfertilized egg to neurula, increasing slightly by tailbud (Miskovic and Heikkila, 1999). BiP message was also heat-inducible, but not until the gastrula stage.

HSP47 is an ER resident molecular chaperone involved in collagen production. Recently, Hamilton and Heikkila (2006) reported that Xenopus hsp 47 mRNA levels were present constitutively throughout development. The message was present in unfertilized eggs and cleavage stage embryos, indicating that the mRNA for this gene was maternally inherited. Heat treatment of embryos resulted in an increase in mRNA accumulation starting at the late blastula stage. Whole mount in situ hybridization analysis determined that $h s p 47$ mRNA was 
enriched in tailbud embryonic tissues associated with collagen production including notochord, somites and head region.

In a study of $h s p 90$ gene expression during early Xenopus development, Ali et al. (1996b) observed that $h s p 90$ mRNA was present constitutively at all stages of embryogenesis. The presence of this message in unfertilized eggs and early cleavage stage embryos indicated that the $h s p 90$ mRNA was maternal in origin. After MBT and the onset of zygotic gene transcription $h s p 90$ mRNA levels were enhanced in response to heat shock treatment.

In summary, some Xenopus hsp mRNAs are constitutively expressed during development, including $h s p 47, h s c 70, B i P$, and $h s p 90$ while others are primarily stress-inducible, such as $h s p 30$ and $h s p 70$. Heat-inducibility of $h s p s$ generally occurs immediately following MBT, as seen for $h s p 47$, $h s p 70$, $h s p 90$ and $B i P$, whereas $h s p 30$ is not heat-inducible until later stages of development. Finally, unlike other $h s p s, h s c 70$ remains non-heat-inducible throughout early development. The presence of some hsps during early development, and some as maternally-derived messages, suggests an important role for these proteins in Xenopus embryogenesis.

\subsection{Small heat shock proteins}

SHSPs are stress-inducible molecular chaperones that range in size from 12 to $43 \mathrm{kDa}$ and include the $\alpha$-crystallins based on their physical and functional properties (Arrigo, 1998; Ehrnsperger et al., 1997; MacRae, 2000; van Montfort et al., 2002). With the exception of the $\alpha$-crystallin domain, a low degree of conservation is shared among sHSPs. Although the sequences of sHSPs are divergent, the structural properties of these proteins have been 
conserved (Lindquist and Craig, 1988). Most sHSPs form high molecular weight aggregates under conditions of cellular stress that are necessary for chaperone activity (Arrigo and Landry, 1994; Ehrnsperger et al., 1997; Leroux et al., 1997). In general, sHSPs bind to unfolded protein, maintaining the solubility and folding competence that permits refolding by other ATP-dependent molecular chaperones (Ehrnsperger et al., 1997; MacRae, 2000; van Montfort et al., 2002).

\subsubsection{Xenopus sHSPs}

The majority of the literature on sHSPs has focused on Drosophila, plant or mammalian model systems. Less information was available regarding sHSPs in amphibians. Until now, the only amphibian sHSP genes that have been studied with respect to their expression and molecular chaperone function were Xenopus hsp30C and hsp30D (Heikkila, 2004). During Xenopus early development the $h s p 30$ genes were repressed and were not heat-inducible until the late neurula/early tailbud stage. This is in contrast to other $h s p$ genes, including $h s p 70$, which were inducible at MBT (Lang et al., 1999; Heikkila, 2004). Additionally, hsp30 genes in tailbud and tadpole embryos were enriched preferentially in selected tissues in response to heat shock. Studies employing recombinant HSP30 proteins have demonstrated their ability to act as molecular chaperones. These proteins, which form multimeric complexes, inhibited heat-induced aggregation of target enzymes by maintaining them in a soluble form (Fernando and Heikkila, 2000; Abdulle et al., 2002; Heikkila, 2004).

As mentioned previously, prior to this study no information was available for $h s p 27$ in Xenopus laevis. The typical mammalian and avian HSP27 has a well-conserved C-terminal 
domain, and shares similarity with $\alpha$-crystallin from the vertebrate eye. The N-terminal domain contains a hydrophobic motif which is necessary for oligomerization (Ciocca et al., 1993). As with most other sHSPs, hsp27 is transcriptionally regulated; however, posttranslational modification in the form of phosphorylation is essential to its function as a molecular chaperone (Norris et al., 1997; Wieske et al., 2001; Thériault et al., 2004). HSP27 in other organisms was constitutively expressed, and increased in response to stress. Accumulation of $h s p 27$ mRNA was induced by a number of naturally occurring components including retinoic acid, estrogen, tumor necrosis factor $\alpha$, interleukin 1, and thrombin ( Ciocca et al., 1993). In other organisms, hsp27 was developmentally regulated, and its expression varied depending on developmental stage and tissue. In Drosophila, the hsp27 gene was activated along with the hormone, $\beta$-ecdysone (Ciocca et al., 1993), and was implicated in Drosophila developmental regulation. Mammalian, avian and Drosophila HSP27s were shown to have molecular chaperone activity. For example, Drosophila, hamster and chicken members of the HSP27 sHSPs were shown to inhibit thermal aggregation of citrate synthase in a dose-dependent manner (Haslbeck and Buchner, 2002; Thériault et al., 2004; Morrow et al., 2006). In mammalian systems, a number of studies have shown an involvement of HSP27 in cell differentiation, modulation of redox parameters, inhibition of apoptosis and actin capping/decapping (MacRae, 2000; van Montfort et al., 2002; Arrigo et al., 2002; 2005). 


\subsection{The HSP70 family}

The HSP70 family includes several highly conserved $68-74 \mathrm{kDa}$ stress-related proteins that regulate protein folding under both non-stressful and stressful conditions. This protein was reported to be the most conserved protein in evolution, present from archaebacteria to humans (Daugaard et al., 2007). Additionally, the HSP70 'superfamily' includes the HSP110/SSE family. HSP70 members are important molecular chaperones involved in the protection of nascent or denatured proteins from aggregation and the proper folding or refolding of cellular proteins (Katschinski, 2004). This gene family has been extensively studied and includes several functional homologs, including cytosolic stress-inducible HSP70, cytosolic constitutively expressed HSC70, mitochondrial p75 and ER-resident BiP (Morimoto, 1998). The high identity within and among species has facilitated identification of $h s p 70$ genes from several organisms. Eukaryotic HSP70s share roughly 50-98\% amino acid identity and roughly 50\% identity with prokaryotic counterparts (Craig et al., 1983). The functional domains for HSP70 include: a conserved ATPase domain, a protease sensitive region, a peptide binding domain and a carboxyl terminal domain responsible for intracellular localization and substrate interaction (Morimoto and Milarski, 1990).

\subsubsection{HSP70 function}

This section does not attempt to summarize the vast literature concerning the role of HSP70, but rather to introduce the reader to some of the diverse functions of this protein. HSP70 has been implicated in roles as diverse as protein transport, degradation of unstable and misfolded protein, prevention and dissolution of protein complexes, folding and 
refolding proteins, uncoating of clathrin-coated vesicles and regulatory protein control (Daugaard et al., 2007). HSP70 synthesis has been reported in response to stressful conditions including elevated temperature, chemical and heavy metal exposure. In general, during periods of stress, HSP70 is synthesized and protects the cell from aggregation of denatured proteins and directs the refolding of misfolded proteins (Boorstein et al., 1994). HSP70 does not fold proteins alone, but requires the help of co-chaperones including HIP, HOP, HSP40 and BAG-1 plus ATP (Katschinski, 2004). In addition to functioning as molecular chaperones, HSP70 family members are important in assembly and transport of cellular proteins between cellular compartments. HSP70 proteins are localized in different areas of the cell; HSC70 and HSP70 are both found in the cytoplasm, whereas BiP resides in the endoplasmic reticulum (Feige and Polla, 1994). Stress initiates translocation of HSC70 and HSP70 to the nucleus, and the presence of a nuclear localization signal (NLS) supports this (Ali et al., 1996a). A role in cellular transport was demonstrated by Shi and Thomas (1992), whereby HSP70 and HSC70 were required for the transport of nucleoplasmin protein into the nucleus.

The most well-known function of HSP70 is as a chaperone. HSP70 has been shown to repair thermally denatured target enzymes in conjunction with other co-chaperones (Hartl et al., 1994; Freeman and Morimoto, 1996). HSP70 proteins have also been shown to influence the organization and function of microtubules, microfilaments, and intermediate filaments (Liang and MacRae, 1997). A role for HSP70 in apoptosis has also been clearly established. In general, HSP70 plays an inhibitory role in stress kinase pathways (Sreedhar and Csermely, 2004) and in apoptosis (Mosser et al., 2000). The ability of HSP70 to prevent apoptosis has 
been reported by several authors (Beere, 2001; Parcellier et al., 2003; Garrido et al., 2006), although the ability of HSP70 to prevent apoptosis has been reported to be dependent on the type of stress (Anderson, 1998). Finally, in Xenopus embryos, elevated expression of $h s p 70$ genes in response to heat shock was correlated to an increase in thermoresistance (Ali et al., 1996a; Heikkila et al., 1985).

\subsubsection{Xenopus $h s p 70$ developmental regulation}

Five Xenopus laevis HSP70 members have been reported, including 2 inducible $h s p 70$ genes, 2 constitutive $h s c 70$ genes and the ER-resident BiP (Ali et al., 1996a; b; Bienz, 1984a; b; Miskovic et al., 1997). Hsc70 mRNA was constitutively present throughout Xenopus development, and was detectable globally (Ali et al., 1996a; Lang et al., 2000). Hsp70 message was not detectable until after MBT in Xenopus embryos, and beyond this stage, hsp70 gene expression was developmentally and spatially regulated (Heikkila et al., 1987; Krone and Heikkila, 1988; 1989; Lang et al., 2000). Hsp70 mRNA was detected in the head region, the lens placode, the cement gland, proctodeum, and somitic regions of heat shocked tailbud embryos (Lang et al., 2000). Finally, BiP gene expression increased during development, and was heat-inducible in Xenopus embryos (Miskovic and Heikkila, 1999). This gene was also spatially regulated in Xenopus embryos, and displayed preferential accumulation in the neural plate and neural fold regions of neurula stage embryos and in dorsal regions at the tailbud stage. 


\subsection{Large molecular mass (LMM) HSPs}

Several reports in the early 1990's suggested a large relative of the HSP70s, which was much more diverged than other family members (Subjeck et al., 1983; Fathallah et al., 1993; Mukai et al., 1993). In 1995, a mammalian hspl10 was cloned, and strong similarities to the HSP70 family in sequence and structure were observed (Lee-Yoon et al., 1995). Although LMM-HSPs shared similarity with the HSP70 proteins, they were designated a separate HSP family. This relatively new HSP group is referred to as the HSP110/SSE family, which belongs to the HSP70 'superfamily', based on sequence similarity (Easton et al., 2000).

The argument for a new HSP family outside of the HSP70 family is as follows: the molecular mass is substantially larger, there are six regions of high identity that are not found in HSP70 but are shared among the LMM-HSPs, there is a region between amino acids 500700 of LMM-HSPs is absent from HSP70, and the cysteine content of this family in the amino-terminal region is high compared to the HSP70 family (Lee-Yoon et al., 1995). There are several members of the HSP110/SSE family, including: APG-1/OSP94, APG-2, IRP94, HSP70RY, HSP105, SSE1, SSE2, PSS1, HSP91 and HSP88. It is worth noting that yeast or bacterial HSP104 does not belong to the HSP110/SSE family, since it displays several differences from HSP110 and exists only in lower eukaryotes, whereas HSP110 exists in organisms from yeast to humans, but has not been seen in prokaryotes (Easton et al., 2000).

\subsection{Mammalian HSP110/105 gene organization}

In 1983, Subjeck et al. published one of the first investigations of HSP110, prompted by previous hyperthermia and thermotolerance studies (Subjeck et al., 1982a; b and c). This 
paper characterized a 110000 dalton (Da) mammalian heat shock protein using an immunological approach, and determined that this protein was analogous to a $107 \mathrm{kDa}$ protein in hepatoma cells (Landry et al., 1982) and a $112 \mathrm{kDa}$ protein in mammary adenocarcinoma cells (Tomosovic et al., 1983). The hamster hsp110 cDNA was eventually cloned by Lee-Yoon et al. (1995) by screening a CHO expression library with an HSP110 antibody. The hamster $h s p 110$ gene was determined to be 3257 base pairs (bp) in length, with an open reading frame of 858 amino acids (aa), and a molecular weight of $96.1 \mathrm{kDa}$.

Four major domains of HSP110 were identified: the N-terminal ATP-binding domain (1394 aa), the peptide-binding domain ( $\beta$-sheet) (394-509 aa), the acidic loop domain (509-607 aa), and the carboxyl end ( $\alpha$-helical) (608-858 aa) (Oh et al., 1997; Oh et al., 1999). First, the N-terminal ATP-binding domain, although shared with HSP70, was found to display more identity with other HSP110 proteins than with HSP70 family members (Lee-Yoon et al., 1995). However, murine ATP-binding experiments indicated that HSP105 was unable to bind ATP (Yasuda et al., 1995). Second, a very highly conserved region present in all HSP70s, part of a peptide binding domain, was absent from HSP110-like proteins. Third, the acidic loop domain appeared to be different from any HSP70 proteins, and also unique among HSP110-like sequences. The major size difference between HSP70 and HSP110 appears to be within the $\alpha$-helical loop/lid region. This acidic loop is connected to the $\beta$-sheet domain by a 100 amino acid segment, and the 'lid' itself is quite a bit larger than the corresponding DnaK structure (Oh et al., 1997). Fourth, several C-terminal regions were identified that shared a very high level of similarity among all HSP110-like proteins (residues 421-450, 476-494, 627-644, 671-689, 698-712 and 776-781). In addition, the 
predicted amino acid sequence indicated five putative $\mathrm{N}$-glycosylation sites at positions 45 , 61, 280, 302 and 466, as well as a nuclear localization consensus sequence (NLS), KKPK, at amino acid 586 (Lee-Yoon, et al., 1995). From the full-length sequence obtained they identified a GCC sequence flanking the initiation codon in the 5' untranslated region (UTR), for optimal initiation of translation, but the $\mathrm{G}$ residue predicted at the $+4 \mathrm{nt}$ position for optimal translation initiation was replaced by a $\mathrm{T}$. They also determined that there were two termination codons (2603 nt and $2633 \mathrm{nt}$ ) and a polyadenylation signal, AATAAA, at 3235 bp, in the 3' UTR.

A full-length murine $h s p 105$ cDNA (the mouse homologue of hamster $h s p 110$ ) was cloned by screening a library from mouse FM3A cells treated at $42^{\circ} \mathrm{C}$ for $2 \mathrm{~h}$ (Yasuda et al., 1995). Two full-length clones were obtained, a $3345 \mathrm{bp}$ sequence with an open reading frame of 858 aa, and a 3268 bp sequence with an open reading frame of only 814 aa. The larger message, $h \operatorname{sp} 105 \alpha$, was constitutively expressed and also responded to temperature stress and chemical treatment. The smaller message, $h s p 105 \beta$, was identical to $h s p 105 \alpha$ but lacked a $131 \mathrm{bp}$ segment. Interestingly, $h s p 105 \beta$ was exclusively heat-inducible at $42^{\circ} \mathrm{C}$ (Yasuda et al., 1995). Other treatments, including temperatures other than $42^{\circ} \mathrm{C}$, sodium arsenite exposure, or exposure to other chemicals did not induce $h s p 105 \beta$ gene expression. Western blot

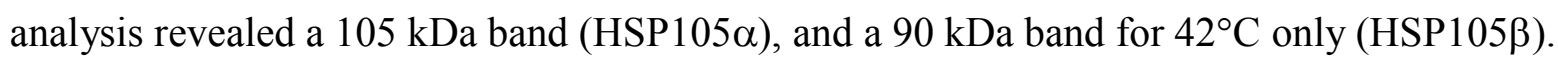
In addition, both HSP105 $\alpha$ and HSP $105 \beta$ were composed of two isoforms, an acidic and a basic, which resulted from post-transcriptional modification (Hatayama et al., 1994). 
A complete genomic cloning and promoter analysis study was carried out by Yasuda et al. (1999) for the mouse $h s p 105$ gene. Briefly, a mouse BALB/c genomic library was screened with an hsp 105 cDNA fragment. This study revealed that the gene was roughly $22 \mathrm{~kb}$ in length, containing 17 exons and 18 introns. All exons were less than $200 \mathrm{~kb}$ in length except for the last one (exon 18) which was composed of 867 bases. On the other hand, intron size ranged from 0.1 to $2.8 \mathrm{~kb}$. Of interest was exon 12, extending from nt 1642 to nt 1773 , which was present in the $h s p 105 \alpha$ isoform but completely lacking in the $h s p 105 \beta$ isoform. They determined that this alternative splicing was due to an inability of exon 11 to splice to exon 12 when cells are exposed to a $42^{\circ} \mathrm{C}$ stress, and only to exon 13 , resulting in the $h s p 105 \beta$ isoform. In addition to determining that hspl05 exists as a single copy in mice, Yasuda et al. (1999) also obtained $1.2 \mathrm{~kb}$ of the 5' UTR, enabling promoter analysis for this gene. With this information they determined that the transcription initiation site lied $165 \mathrm{nt}$ upstream of the initiation codon. Both constitutive and heat inducible promoters were revealed in the 5 , UTR. Constitutive promoter elements included a TATA box (at -33 nt), a CAAT box (at -210 nt), an inverted CAAT box (at -141 nt), and $2 \mathrm{GC}$ boxes (at -248 and $-166 \mathrm{nt}$ ). In addition to these, 2 HSE consensus sequences were identified (from -46 to -64 nt, and from -99 to -128 nt). This study also determined that both of the HSEs were required for sufficient heatinducibility of this gene. Human $h s p 105 \alpha$ and $h s p 105 \beta$ were cloned from a cDNA library prepared from HeLa cells (Ishihara et al., 1999). The characteristics of human hsp105were sufficiently similar to murine $h s p 105$ that another description is not warranted. 


\subsubsection{Other HSP110/SSE family members}

Hsp70RY, a cDNA isolated from transformed lymphocytes (Fathallah et al., 1993), was discovered in Genbank as having identity with hsp110 (Lee-Yoon et al., 1995). Efforts to obtain a full length clone of hsp70RY have proven unsuccessful (Nonoguchi et al., 1999), and it has been suggested that this may have been an artificial product, or anomaly (Easton et al., 2000).

APG-1 and APG-2 (A: ATP-binding domain, P: peptide-binding domain, G: germ cellderived) have been observed in both mice and humans. Apg-1 message was present in all mouse tissues, but was predominantly expressed in the testes, and is likely involved in spermatogenesis. The apg-1 mRNA was also heat-inducible, but displayed a different pattern of heat-induced accumulation than $h s p 70$, implying it should not be grouped with the HSP70 family (Kaneko et al., 1997; Nonoguchi et al., 1999). Kojima et al. (1996) reported an osmotic stress protein isolated from mouse kidney, osp94, which was inducible by heat as well as hyperosmotic stress. This protein appears to be the same as APG-1, but was

originally named differently as a result of the conditions under which it was observed (Easton et al., 2000). Both apg-1 and apg-2 have been identified in humans as well. The apg-2 transcript was identified in all human tissues, similar to mice, but was present at higher levels in gonadal tissue, and demonstrated a pattern of heat-inducibility unique from apg-1 (Nonoguchi et al., 1999). Gotoh et al. (2004) have demonstrated chaperone activity for apg-2 in vitro, and also observed that the apg-2 transcript (in addition to hsp110) was overexpressed in hepatocellular carcinoma. 
The ischemia-responsive gene (irp94), another member of the HSP110/SSE family, was abundant in neurons in the rat brain, and was enhanced following transient forebrain ischemia (Yagita et al., 1999). Two different sized transcripts were observed for irp 94 , differing only in 3'UTR length. The second, shorter transcript, for irp 94 appeared in the testes. The longer length of the brain-resident irp 94 contained two stabilization motifs. The different location and stabilities of these transcripts suggest a different function in each organ (Yagita et al., 1999).

Hsp110 homologs have been identified for several invertebrate species as well, including C. elegans, Drosophila, and sea urchin, although the C. elegans and Drosophila genes have not been fully characterized. Foltz et al. (1993) and Mauk et al. (1997) have reported the 'sea urchin egg surface receptor for sperm' in two different sea urchin species. These proteins shared $45 \%$ and $48 \%$ identity to hamster HSP 110 . Members of the HSP110/SSE family have also been identified in two yeast species, sse 1 from Saccharomyces cerevisiae (Mukai et al., 1993) and pss 1 from Schizosaccharomyces pombe (Chung, et al., 1998). Yeast stress proteins follow a different nomenclature, and are referred to as stress seventy (SS) proteins. The SSEs (SSE1 and SSE2) of S. cerevisiae share sequence identity with HSP110 group members albeit low (25\% identity to hamster HSP110), but are included on the basis of gene organization (Easton et al., 2000). In addition, SSE1 possesses chaperone activity, and its genetics have been well-studied (Shaner et al., 2004). In S. pombe, the pss 1 transcript was constitutively expressed, and was also induced by heat shock and nitrogen starvation (Chung et al., 1998). An HSP110/SSE family member has been reported in Arabidopsis thaliana, and is referred to as HSP91. Recently, other Arabidopsis candidates have been proposed as 
members of this family as well (Lin et al., 2001). HSP88, in the mold Neurospora crassa, is a constitutively expressed, heat-inducible protein, which has been shown to bind preferentially to HSP30 (Plesofsky-Vig and Brambl, 1998). Although it differs in size, as several of the family members do, the structure and organization of the gene is very similar to others in the HSP110/SSE family.

\subsubsection{HSP110 tissue and intracellular localization}

The cellular localization of HSP110 has been previously characterized in mammalian systems. HSP110 was observed in all hamster tissues but was most abundant in the brain, followed by the liver (Lee-Yoon et al., 1995). Similarly, HSP105 was present in all adult mouse tissues, and was also enriched in the brain (Hatayama et al., 1997). This data was also supported by mouse embryo studies, although HSP105 was not only enriched in the brain, but also liver, dorsal root ganglion and chondrocytes. The lowest levels were observed in the heart and lung.

Subjeck et al. (1983) observed a heterogeneous nuclear localization as well as a nucleolar association for HSP110 in chinese hamster ovary $(\mathrm{CHO})$ cells, $\mathrm{C} 3 \mathrm{H}$ mouse embryo 10T1/2 cells and murine tissues. In later studies, Lee-Yoon et al. (1995) reported that in mouse 3T3 and $\mathrm{CHO}$ cells HSP110 was primarily cytoplasmic, but also associated with peripheral regions of nucleoli. Similar studies in mice revealed that HSP105 was mainly localized in the cytoplasm and nuclei of several mouse cell lines, similar to HSP110 in hamster cells (Hatayama et al., 1994; Hatayama et al., 1997; Yasuda et al., 1995). However, mouse HSP105 was not found in the nucleoli under any conditions. Furthermore, HSP110 
intracellular localization was not significantly affected by heat shock (Lee-Yoon et al., 1995). This observation was supported in mice as well, since a similar pattern of HSP105 localization was observed under both control and stressed conditions (Hatayama et al., 1997). These findings were in contrast to HSP70, which responded to heat shock by localizing to the nucleus (Lee-Yoon et al., 1995). These observations are in agreement with observations in human systems as well. In human HeLa cells, HSP105 localized primarily in the cytoplasm in control cells, and accumulated around nuclei following heat shock, but was not found in the nucleoli (Ishihara et al., 1999). This was also in direct contrast to HSP70 in HeLa cells, which localized in the cytoplasm of non-stressed cells, but accumulated in nucleoli and around the nuclei following heat shock.

The cellular function of of HSP110/105 is not clear. Subjeck et al. (1983) treated cells with ribonuclease, which resulted in the release of HSP110 from the nucleus. The authors suggested that this was because HSP110 was bound to RNA either directly or indirectly, and speculated that HSP110 might be involved in ribosome assembly (Subjeck et al., 1983). Also mouse HSP105 may be involved in apoptosis as suggested by studies with mouse embryos which will be outlined in the next section.

Previously, a differentiation between the localization of mouse HSP $105 \alpha$ and HSP $105 \beta$ was not possible, since the HSP105 $\alpha$ antibody detected both proteins. Recently, Saito et al. (2007) produced antibodies that were able to distinguish between HSP105 $\alpha$ and HSP $105 \beta$. This study revealed that HSP105 $\alpha$ and HSP105 $\beta$ localized in different subcellular compartments, with HSP $105 \beta$ predominantly in the nucleus of monkey COS-7 cells. Both 
HSP105 $\alpha$ and $\beta$ contain functional NLS and nuclear export signal (NES) signals (Saito et al., 2007). Since both of these elements were functional, how was HSP $105 \alpha$ maintained in the cytoplasm and HSP $105 \beta$ in the nucleus? The difference between the two proteins lies in the 44 amino acid region that was alternatively spliced out of HSP $105 \alpha$. Studies with deletion mutants of this region showed that with increasing deletions in this region, HSP $105 \alpha$ was less able to localize in the cytoplasm (Saito et al., 2007). The ability of HSP $105 \beta$ to move in to the nucleus also appeared to be importin- $\beta$ dependent. The NLS is recognized by importin $\alpha$ in the cytoplasm and a heteromeric complex is formed with importin $\beta$ (Kohler et al., 1999). This HSP 105 -importin $\alpha$-importin $\beta$ complex interacts with the nuclear pore complex and is transported through a nuclear pore (Gorlich et al., 1995). Although this study provides insight into the difference in subcellular localization of HSP 105 , the roles of $\alpha$ and $\beta$ in the different areas of the cell are still unclear.

\subsubsection{HSP110/105 developmental regulation and involvement in apoptosis}

Support for a role for HSP110/105 in development was provided by mouse embryo studies. Differential levels of hsp105 mRNA during mouse embryo development were reported by Hatayama et al. (1997). Relatively high message levels were observed between gestational day (GD) 8-12, and declined by GD17. HSP105 protein was low in mice at GD8, increased to maximal expression levels at GD9-11, and then declined to half of the maximal level by GD17. This was contrasted by HSC70 levels which were unaltered throughout development. In light of the observed variation in the amount of HSP105 protein during embryogenesis, the 
authors speculated that HSP105 may play an important role in organogenesis (Hatayama et al., 1998). They also observed that the expression of HSP 105 was particularly high in condensed cells and apoptotic bodies at the interdigital region of limbs implying a role in apoptosis (Hatayama et al., 1997).

In order to further investigate the pro-apoptotic effect in mouse embryos, the mouse embryonal F9 cell line was established which constitutively over-expressed HSP105 (Yamagishi et al., 2002). The overexpression of HSP 105 was found to enhance caspase-3 activation, cytochrome $c$ release, and p38 activation, ultimately enhancing stress-induced apoptosis. Evrard et al. (1999) demonstrated a localized expression of HSP110 in mouse embryo mesectodermal and ganglionic cells that were undergoing apoptosis. A more detailed analysis revealed that $h \operatorname{sp} 110 \mathrm{mRNA}$ was elevated within $12 \mathrm{~h}$ of all-trans-retinoic acid exposure, and was depleted prior to the detection of the majority of apoptotic cells (Evrard et al., 2000). Given this information, the authors hypothesized that HSP110 played a role in the early stages of apoptosis, but did not offer a mechanism. This study was supported by the findings of Gashegu et al. (2007), who observed that HSP110 was expressed before caspase3 during development of the mouse eye, and suggested a pro-apoptotic role for HSP110 in caspase activation. Although several studies agree that HSP110 is involved at some level in apoptosis in the developing embryo, its exact role has not yet been clarified.

A protective role for HSP105 in neuronal PC12 cells was proposed by Hatayama et al. (2001). They reported that HSP 105 protected neuronal cells against stress-induced apoptosis by inhibiting the activation of both caspase-3 and JNK. A similar protective role was suggested by Yamagishi et al. (2006) who reported that staurosporine-induced apoptosis was 
suppressed by overexpression of HSP105. In an attempt to establish a mechanism by which HSP105 protected against apoptosis in HeLa cells, they determined that HSP105 suppressed the translocation of Bax to mitochondria, which prevents the downstream activation of caspases. In conclusion, it appears that HSP110/105 is able to function as either an enhancer or a suppressor of apoptosis, depending on the cell system being observed.

\subsubsection{Molecular chaperone activity of HSP110}

HSP110 has long been implicated in thermotolerance (Subjeck et al., 1982). The first description of the protective properties of HSP110 was reported by Oh et al. (1997). They demonstrated that Rat-1 and HeLa cell lines overexpressing HSP110 were more resistant to lethal heat exposures. HSP110 alone provided a $25-33 \%$ full thermotolerant effect, as compared to pre-heat treated thermotolerant cells in which multiple HSP family members are induced (Oh et al., 1997). HSP110 was also efficient in preventing heat-induced aggregation of luciferase in vitro in an ATP-independent manner. Coprecipitation of HSP110 with luciferase demonstrated its ability to selectively recognize denatured proteins in vitro. HSP110 was able to maintain luciferase in a folding competent state at a 1:1 (HSP110: luciferase) ratio, whereas $\mathrm{HSC} 70$ required a ratio of 4:1 to achieve the same result (Oh et al., 1997). Targeted deletion studies revealed that the protective characteristics of HSP110 were conferred through the peptide binding domain and two of the conserved C-terminal domains (Oh et al., 1999). Although HSP110 was unable to refold heat-denatured proteins alone, when added in conjunction with HSC70 and Hdj-1 to a denatured protein complex, protein refolding was increased to $25 \%$ of original activity (Oh et al., 1997). In summary, HSP 110 
possesses potent chaperone capabilities, but is unable to refold heat-denatured protein alone, and has thus been described as an efficient 'holdase'. A role for HSP110 in the HSP70 folding complex was supported by the results of Dragovic et al. (2006). They showed that HSP110 functioned as a nucleotide exchange factor (NEF) in the HSP70 folding complex, and regulated its kinetics by enhancing the rate of HSP70 folding. A special role for HSP110 in folding complex multidomain proteins was proposed by Dragovic et al. (2006) based on the ability of HSP 110 to function as both a chaperone and a NEF. This proposed role would be useful for the prevention of untoward reactions between the different domains of a folding protein.

Alternatively, a role for HSP110 as an 'RNA chaperone' was proposed (Henics et al., 1999). In this study, HSP70, HSC70 and HSP110 were shown to bind to AU-rich 3'UTR RNA sequences (instability elements of proto-oncogene and lymphokine mRNAs). RNA binding was shown to occur in the N-terminal domain of HSP110. What is the purpose of this RNA-binding? Perhaps the binding facilitates the unwinding of complex secondary structures, exposing cis-acting elements for other proteins to bind. Alternatively, these HSPs may play a 'RNA chaperone' function enabling the proper folding of RNA to expose critical motifs for translation or degradation (Henics et al., 1999).

While it is tempting to speculate that HSP110 shares a common chaperone role in all organisms, a recent study by Raviol et al. (2006) demonstrated otherwise. In this study, the chaperone abilities of two HSP110 homologues, human APG-2 and yeast SSE1, were compared. The results indicated that these two proteins have diverged substantially in function and although they both demonstrated ATPase activity, biochemically they were 
quite different. As such, conclusions based on the activity and function in other species should be made with caution. 


\section{Objectives}

The aim of the present study was to examine the expression of the $h s p 110$ gene in Xenopus laevis. HSP110 has not been studied as intensively as other HSPs including HSP90, HSP70, and the sHSPs. Most of the available information on HSP110 was derived from mammalian and yeast systems. Prior to my thesis research, no information was available on the expression of the $h s p 110$ gene in amphibians.

The main objectives of my thesis are as follows:

1. Obtain a full-length sequence of the Xenopus laevis hsp 110 cDNA.

2. Sequence analysis of the $h s p 110 \mathrm{cDNA}$ and comparison with $h s p 110 / 105$ genes in other organisms.

3. Northern blot analysis of the relative levels of $h s p 110 \mathrm{mRNA}$ in control, heat shocked and sodium arsenite-treated A6 cells or embryos.

4. Whole mount in situ hybridization analysis to examine the pattern of hsp 110 mRNA accumulation in control and heat shocked Xenopus embryos.

5. Western blot analysis of HSP110 protein levels in control, heat shocked and sodium arsenite-treated A6 cells.

6. Intracellular localization of HSP110 protein in control, heat shocked and sodium arsenite-treated A6 cells employing immunocytochemistry coupled with confocal laser scanning microscopy. 


\section{Chapter 2: Materials and Methods}

\subsection{Maintenance of Xenopus laevis A6 cells and embryos}

Xenopus laevis A6 kidney epithelial cells (CCL-102; American Type Culture Collection (ATCC), Rockville, MD) were maintained at $22^{\circ} \mathrm{C}$ in $\mathrm{T} 75 \mathrm{~cm}^{2}$ tissue-culture flasks (BD Falcon, Oakville, ON). Leibovitz (L)-15 media (Sigma-Aldrich, Oakville, ON) diluted to $55 \%(\mathrm{v} / \mathrm{v})$, and supplemented with 10\% (v/v) fetal bovine serum (FBS) (Sigma-Aldrich), 100 units(U)/mL penicillin (Sigma-Aldrich) and $100 \mu \mathrm{g} / \mathrm{mL}$ streptomycin (Sigma-Aldrich) was used for routine culturing. A6 cells were detached from the flask upon $90 \%$ confluency by first aspirating spent media, a brief treatment with $1 \mathrm{X}$ versene $(2.68 \mu \mathrm{M} \mathrm{KCl}, 0.137 \mathrm{mM}$ $\mathrm{NaCl}, 1.47 \mu \mathrm{M}$ KH2PO4, 8.1 $\mu \mathrm{M}$ Na2HPO4, $10.7 \mu \mathrm{M}$ EDTA, $\mathrm{pH}$ 7.2) followed by a brief treatment with $1 \mathrm{X}$ trypsin (Sigma-Aldrich) and then evenly redistributed into new tissue culture flasks. Cells were passaged in this manner 2 to 3 times per week, and all cells were used between passage numbers 12 and 80 .

\subsubsection{Treatment of Xenopus A6 cells}

Cell treatments were performed upon cell confluency (80-90\%), generally 2 days following sub-culturing. Heat-shock cell treatments were carried out in the original flask secured with parafilm and immersed in a water bath at the temperatures and times indicated. Chemical cell treatments were carried out in fresh media at $22^{\circ} \mathrm{C}$ at the indicated concentrations and for the indicated times. Following a treatment or recovery period cells were harvested. Cells destined for RNA isolation were immediately subjected to the following harvesting 
procedure while cells destined for protein isolation were first allowed to recover at $22^{\circ} \mathrm{C}$ for $2 \mathrm{~h}$ and then were subjected to the harvesting procedure. The spent media was removed by aspiration and the cells were then rinsed in $2 \mathrm{~mL}$ of $65 \%$ Hanks Balanced Salt Solution (HBSS; Sigma-Aldrich) which was subsequently aspirated as well. Finally, the cells were physically removed from the surface using cell scrapers, and suspended in $1 \mathrm{~mL}$ of $100 \%$ HBSS. This cell suspension was pelleted by centrifugation in an Eppendorf 5415D microcentrifuge (Brinkmann Instruments Ltd., Mississauga, ON) for 1 min at 13200 revolutions per min (rpm). The supernatant was discarded and the cell pellet frozen at $-80^{\circ} \mathrm{C}$. Also, unless otherwise noted, all experiments were carried out multiple times, using separately treated cell extracts, and a representative result is presented.

\subsubsection{Maintenance of Xenopus embryos}

Isolation and maintenance of embryos was according to methods previously described in Sive et al. (2000). Xenopus female frogs (Boreal, St. Catharines, ON) were injected with 50 U human chorionic gonadotropin (hCG; Sigma-Aldrich) in sterile $0.65 \% \mathrm{NaCl}(\mathrm{w} / \mathrm{v})$ in the dorsal lymph sac with a 26 gauge needle 5 days prior to fertilization to prime for ovulation. Frogs were then injected with $1000 \mathrm{U}$ hCG $9 \mathrm{~h}$ prior to egg collection to induce ovulation. Eggs were collected, by applying gentle pressure to the abdomen of the frogs, into $1 \mathrm{X}$ Modified Barth's Saline (MBS; $88 \mathrm{mM} \mathrm{NaCl}, 1 \mathrm{mM} \mathrm{KCl}, 0.7 \mathrm{mM} \mathrm{CaCl}_{2}, 1 \mathrm{mM} \mathrm{MgSO}_{4}$, 5mM HEPES-KOH, $2.5 \mathrm{mM} \mathrm{NaHCO}_{3}, \mathrm{pH} 7.8$ ).

Sperm for in vitro fertilization was obtained by removing the testes of a male Xenopus frog and the testes were stored in 1X MBS. Fertilization was carried out manually in vitro by first 
removing the MBS bathing the eggs, and touching each egg with a portion of the testes. Eggs were then immersed in 0.1X MBS and left to fertilize for $30 \mathrm{~min}$ on an orbital shaker. Fertilization was determined by observing cortical rotation of fertilized eggs, which results in the animal pole of the eggs oriented upward. Following fertilization the jelly coat of the embryo was removed by agitation in 2\% L-cysteine (Sigma-Aldrich) in $0.1 \mathrm{X}$ MBS (w/v), $\mathrm{pH}$ 8.0. Once embryos were de-jellied they were immediately washed 6 times in 0.1X MBS to remove the L-cysteine.

Embryos were subsequently maintained in $0.1 \mathrm{X} \mathrm{MBS}$ at $22^{\circ} \mathrm{C}$ throughout development. Embryos were regularly monitored and any dead or deformed individuals were removed, and media was replaced periodically. External morphologies, described previously by Nieuwkoop and Faber (1967), were used for developmental staging.

\subsubsection{Treatment of Xenopus embryos}

When embryos reached the desired stages for study, a sample (approximately 30 embryos per treatment) was removed to a separate beaker. Heat-shock treatments were carried out in 0.1X MBS in beakers sealed with parafilm and immersed in a $33^{\circ} \mathrm{C}$ water bath for $1 \mathrm{~h}$. Control embryos were maintained at $22^{\circ} \mathrm{C}$. Following treatment the embryos destined for RNA isolation were transferred to microcentrifuge tubes, excess media was removed and tubes were immersed in liquid nitrogen and then stored at $-80^{\circ} \mathrm{C}$. Embryos destined for whole mount in situ hybridization were fixed in MEMPFA (0.1 M 3-morpholino propane sulfonic acid (MOPS; BioShop, Burlington, ON), pH 7.4, 2 mM ethylenediamine tetraacetic acid 
(EDTA; BioShop), $1 \mathrm{mM} \mathrm{MgSO}_{4}, 4 \%$ paraformaldehyde (PFA; Bioshop)) for $2 \mathrm{~h}$ at room temperature on a nutating table, transferred to $100 \%$ methanol, and then frozen at $-20^{\circ} \mathrm{C}$.

\subsection{Characterization of Xenopus hsp110 cDNA}

\subsubsection{Hsp110 cDNA}

A partially sequenced expressed sequence tag clone encoding a putative HSP105-like protein (ID no. 4055839) was purchased from the Integrated Molecular Analysis of Genomes and their Expression (I.M.A.G.E.) consortium of the ATCC. The hsp 105 clone was received in DH10 cells, in pCMV-SPORT6 plasmid, cloned into Not1 and Sal1 restriction endonuclease sites. The inserted region of this clone was sequenced (Mobix, Hamilton, ON), which required several sequencing reactions to obtain overlapping high quality sequence for this large gene. At each step of sequencing, gene specific primers were synthesized (Mobix) and another sequencing reaction performed until reliable sequence was obtained for the entire length of the inserted cDNA.

\subsubsection{DNA sequencing}

To obtain the nucleotide sequence of the plasmid insert, automated sequencing was contracted from MOBIX. Initially, standard T7 and SP6 primers were used to obtain sequence from each end of the plasmid insert. From this sequence information, custom internal primers were chosen to further elongate the sequence (Table 1). This process was repeated until the sequence overlapped in the middle of the insert. Computer analysis of 
nucleotide sequences was done with Gene Tools Lite 1.0 (Bio Tools Incorporated, 2000). Eventually the DNA sequence was used to obtain a putative amino acid sequence using the Expasy proteomics server. Alignment of nucleotide and amino acid sequences was performed with ClustalW. The expasy proteomics server was also used to determine potential glycosylation sites also.

Table 1. PCR primers used for $h s p 110$ sequencing

\begin{tabular}{ll}
\hline \multicolumn{1}{c}{ Forward primers } & \multicolumn{1}{c}{ Reverse primers } \\
\hline SP6 : GATTTAGGTGACACTATAG & T7 : TAATACGACTCACTATAGGG \\
105b : GGATGCTGCCCAGATTGT & $105 \mathrm{a}:$ CCACCGGGTCCTGATCCA \\
105d : TTGCGTGCCGAAGATGTC & $105 \mathrm{c}:$ GGGCTTCTTCGCTTCTGG \\
\hline
\end{tabular}

\subsubsection{Plasmid isolation}

Plasmids were isolated using a phenol chloroform method, modified from Sambrook and Russell, (2001). Cells containing the plasmid of interest in $5 \mathrm{~mL}$ LB broth $(1 \%(\mathrm{w} / \mathrm{v})$ tryptone (Difco, Lawrence, KS), 0.5\% (w/v) yeast extract (Difco), 1\% (w/v) NaCl (BioShop) supplemented with $100 \mu \mathrm{g} / \mathrm{mL}$ ampicillin (BioShop) propagated overnight at $37^{\circ} \mathrm{C}$ were centrifuged at $5000 \mathrm{rpm}$ for $5 \mathrm{~min}$ at $4^{\circ} \mathrm{C}$ in an Eppendorf Centrifuge 5810R (Brinkmann Instruments Ltd.) with a swinging bucket rotor. After the supernatant was removed the bacterial pellet was resuspended in $200 \mu \mathrm{L}$ of ice-cold alkaline lysis solution I ( $50 \mathrm{mM}$ glucose (Sigma-Aldrich), $25 \mathrm{mM}$ Tris (BioShop) (pH 8.0), 1 mM EDTA (pH 8.0)) and transferred to a $1.5 \mathrm{~mL}$ microcentrifuge tube. To each suspension $200 \mu \mathrm{L}$ of freshly made alkaline lysis solution II (0.2 N NaOH (BioShop), 1\% (w/v) SDS (BioShop)) was added and 
gently mixed by slowly inverting the tube several times and placed on ice. Next, $200 \mu \mathrm{L}$ of ice-cold alkaline lysis solution III (3 M potassium acetate (Sigma-Aldrich), $5 \mathrm{M}$ glacial acetic acid (Fisher Scientific, Pittsburgh, PA) was added and tubes were slowly inverted 3 - 5 times and then placed on ice for $5 \mathrm{~min}$. The tubes were then centrifuged at $14000 \mathrm{rpm}$ at $4^{\circ} \mathrm{C}$ for 5 min and supernatant transferred to a fresh tube.

Residual RNA was eliminated with $20 \mu \mathrm{L}$ RNase A (10 $\mu \mathrm{g} / \mathrm{mL}$; Roche Molecular Biochemicals, Laval, QC) and incubating at $37^{\circ} \mathrm{C}$ for $2 \mathrm{~h}$. Following incubation, $600 \mu \mathrm{L}$ of phenol:chloroform:isoamyl alcohol (25:24:1) was added to each tube and vortexed. Tubes were then centrifuged for $3 \mathrm{~min}$ at $4^{\circ} \mathrm{C}$ and the upper aqueous layer transferred to a new tube and the previous step repeated. The top aqueous layer was once again transferred to a new tube and $600 \mu \mathrm{L}$ of choloform:isoamyl alcohol (24:1) was added. Tubes were vortexed, centrifuged at the above settings and the upper aqueous layer was transferred to a fresh tube. Precipitation of plasmids was accomplished with $600 \mu \mathrm{L}$ of isopropanol at room temperature (RT) for $2 \mathrm{~min}$ followed by centrifugation at $14000 \mathrm{rpm}$ in a microcentrifuge for $5 \mathrm{~min}$. The supernatant was discarded and the tubes were inverted to allow all fluid to drain out, and the pellet to dry. To wash the pellet $1 \mathrm{~mL}$ of $70 \%$ ethanol was added and then the tubes were centrifuged at $14000 \mathrm{rpm}$ for $2 \mathrm{~min}$. The supernatant was once again discarded and the tubes were once again inverted to dry the pellet. Upon drying the pellet the plasmids were dissolved in $50 \mu \mathrm{L}$ of TE buffer ( $50 \mathrm{mM}$ Tris, $2 \mathrm{mM}$ EDTA, $\mathrm{pH} 8.0$ ). At this point plasmids could be subjected to UV-spectrophotometry for quantification and agarose gel electrophoresis for determination of plasmid integrity. 


\subsubsection{Rapid amplification of CDNA ends (RACE)-polymerase chain reaction (PCR)}

In order to obtain the missing segment of the Xenopus hsp110 gene, 5' RACE-PCR was required. 5' RACE-PCR was carried out using the SMART-RACE cDNA amplification system according to the manufacturer's instructions (BD Biosciences, Mississauga, ON). One $\mu \mathrm{g}$ of total RNA isolated from heat-shocked A6 cells was used for first strand cDNA synthesis. This reaction consisted of $1 \mu \mathrm{g}$ total A6 RNA, $1 \mu \mathrm{L}$ 5' CDS primer, $1 \mu \mathrm{L}$ BD SMART II A oligo, and water for $5 \mu \mathrm{L}$ total volume. The components were gently mixed, pulse-spun and then incubated at $70^{\circ} \mathrm{C}$ for 2 min followed by 2 min on ice with a final pulse spin. At this point $2 \mu \mathrm{L} 5 \mathrm{X}$ first strand buffer, $1 \mu \mathrm{L} 20 \mathrm{mM}$ dithiothreitol (DTT), $1 \mu \mathrm{L} 10 \mathrm{mM}$ dNTP mix and I $\mu \mathrm{L}$ BD Powerscript reverse transcriptase were added to the initial components. The tube was then gently mixed again, pulse-spun, incubated at $42^{\circ} \mathrm{C}$ for $1.5 \mathrm{~h}$, $100 \mu \mathrm{L}$ Tricine-EDTA buffer was added, a final incubation at $72^{\circ} \mathrm{C}$ for $7 \mathrm{~min}$ and this first strand cDNA product was then stored at $-20^{\circ} \mathrm{C}$.

For 5' RACE, $3 \mu \mathrm{L}$ of 5' cDNA was added to the reverse gene-specific primer (HSP110R CCGGTTCTGTATTGGAGTGCC) and the universal primer (UPM - provided), in addition to the appropriate amount of prepared master mix (containing BD Advantage 2 PCR buffer, dNTP mix and BD Advantage 2 Polymerase Mix). The tube contents were gently mixed and pulse-spun to collect in the bottom of the tube. After 2 min at $94{ }^{\circ} \mathrm{C}, 30$ cycles with the following parameters ensued: $30 \mathrm{~s} @ 94^{\circ} \mathrm{C}, 30 \mathrm{~s} @ 62^{\circ} \mathrm{C}$ and $3.5 \min @ 72^{\circ} \mathrm{C}$. All PCR products were electrophoresed on a $0.8 \%$ agarose gel (in $1 \mathrm{X}$ TAE; $40 \mathrm{mM}$ Tris-acetate, 1 $\mathrm{mM}$ EDTA) and visualized with ethidium bromide. The $2.5 \mathrm{~kb}$ bands that resulted were 
excised from the gel and purified using the NucleoTrap Band Purification kit (Clontech, Mountain View, CA).

The excised band was combined in a tube with buffer NT1 and nucleotrap suspension and then incubated at $50^{\circ} \mathrm{C}$ for $15 \mathrm{~min}$. The contents were centrifuged at $10000 \mathrm{~g}$ for $30 \mathrm{~s}$ at RT and the supernatant discarded. The pellet was combined with buffer NT2 and centrifuged under the same conditions, and the same was repeated with buffer NT3. The resulting DNA pellet was dried and solubilized in $20 \mu \mathrm{L}$ Tris EDTA buffer (TE; $10 \mathrm{mM}$ Tris-HCl, 1mM EDTA, $\mathrm{pH}$ 8.0). This solution was centrifuged at $10000 \mathrm{~g}$ for $30 \mathrm{~s}$ at RT and the supernatant (DNA) was transferred to a clean tube. A $1 \mu \mathrm{L}$ sample of the purified DNA was electrophoresed on a $0.8 \%$ agarose gel with a molecular mass marker to determine the approximate yield of DNA.

The 5'RACE products were then ligated into the T/A cloning vector, pGEM®-T Easy (Promega, Madison, WI) for sequencing. The ligation reaction contained approximately 30 ng of 5'RACE cDNA insert, 50 ng pGEM®-T Easy, DNA ligase, and $1 \mathrm{X}$ ligase buffer and was incubated overnight at $4^{\circ} \mathrm{C}$. Competent JM109 cells (50 $\mu \mathrm{L}$; Promega) were then transformed with the ligated hsp110-pGEM®-T Easy products via a $60 \mathrm{~s} 42^{\circ} \mathrm{C}$ 'heat shock' following a $20 \mathrm{~min}$ incubation on ice. The cells were allowed to recover on ice for $2 \mathrm{~min}$ and then $950 \mu \mathrm{L}$ warm LB was added and the cells were incubated at $37^{\circ} \mathrm{C}$ for $1.5 \mathrm{~h}$. At this point all cells were plated on LB-agar plates containing $100 \mu \mathrm{g} / \mathrm{mL}$ ampicillin (BioShop), with 40 $\mu \mathrm{L} 20 \mathrm{mg} / \mathrm{mL}$ 5-bromo-4-chloro-3-indolyl-beta-D-galactopyranoside (X-gal; BioShop) and 4 
$\mu \mathrm{L}$ isopropyl $\beta$-D-1-thiogalactopyranoside (1M IPTG; BioShop) and grown overnight at $37^{\circ} \mathrm{C}$.

The next day, colonies were selected that had incorporated the hsp110-pGEM $®$-T Easy plasmid and grown overnight in LB broth containing $100 \mu \mathrm{g} / \mathrm{mL}$ ampicillin. Plasmid was isolated from broth cultures the following day and the insert was removed from the plasmid using EcoRI. This revealed that an insert of approximately the correct size was present in some of the isolated plasmid, and samples of the successfully ligated plasmid were sequenced yielding a full-length hsp 110 nucleotide sequence.

\subsection{5 cDNA sequence analysis}

Phylogenetic analyses were conducted using MEGA version 3.1 (Kumar et al., 2004). The tree was prepared using the neighbour-joining method with pairwise deletion, and Jukes and Cantor (1969) correction. A bootstrap value of 1000 was employed. Putative amino acid sequences were inferred from nucleotide sequences (Expasy Proteomics Server online) and aligned using ClustalW (Thompson et al., 1994). Generunner software was used to display aligned nucleotides and corresponding amino acids.

\subsection{RNA isolation}

\subsubsection{RNA isolation from A6 cells}

RNA was isolated from A6 cells for use as a template for first strand cDNA synthesis or for analysis with northern hybridization. Total RNA was isolated from Xenopus A6 cells 
using the RNeasy mini RNA extraction kit (Qiagen, Mississauga, ON) following the manufacturer's instructions. Briefly, $600 \mu \mathrm{L}$ of buffer RLT supplemented with $0.1 \%$ (v/v) $\beta$ mercaptoethanol (BioShop) was added to frozen cell pellets and this mixture was vortexed thoroughly. Next, the solution was passed through a 20 -gauge needle attached to a $1 \mathrm{~mL}$ syringe 10 times to shear genomic DNA. At this point an equal volume of $70 \%$ cold ethanol was added to the lysate. The lysate was loaded onto an RNeasy mini column and centrifuged for $15 \mathrm{~s}$ at $14000 \mathrm{rpm}$ in an Eppendorf 5415D microcentrifuge (Brinkmann Instruments Ltd.) (this was repeated until all lysate was loaded onto the column). After all flow-through had been discarded $750 \mathrm{~mL}$ of buffer RPE was added to the column and centrifuged as previously described. Upon placement of the column in a fresh microcentrifuge tube $750 \mu \mathrm{L}$ buffer RW1 was added. After centrifugation and discarding the flow-through this process was repeated. The column was then dried by centrifuging void of buffer for 2 min at $14000 \mathrm{rpm}$. Finally, the columns were transferred to a fresh microcentrifuge tube, and $30 \mu \mathrm{L}$ of RNasefree water was added to the column filter. After centrifugation, the eluant was collected in the bottom of the tube, and $30 \mu \mathrm{L}$ more RNase-free water was added to the column to increase the RNA yield. Finally $60 \mu \mathrm{L}$ of high yield total RNA was placed on ice prior to quantification.

\subsubsection{RNA isolation from Xenopus laevis embryos}

RNA was isolated from Xenopus embryos for analysis with northern hybridization. Total RNA was isolated from Xenopus embryos using a GIT/CsCl ultracentrifugation method originally described by Chirgwin et al. (1979), and modified by Ohan and Heikkila (1995). 
As a precaution against RNA contamination all glassware used for RNA isolation was subjected to $140^{\circ} \mathrm{C}$ for $8 \mathrm{~h}$. Plasticware was sprayed with RNase Away (VWR, Mississauga, $\mathrm{ON}$ ) and rinsed with $0.1 \%$ diethyl pyrocarbonate-(DEPC; Sigma-Aldrich) treated water, or treated with 3\% (v/v) hydrogen peroxide. Similarly, any solutions used were prepared in $0.1 \%$ DEPC, and subsequently autoclaved to inactivate the DEPC.

Approximately thirty embryos were homogenized in $9 \mathrm{~mL}$ GIT (4 M guanidine isothiocyanate (BioShop), $25 \mathrm{mM}$ sodium acetate (BioShop), pH 6.0, $120 \mathrm{mM} \beta$ mercaptoethanol (Sigma-Aldrich) -in DEPC-treated water) using a PowerGen 125 homogenizer (Fisher). The homogenate was carefully layered onto $3.3 \mathrm{~mL}$ cesium chloride buffer (5.7 M cesium chloride (BioShop), $25 \mathrm{mM}$ sodium acetate (BioShop) pH 6.0 in 0.1\% DEPC-treated water) in ultra-clear centrifuge tubes (Beckman, Palo Alto, CA). Samples were centrifuged at $30000 \mathrm{rpm}$ for $23 \mathrm{~h}$ at $21^{\circ} \mathrm{C}$ (SW41 rotor, Beckman L-90K ultracentrifuge) to pellet RNA.

Following centrifugation, the supernatant was removed from the pellet and the pellet was allowed to dry. The pellets were then resuspended in $360 \mu \mathrm{L}$ of TES buffer $(0.01 \mathrm{M}$ Tris (BioShop), $\mathrm{pH} 7.4,5 \mathrm{mM}$ ethylenediamine tetraacetic acid (EDTA) (BioShop), $\mathrm{pH}$ 8.0, 1\% (w/v) sodium dodecyl sulphate (SDS) (BioShop) on ice for $15 \mathrm{~min}$ and transferred to a microcentrifuge tube. To precipitate the RNA, $0.3 \mathrm{M}$ sodium acetate was added to the solution as well as $1 \mathrm{~mL}$ of $100 \%$ ice-cold ethanol, and was placed at $-20^{\circ} \mathrm{C}$ for $30 \mathrm{~min}$. Finally, the samples were centrifuged at $14000 \mathrm{rpm}$ at $4^{\circ} \mathrm{C}$ for $10 \mathrm{~min}$. After removal of the supernatant, this set of precipitation steps was repeated. The pellet was dissolved in $50 \mu \mathrm{L}$ of 
DEPC-treated water. Purity, integrity and concentration of RNA were established by spectrophotometry and formaldehyde agarose gel electrophoresis.

\subsubsection{RNA concentration and integrity}

Total RNA isolated from both A6 cells and embryos was subjected to quantification and quality assessment. UV-spectrophotometry was used to assess the concentration of nucleic acids present. Of each sample, $5 \mu \mathrm{L}$ was diluted to $1000 \mu \mathrm{L}$ with RNase-free water and the absorbance at $260 \mathrm{~nm}$ was measured using quartz cuvettes and a Varian Cary 50 Bio UVVisible spectrophotometer (Varian Medical Systems, Palo Alto, CA). The absorbance at 260 nm was multiplied by 200 (dilution factor), and by 40 (RNA OD value), and finally divided by 1000 (to move from the $\mathrm{mL}$ value provided by the machine, to $\mu \mathrm{L}$ ) to arrive at the concentration of RNA in $\mu \mathrm{g} / \mu \mathrm{L}$ units. Also, the ratio of absorbance at $260 \mathrm{~nm}: 280 \mathrm{~nm}$ was determined to estimate RNA purity. All RNA values used in this thesis were greater than 1.6.

Once the concentration was determined the samples were subjected to formaldehydeagarose gel electrophoresis. Generally $1 \mu \mathrm{g}$ total RNA was resuspended in denaturing loading buffer ( $1 \mu \mathrm{L}$ 10X MOPS, $\mathrm{pH}$ 7.0, $1.6 \mu \mathrm{L}$ formaldehyde (37\%; BioShop), $5 \mu \mathrm{L}$ formamide (BioShop), $2 \mu \mathrm{L}$ loading dye $(0.2 \%$ (w/v) bromophenol blue, $1 \mathrm{mM}$ EDTA, $\mathrm{pH}$ $8.0,50 \%$ (v/v) glycerol (Sigma-Aldrich), $0.5 \mu \mathrm{L} 10 \mathrm{mg} / \mathrm{mL}$ ethidium bromide). The RNA was mixed gently with the loading buffer and denatured at $68^{\circ} \mathrm{C}$ for $10 \mathrm{~min}$ and immediately placed on ice for $5 \mathrm{~min}$. The samples were then electrophoresed in a formaldehyde-agarose gel (1.2\% (w/v) agarose (BioShop), 10\% (v/v) 10X MOPS, 16\% (v/v) formaldehyde (37\%)) 
for approximately $2 \mathrm{~h}$ in $1 \mathrm{X}$ MOPS running buffer. Visualization with UV light showed ribosomal RNA bands (18s and 28s) that could be used to determine if the RNA was degraded or was equally loaded into each lane.

\subsection{Restriction enzmye (RE) digestion}

Many RE digests were performed both for confirming plasmid insert sizes as well as for preparing linear templates for in vitro transcription reactions. RE digestion of recombinant plasmid DNA was performed as described in Sambrook and Russell (2001). The appropriate amount of DNA was used for each case: $1 \mu \mathrm{g}$ for insert checking, or up to $10 \mu \mathrm{g}$ for linear template preparation. In the case of template preparation $10 \mu \mathrm{g}$ of plasmid was added to a microcentrifuge tube $(16 \mu \mathrm{L}$ ), along with $2 \mu \mathrm{L}$ of $10 \mathrm{X}$ RE buffer (supplied with each RE by the manufacturer) and $2 \mu \mathrm{L}$ of RE. The contents of the tube were gently mixed and incubated at $37^{\circ} \mathrm{C}$ for $2 \mathrm{~h}$ (unless the enzyme worked optimally at another temperature, for example Sma1@ $\left.25^{\circ} \mathrm{C}\right)$. After the reaction was completed the digested plasmid DNA was run on a gel to confirm complete digestion and product size. In general a $1 \%$ agarose $(\mathrm{w} / \mathrm{v})$ gel in $1 \mathrm{X}$ TAE with $0.2 \mu \mathrm{g} / \mathrm{mL}$ ethidium bromide was used, and the entire $20 \mu \mathrm{L}$ digest reaction volume was loaded with the appropriate amount of $6 \mathrm{X}$ gel-loading buffer $(50 \%(\mathrm{v} / \mathrm{v})$ glycerol, $0.1 \%$ bromophenol blue) into individual lanes.

\subsection{Gel purification of DNA templates}

The linearized templates produced by restriction enzyme digestion were purified out of the agarose gel for downstream in vitro transcription reactions as per the following. This 
procedure provides a pure pool of DNA of the same size and prevents any carryover of indigested DNA. Individual bands of the correct size were excised from the agarose gel using a clean razor blade, taking as little agarose as possible, and placed into a gel nebulizer within an ultrafree-MC purification column from a Montage Ultrafree-DA kit (Millipore, Billerica, MA). This step had to be done using a hand-held UV lamp in order to see the band of interest. The tube(s) were centrifuged at $5000 \mathrm{xg}$ for $10 \mathrm{~min}$. The flow-through contained the DNA in electrophoresis buffer separated from the agarose gel. To further purify the DNA it was precipitated using 0.1 volume of $3 \mathrm{M}$ sodium acetate (BioShop), $\mathrm{pH}$ 5.2, and 2.5 volumes of $100 \%$ ethanol. This solution was placed at $-20^{\circ} \mathrm{C}$ for 30 min and then collected by centrifuging at $14000 \mathrm{rpm}$ at $4^{\circ} \mathrm{C}$ for $10 \mathrm{~min}$. The supernatant was discarded and the pellet resuspended in $30 \mu \mathrm{L}$ of DEPC-treated water.

\subsection{Riboprobe preparation}

Digoxygenin (DIG)-labelled anti-sense riboprobes were employed for both northern hybridization and whole mount in situ hybridization. Probe synthesis was carried out according to manufacturer's instructions with minor modifications (Roche Molecular Biochemicals). In vitro transcription reactions were carried out similarly for each probe/gene except that each linearized template was unique and the RNA polymerase used was dictated by the orientation of the insert with respect to the polymerase site on the plasmid. Each reaction consisted of $5.5 \mu \mathrm{L}$ linearized template, $4 \mu \mathrm{L}$ NTP's (2.5 mM rGTP, $2.5 \mathrm{mM}$ rATP, $2.5 \mathrm{mM} \mathrm{rCTP}, 1.65 \mathrm{mM}$ rUTP and 0.875 mM DIG-11-UTP) (Roche Molecular Biochemicals), $4 \mu \mathrm{L} 100 \mathrm{mM}$ dithiothreitol (DTT) (BioShop), $4 \mu \mathrm{L} 5 \mathrm{X}$ transcription buffer 
(Roche Molecular Biochemicals), $0.5 \mu \mathrm{L}$ RNase inhibitor (Roche Molecular Biochemicals) and $2 \mu \mathrm{L}$ RNA polymerase (MBI Fermentas, Burlington, ON). This solution was mixed gently and incubated at $37^{\circ} \mathrm{C}$ for $2 \mathrm{~h}$. Following this, $2 \mu \mathrm{L}$ RNase-free DNase 1 (Roche Molecular Biochemicals) was added to digest the original DNA template and left to incubate for $15 \mathrm{~min}$ at $37^{\circ} \mathrm{C}$. The resulting transcripts were precipitated with $10 \mu \mathrm{L} 3 \mathrm{M}$ sodium acetate (BioShop), pH 5.2, $220 \mu \mathrm{L} \mathrm{100 \%} \mathrm{ethanol,} 80 \mu \mathrm{L}$ of 1\% SDS (w/v) (BioShop) in Tris-EDTA buffer (TE) at $-20^{\circ} \mathrm{C}$ for $30 \mathrm{~min}$. The RNA was collected by centrifugation at $14000 \mathrm{rpm}$ at $4^{\circ} \mathrm{C}$ for $10 \mathrm{~min}$. The transcripts were stored at $-80^{\circ} \mathrm{C}$ until used for hybridization. The supernatant was removed and the pellet resuspended in $21 \mu \mathrm{L}$ DEPC-treated water. A $1 \mu \mathrm{L}$ aliquot of the riboprobe was run on a formaldehyde-agarose gel containing ethidium bromide and visualized with UV light to ensure a single band of the expected size.

\subsubsection{Specific riboprobe conditions}

The $h s p 110$ and ef-1 $\alpha$ cDNA clones (Genbank accession no. BF428504 and BG160504 respectively) in pCMV-Sport6 vectors (Invitrogen Life Technologies, Frederick, MD) were obtained from the ATCC. Both $h s p 110$, and ef-1 $\alpha$, anti-sense riboprobes were produced by linearizing the vector constructs with Smal, and transcribing with T7 RNA polymerase, as described previously (Figure 3 and Figure 4). Sense hsp 110-riboprobe was produced by linearizing the construct with Xhol and transcribing with SP6 RNA polymerase. The $h s p 27$ clone (Genbank accession no. DQ473544) in pCS107 plasmid was also obtained from the 
ATCC. To synthesize anti-sense riboprobe, pCS107-hsp27 was linearized with BamHI, and transcribed in vitro with T7 RNA polymerase (Figure 5). 
Figure 3. Template for hsp110 in vitro transcription

A portion of the coding region of $h s p 110$ was cloned into pCMV-SPORT6 (Invitrogen) to generate pCMV-SPORT6-hsp110 (ATCC). To generate antisense riboprobe, pCMVSPORT6-hsp110 was linearized with SmaI and transcribed in vitro with T7 RNA

polymerase. To generate sense riboprobe, pCMV-SPORT6 was linearized with XhoI and transcribed with SP6 RNA polymerase. 


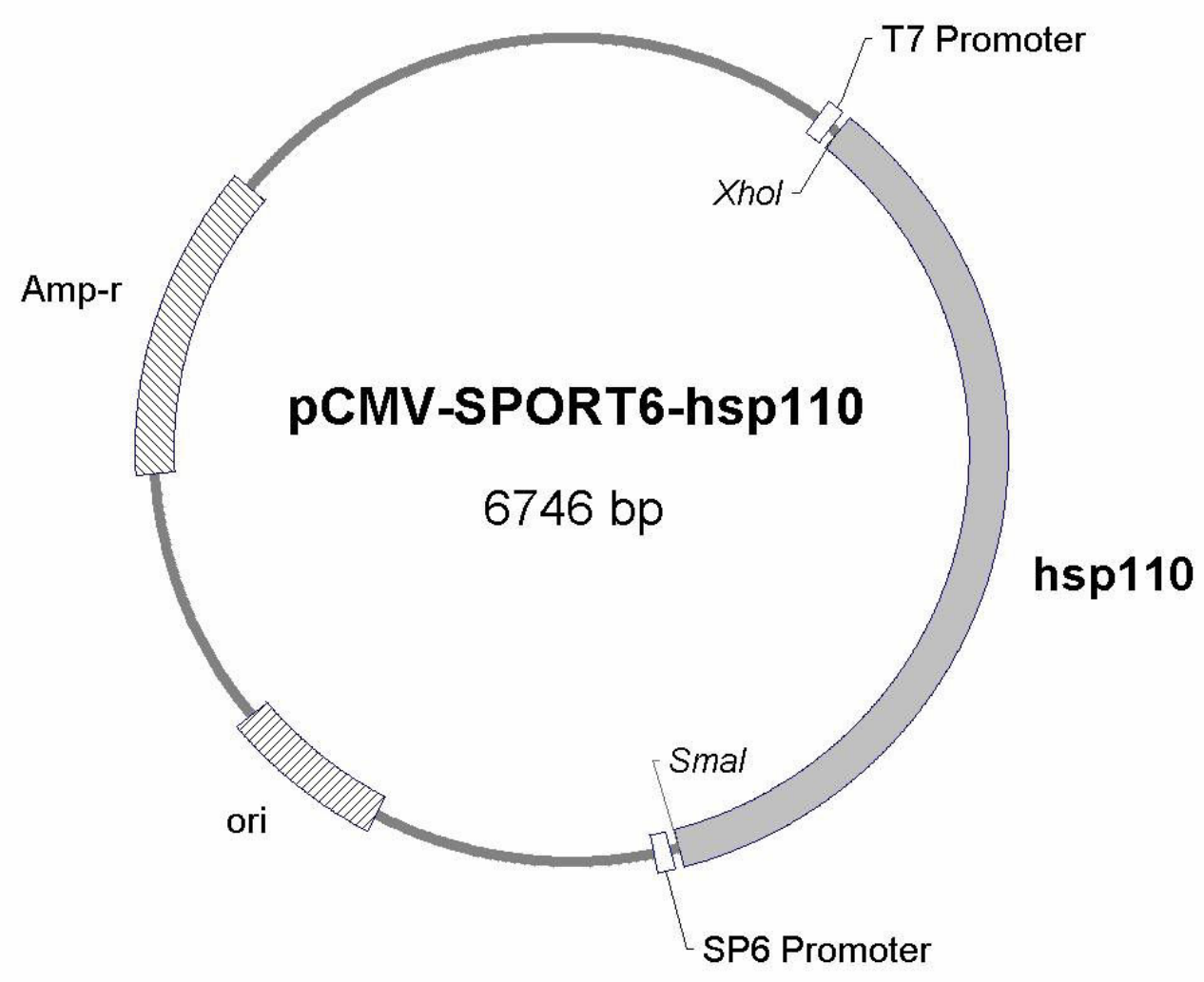




\section{Figure 4. Template for ef-1 $\alpha$ in vitro transcription}

The coding region of ef- $1 \alpha$ was cloned into pCMV-SPORT6 (Invitrogen), generating

pCMV-SPORT6-ef-1 $\alpha$ (ATCC). To synthesize antisense riboprobe, pCMV-SPORT6-ef-1 $\alpha$ was linearized with SmaI and transcribed in vitro with T7 polymerase. 


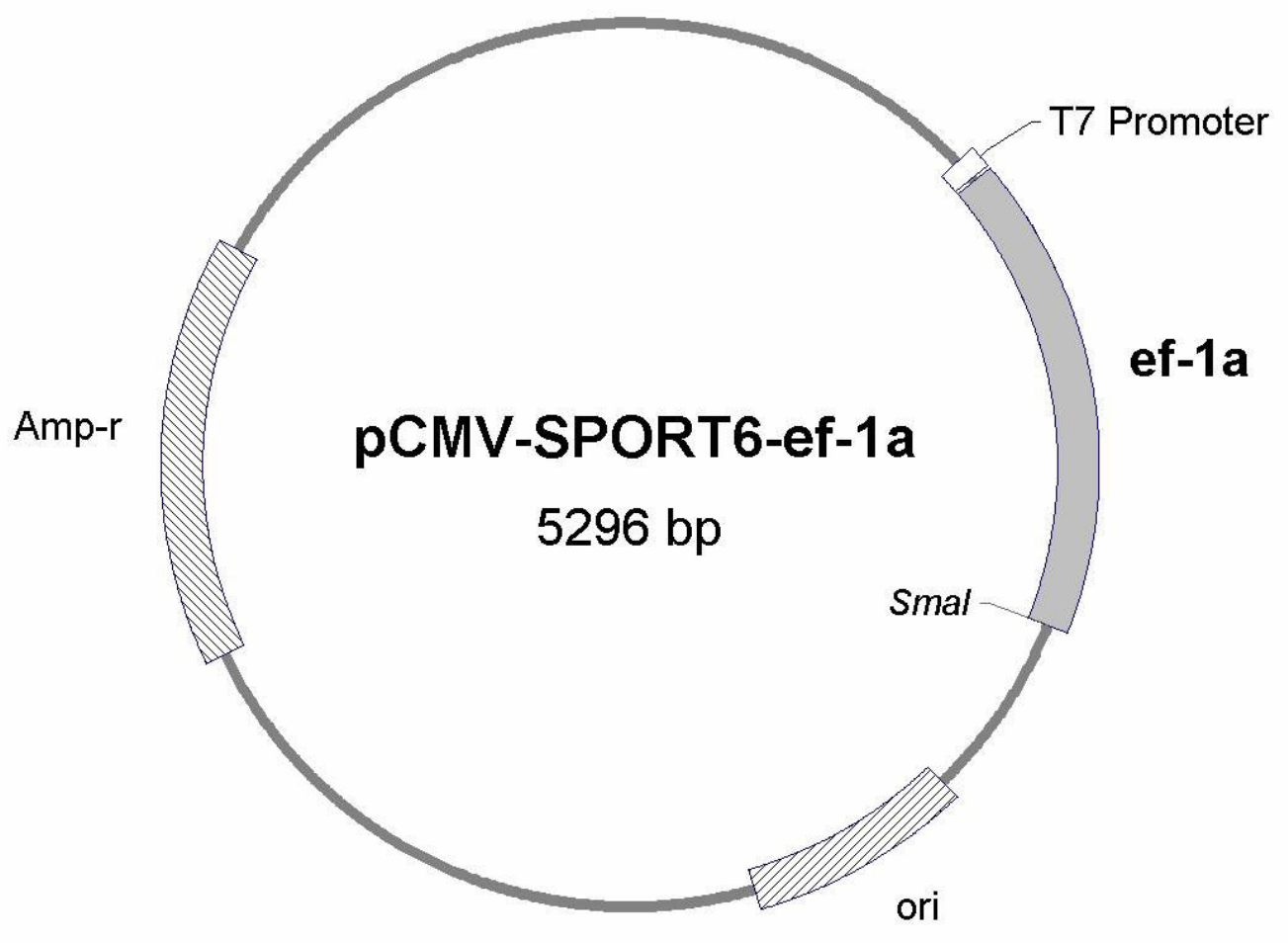




\section{Figure 5. Template for hsp27 in vitro transcription}

The coding region of the hsp27 gene was cloned into pCS107 (Invitrogen) to generate

pCMV-SPORT6-hsp27 (ATCC). To synthesize antisense riboprobe, pCMVSPORT6-hsp27

was linearized with BamHI and transcribed in vitro with T7 RNA polymerase. 


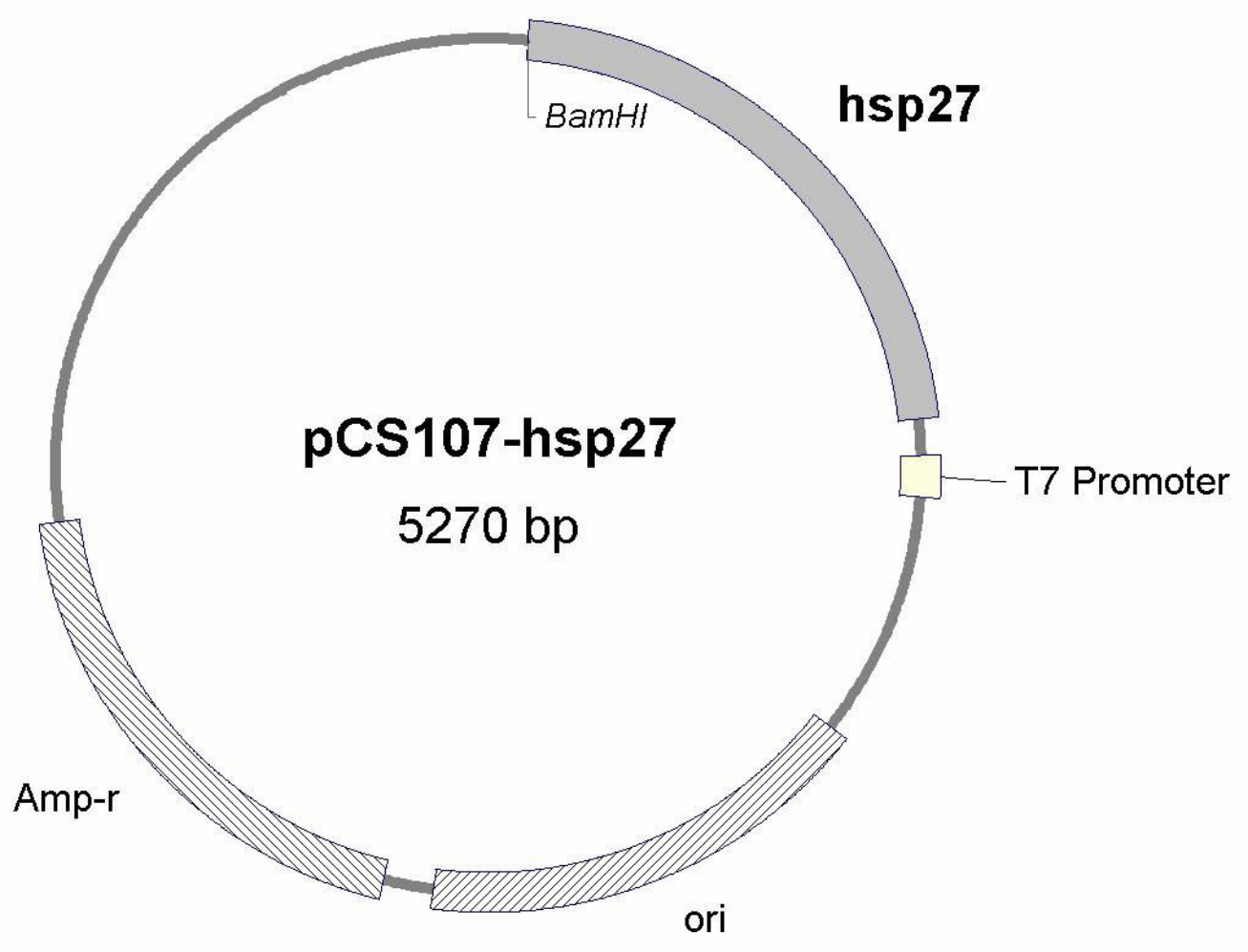


The actin clone used here was the type 8 cytoskeletal actin cDNA from pXIcAI (Mohun et al., 1983). The coding region of actin was previously cloned into the HindIII site of pBlueScript KS (Gibco/BRL Laboratories, Burlington, ON) generating pBlue-actin. To synthesize anti-sense riboprobe, pBlue-actin was linearized with EcoRI and transcribed in vitro with T3 polymerase (Figure 6). The coding region of hsp70 from pXL16P (Bienz, 1984) was excised with Fsp 1 and Pstl, and cloned into SmaI and PstI of pSP72 (Promega) generating pSP72-hsp70. To synthesize anti-sense riboprobe, pSP72-hsp70 was linearized with MluNI and transcribed in vitro with SP6 RNA polymerase (Figure 7). To synthesize sense riboprobe, pSP72-hsp70 was linearized with $X h o I$ and transcribed in vitro with T7 RNA polymerase, as described previously (Lang et al., 2000). All specific riboprobe generation information has been summarized in Table 2.

Table 2. Specific riboprobe generation conditions

\begin{tabular}{cccc}
\hline Gene Insert & Plasmid & Restriction Enzyme & RNA Polymerase \\
\hline Hsp110 & pCMV-SPORT6 & Smal & T7 \\
Hsp27 & pCS107 & BamH1 & T7 \\
Hsp70 & pSP72 & MluN1 & SP6 \\
Actin & pBluescript KS & EcoR1 & $\mathrm{T} 3$ \\
EF-1 $\alpha$ & pCMV-SPORT6 & Smal & $\mathrm{T} 7$ \\
\hline
\end{tabular}




\section{Figure 6. Template for actin in vitro transcription}

The coding region of the type 8 cytoskeletal actin gene contained in pXIcAI (Mohun et al., 1983) was cloned into the HindIII site of pBluescript KS (Fermentas), generating pBlue-

actin. To generate antisense riboprobe template, the plasmid was linearized with EcoRI and transcribed with T3 RNA polymerase. 


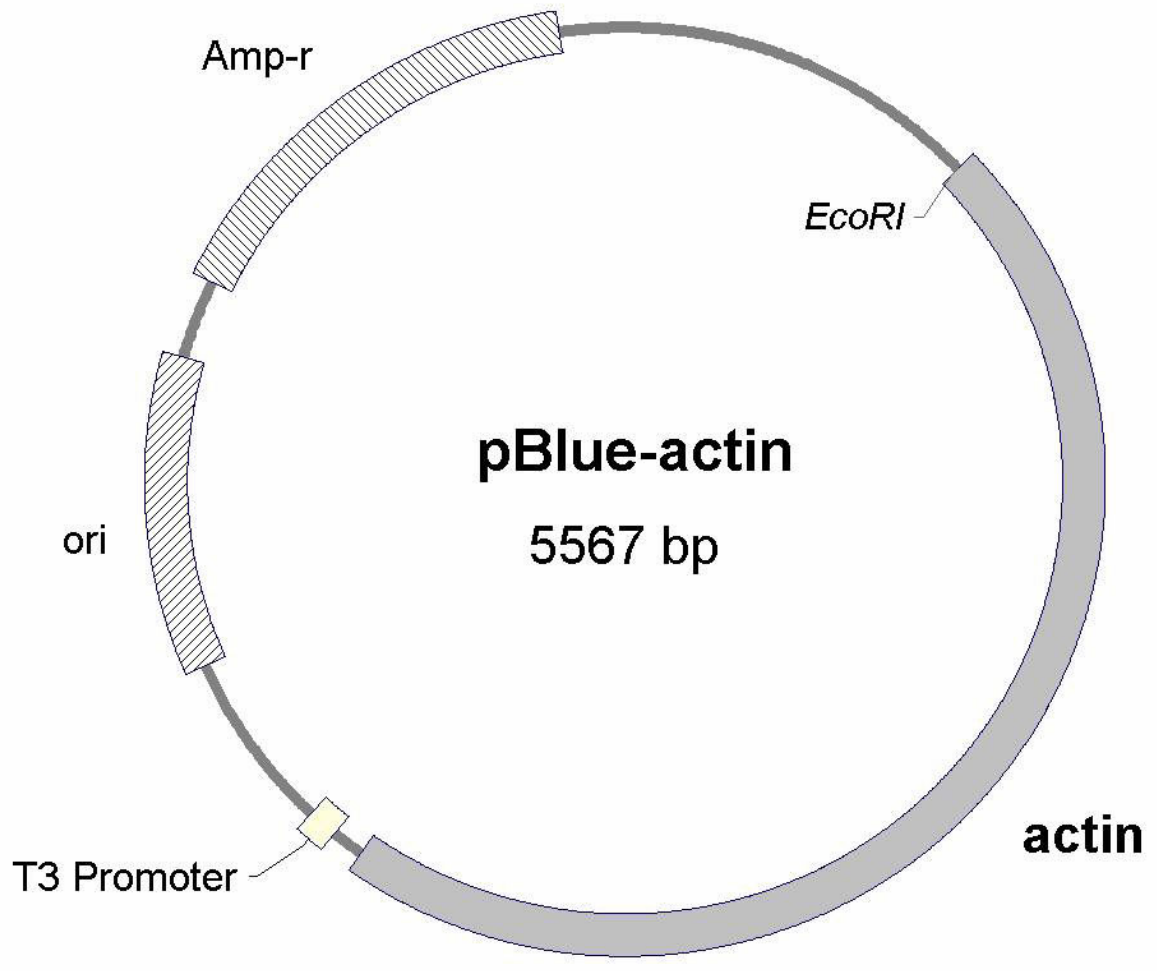




\section{Figure 7. Template for hsp70 in vitro transcription}

The coding region of the $h s p 70$ gene contained in pXL16P (Bienz, 1984b) was cloned into the SmaI and Pst1 sites of pSP72 (Promega), generating pSP72-hsp70. To generate antisense riboprobe template, the plasmid was linearized with MluNI and transcribed with SP6 polymerase. To generate sense riboprobe template, the plasmid was linearized with XhoI and transcribed with T7 RNA polymerase. 


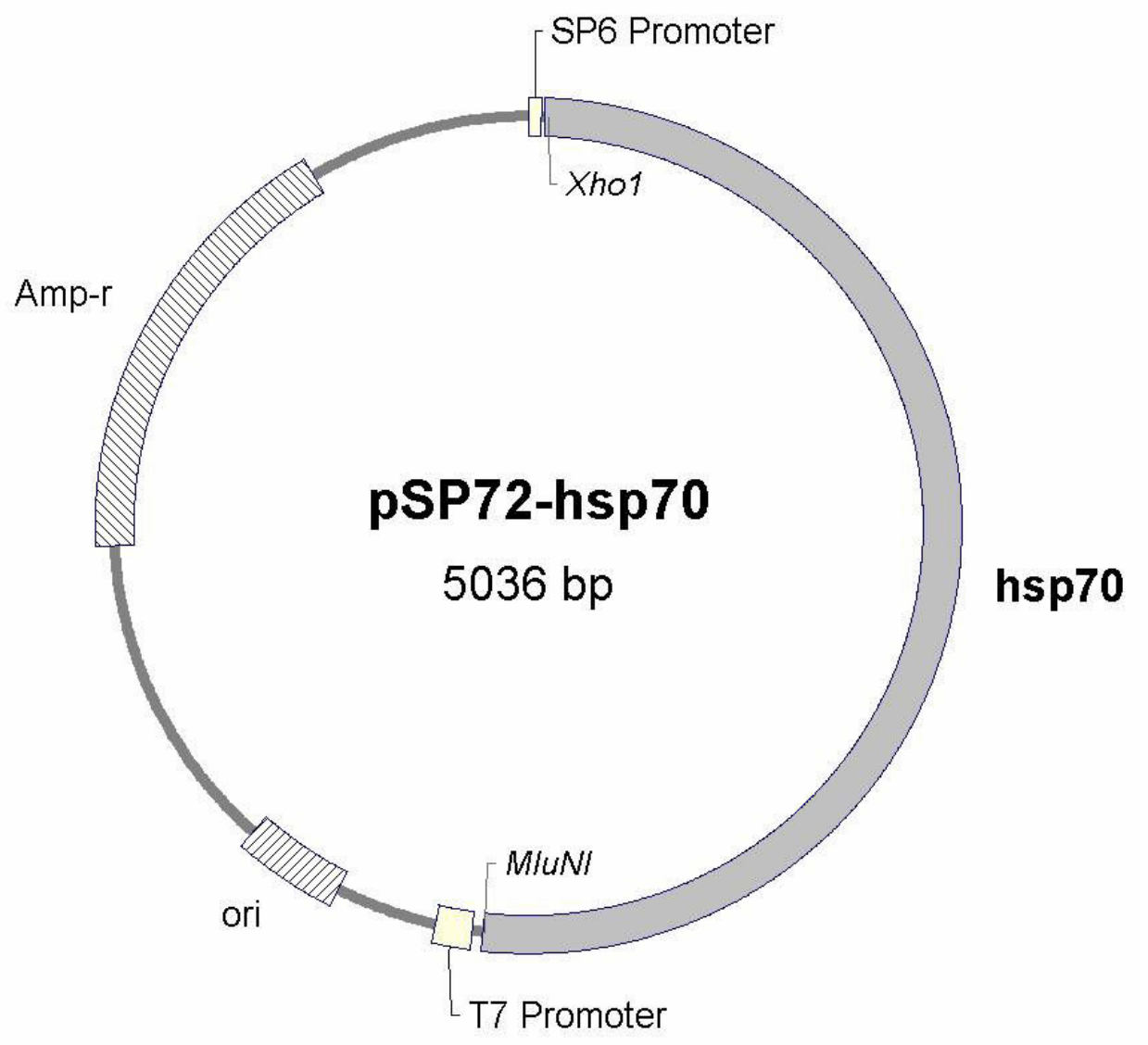




\subsection{Northern hybridization}

Northern hybridizations were performed, with modifications, as per Sambrook and Russell (2001), and manufacturer's directions (Roche Molecular Biochemicals). RNA samples were aliquotted in microcentrifuge tubes, and if necessary, concentrated using a speed vac (Savant, Ramsey, MN). RNA was electrophoresed as described previously, at $60 \mathrm{~V}$ for approximately $4 \mathrm{~h}$ to ensure adequate resolution. To prepare the gel for transfer it was immersed for $20 \mathrm{~min}$ in $0.05 \mathrm{~N} \mathrm{NaOH}$, followed by two 20 min soaks in $20 \mathrm{X} \mathrm{SSC}(3 \mathrm{M} \mathrm{NaCl}, 300 \mathrm{mM}$ sodium citrate, $\mathrm{pH} 7.0$, in DEPC-treated water).

At this point the RNA was transferred by capillary action to a positively charged nylon membrane (Roche Molecular Biochemicals). The gel was placed on a 3MM Whatman filter paper wick, inverted. This apparatus was positioned in a dish containing 20X SSC to saturate the wick and gel continuously. A positively charged nylon membrane was cut to the size of the gel and placed directly on it. Then two pieces of 3MM Whatman filter paper of the same size were placed on the membrane, followed by a stack (approximately $10 \mathrm{~cm}$ tall) of paper towels, also cut to the size of the gel. At each step, air bubbles were eliminated by gently rolling with a clean pipette. Parafilm was placed on all edges of the gel support to prevent any contact between the wick and any element of the transfer above the gel. Finally, a glass plate was placed on the paper towel stack with a weight of approximately $500 \mathrm{~g}$ to evenly distribute weight and facilitate overnight capillary transfer.

The next day the RNA was cross-linked using a UVC 515 Ultraviolet Multilinker (120 000 $\mu \mathrm{J} / \mathrm{cm} 2$; UltraLum Inc., Claremont, $\mathrm{CA}$ ) to the membranes with UV light and stained with 
reversible RNA blot stain (Sigma-Aldrich) to verify equal sample loading and transfer efficiency prior to hybridization. This was done by first immersing the membrane in $10 \%$ (v/v) acetic-acid (in DEPC-treated water) for $5 \mathrm{~min}$, followed by $5 \mathrm{~min}$ in a 1:10 dilution of Blot Stain Blue blot staining solution (Sigma-Aldrich). The membrane was then rinsed with water to remove any non-specific background staining. The membrane was then scanned with a conventional computer scanner. Upon confirmation of a good transfer, the membrane was probed for the gene of interest.

Prior to adding the riboprobe the membrane was prepared for hybridization. The membrane was sealed in a KAPAK sealable pouch (VWR Canlabs, Mississauga, ON) with $50 \mathrm{~mL}$ prehybridization buffer (5X SSC, 50\% formamide, $2 \%(\mathrm{w} / \mathrm{v})$ blocking reagent (Roche Molecular Biochemicals), 0.1\% (w/v) N-laurylsarcosine, 0.02\% (w/v) SDS) and gently mixed at $68^{\circ} \mathrm{C}$ for $4 \mathrm{~h}$. Then the hybridization buffer was added, which is $50 \mathrm{~mL}$ of 'prehybridization buffer with $20 \mu \mathrm{L}$ of riboprobe prepared as previously described. The hybridization was left overnight.

The hybridization buffer was removed (and could be reused in the future) and the membrane was washed twice in $2 \mathrm{X} \mathrm{SSC}, 0.1 \%(\mathrm{w} / \mathrm{v}) \mathrm{SDS}$ at $68^{\circ} \mathrm{C}$ for $5 \mathrm{~min}$, once in $0.5 \mathrm{X}$ $\mathrm{SSC}, 0.1 \%(\mathrm{w} / \mathrm{v}) \mathrm{SDS}$ at $68^{\circ} \mathrm{C}$ for $15 \mathrm{~min}$, and once in $0.1 \mathrm{X} \mathrm{SSC}, 0.1 \%(\mathrm{w} / \mathrm{v}) \mathrm{SDS}$ at room temperature (RT) for $15 \mathrm{~min}$. The membrane was then briefly washed in washing buffer (100 mM maleic acid (BioShop), $150 \mathrm{mM} \mathrm{NaCl}, \mathrm{pH}$ 7.5, 0.3\% (v/v) Tween 20 (Sigma-Aldrich) for $1 \mathrm{~min}$ and then blocked in $2 \%$ blocking buffer $(2 \%(\mathrm{w} / \mathrm{v})$ blocking reagent, $100 \mathrm{mM}$ maleic acid, $150 \mathrm{mM} \mathrm{NaCl}, \mathrm{pH} 7.5$ ) for 30 min with gentle shaking at RT. The anti-DIG 
alkaline phosphatise FAB fragments antibody (Roche Molecular Biochemicals) was then added to the membrane in fresh $2 \%$ blocking buffer at 1:8000 dilution for $30 \mathrm{~min}$ at RT. The membrane was then washed twice in washing buffer for $15 \mathrm{~min}$ at RT, and once in detection buffer $(0.1 \mathrm{M}$ Tris, $\mathrm{pH} 9.5,0.1 \mathrm{M} \mathrm{NaCl})$ for $2 \mathrm{~min}$ at RT. Finally, the membrane was placed on a fresh sealable bag and the substrate CDP-Star (Roche Molecular Biochemicals) was added evenly to the membrane, avoiding air bubbles, for $10 \mathrm{~min}$ in the dark at RT. Chemiluminescence was detected using a FluorChem imager (Alpha Innotech, San Leandro, CA).

\subsection{Whole mount in situ hybridization}

Albino embryos were solely used for whole mount in situ hybridization, to avoid any confusion between natural pigmentation and colorimetric detection of the DIG-labelled riboprobe, using procedures modified from those previously described (Harland, 1991; Lang et al., 1999; 2000). The riboprobes were prepared exactly as for a northern hybridization, as described above. Sense-riboprobes were used for in situ as a negative control in these experiments. For each experimental condition/stage, approximately 15 embryos were used, to ensure representative information.

Embryos previously treated and fixed, as described previously, were transferred to appropriately labelled $6 \mathrm{~mL}$ glass vials (VWR Canlabs) which had been previously treated with Sigmacote (Sigma-Aldrich) to prevent embryos from sticking to the glass. Since the embryos had been stored in $100 \%$ methanol, they were gradually rehydrated. This was done by washing them in decreasing concentrations of methanol (100\% to $75 \%$ to $50 \%$ methanol 
in water, to $25 \%$ methanol in TTw buffer ( $10 \mathrm{mM} \mathrm{NaCl}, 2.5 \mathrm{mM}$ Tris, $\mathrm{pH} 7.4,0.1 \%$ (v/v) Tween 20), and finally to straight TTw for 3 washes). After this the embryos were permeabilized for 20 min with $5 \mu \mathrm{g} / \mathrm{mL}$ proteinase $\mathrm{K}$ (Roche Molecular Biochemicals), and then immersed twice for $5 \mathrm{~min}$ in $0.1 \mathrm{M}$ triethanolamine, $\mathrm{pH}$ 7. Next the embryos were treated with $5 \mu \mathrm{L} /$ vial acetic anhydride for $5 \mathrm{~min}$ to prevent non-specific binding of the riboprobe. This step was repeated to refresh the acetic anhydride. The embryos were then washed twice for $5 \mathrm{~min}$ in TTw and then re-fixed in MEMPFA for $20 \mathrm{~min}$. After this, the embryos were washed thoroughly 5 times to prepare for hybridization. Embryos were rinsed in prehybridization buffer ( $50 \%(\mathrm{v} / \mathrm{v})$ formamide, $5 \mathrm{X} \mathrm{SSC}, 1 \mathrm{mg} / \mathrm{mL}$ Torula RNA, $1 \mathrm{X}$ Denhardts solution, $0.1 \%$ (v/v) Tween 20, $5 \mathrm{mM}$ EDTA, $100 \mu \mathrm{g} / \mathrm{mL}$ heparin) briefly. After this was removed, the embryos were immersed in fresh prehybridization buffer for $2 \mathrm{~h}$ at $65^{\circ} \mathrm{C}$. Finally, the prehybridization buffer was removed, and replaced with the appropriate DIG-labelled riboprobes in the same buffer. The embryos were then allowed to hybridize overnight at $60^{\circ} \mathrm{C}$.

The next day, the probe was removed (for reuse) and the embryos were gradually moved out of hybridization buffer. First they were rinsed in $100 \%$ hybridization buffer for $10 \mathrm{~min}$ at $60^{\circ} \mathrm{C}$, followed by $50 \%$ hybridization buffer $/ 50 \% 2 \mathrm{XSC}$ for $10 \mathrm{~min}$ at $60^{\circ} \mathrm{C}$, followed by $25 \%$ hybridization buffer $/ 75 \% 2 \mathrm{X} \mathrm{SSC}$ at $60^{\circ} \mathrm{C}$, and finally $100 \% 2 \mathrm{XSSC}$ twice for $20 \mathrm{~min}$ at RT. At this time $1 \mu \mathrm{L} / \mathrm{mL}$ RNase A in $2 \mathrm{X}$ SSC was added to the embryos for $30 \mathrm{~min}$ at $37^{\circ} \mathrm{C}$ to degrade any remaining probe. This was followed by two high stringency washes in $0.2 \mathrm{X} \mathrm{SSC}$ at $60^{\circ} \mathrm{C}$ for $1 \mathrm{~h}$. At this point the embryos were prepared for the secondary 
antibody incubation with a 10 min incubation in TTw at RT, followed by a 10 min incubation in TBT (20 mM NaCl, $2.5 \mathrm{mM}$ Tris, $\mathrm{pH}$ 7.4, $2 \mathrm{mg} / \mathrm{mL}$ BSA, 0.1\% (v/v) Triton X-100) at RT. In order to prevent non-specific binding, the embryos were blocked with TBT containing $20 \%$ lamb serum at RT for $1 \mathrm{~h}$, and then the same solution was again added to the embryos, but this time containing a 1:3 000 dilution of alkaline phosphatase-conjugated anti-DIG antibody. The embryos were then left overnight at $4{ }^{\circ} \mathrm{C}$ with gentle shaking.

The next day, the embryos were washed 12 times for $30 \mathrm{~min}$ in TBT at RT, to remove excess antibody. Then they were incubated twice for $15 \mathrm{~min}$ at RT with alkaline phosphatase (AP) buffer (100 mM Tris, pH 9.5, $100 \mathrm{mM} \mathrm{NaCl}, 50 \mathrm{mM} \mathrm{MgCl} 2,2 \mathrm{mM}$ levamisol (SigmaAldrich), $0.1 \%$ Tween 20 ). They were then incubated overnight at $4^{\circ} \mathrm{C}$ with staining solution ( $0.85 \mu \mathrm{L} / \mathrm{mL}$ nitroblue tetrazolium chloride (NBT; Roche Molecular Biochemicals), 0.875 $\mu \mathrm{L} / \mathrm{mL}$ bromo-4-chloro-3-indolyl phosphate (BCIP; Roche Molecular Biochemicals) in AP buffer).

On the second last day of the procedure the hybridized message was visualized in the embryos. First the staining reaction was stopped by dehydrating the embryos in methanol gradually ( $0 \%$ to $25 \%$ to $50 \%$ to $75 \%$ to $100 \%$ methanol: water). The embryos were maintained in chilled $100 \%$ methanol until any background staining was sufficiently removed (no more stain was leaching out). When the results looked satisfactory the embryos were rehydrated by gradually decreasing the concentrations of methanol and finally counterstained with Bouin's Fixative (VWR Canlabs) overnight at RT. 
On the last day of the procedure visualization of embryos was facilitated by clearing. They were once again dehydrated by subjecting them to increasing concentrations of methanol (as previously described). Finally, they were immersed in clearing buffer (benzyl alcohol:benzyl benzoate, 1:2; BABB) in the wells of a glass watchplate. Embryos were viewed using a Nikon SMZ 1500 dissecting microscope and photographed with a Nikon Coolpix 995 digital camera. After photographing the embryos were rinsed twice in $100 \%$ methanol and then stored in $100 \%$ methanol at $-20^{\circ} \mathrm{C}$.

\subsection{A6 cell protein isolation}

A6 cell pellets were resuspended in homogenization buffer (200 mM sucrose, $2 \mathrm{mM}$ EGTA, 1mM EDTA, 40 mM NaCl, 30 mM HEPES, 1\% SDS, $100 \mu \mathrm{g} / \mathrm{mL}$ PMSF, $1 \mu \mathrm{g} / \mathrm{mL}$ aprotnin, $0.5 \mu \mathrm{g} / \mathrm{mL}$ leupeptin, $\mathrm{pH} 7.4$ ) in a micro-centrifuge tube, homogenized with 10 passes of a Teflon pestle, and sonicated using 15 0.65-s pulses at $35 \mathrm{~W}$ (Branson model 240 Sonifier, Danbury, CT). Cellular debris was removed by centrifugation at $14000 \mathrm{rpm}$ in an Eppendorf Centrifuge 5810R (Brinkmann Instruments Ltd.) for $30 \mathrm{~min}$ at $4^{\circ} \mathrm{C}$ and the protein-containing supernatant was transferred to a new tube.

\subsubsection{Protein quantification}

In order to determine the protein concentration in each sample the bicinchoninic acid (BCA) method was used according to manufacturer's instructions (Pierce, Brockville, ON). Bovine serum albumin (BSA) was used as the standard and was diluted in $0.2 \mathrm{mg} / \mathrm{mL}$ increments from the original $2 \mathrm{mg} / \mathrm{mL}$ concentration to zero, to obtain a standard dilution 
curve. A6 cell protein samples were diluted 1:10 in water prior to assaying to obtain values within the standard curve dimensions. For the assay, $10 \mu \mathrm{L}$ of all samples, including A6 cell protein unknowns and BSA standard dilutions, was added to individual wells of a 96-well plate in triplicate. $\mathrm{BCA}$ reagent (reagent $\mathrm{A}$ : reagent $\mathrm{B}, 50: 1$ ) was mixed immediately prior to use, and $80 \mu \mathrm{L}$ was added per well. The plate was incubated at $37^{\circ} \mathrm{C}$ for $30 \mathrm{~min}$, and then at RT for 10 min following. The absorbance at $562 \mathrm{~nm}$ was measured using a Versamax Tunable microplate reader (Molecular Devices, Sunnyvale, CA) and Soft Max pro software. The protein concentrations in each sample were determined using the absorbance values and interpolating concentrations from the standard curves generated from the BSA standards. The protein was then resolved on a Coomassie Brilliant Blue stained gel described in the next section) to assess reliability of protein concentrations and protein degradation.

\subsection{Custom antibody production}

Several commercially available antibodies for Hsp110 were tried in immunoblot analyses with Xenopus laevis protein, although they were not marketed to display cross-reactivity with Xenopus. I tried SPA1101D, SPA1103D (Stressgen, Victoria, BC) and H-7287(HD19) (Sigma-Aldrich), each of which are hsp110 antibodies with differing epitope regions. Unfortunately all antibodies produced extensive non-specific binding of the antibody to the membrane, rendering them ineffective for western blotting, and especially for immunohistochemical analysis.

Rabbit anti-(Xenopus) antibodies against Hsp110 and Hsp70 were custom produced for our laboratory (Abgent, San Diego, CA). Briefly, a C-terminal peptide was synthesized (Hsp110 
- ACHPNEKSTIDMDFD, Hsp70 - AEKYKADDDAQRERVC), with a cysteine added to the N-terminal end of the peptide to enable keyhole limpet hemocyanin (KLH) conjugation, which ultimately increases antigenicity. The methodology employed by the company involved the collection of a serum sample prior to immunization of the rabbits (pre-immune serum). Rabbits were then immunized subcutaneously and intra-muscularly with $200 \mu \mathrm{g} / \mathrm{mL}$ conjugated peptide emulsified in Complete Freund's Adjuvant (CFA) (week 0). The rabbits were re-immunized $100 \mu \mathrm{g}$ antigen 2 weeks later (week 2). Two weeks following that, they were immunized with $100 \mu \mathrm{g}$ antigen in Incomplete Freund's Adjuvant (IFA) (week 4). From then until week 9 the rabbits received $100 \mu \mathrm{g}$ antigen in PBS per week. Test bleeds were collected from rabbits on week 5, and enzyme-linked immunosorbent assay's (ELISA's) and western blots were carried out to ensure that antibody was being produced. The terminal bleed was carried out on week 10 . The antibody was then affinity purified against the peptide and a final ELISA and western blot was done to ensure specificity and titre of the antibody.

\section{$2.11 \mathrm{Immunoblot}$ analysis}

Protein samples to be subjected to immunoblot analysis were thawed slowly and aliquotted into new microcentrifuge tubes based on the protein concentrations from the BCA assay. The amount of protein loaded on the gel was dependent upon the potency of the antibody to be used. The protein was mixed with an appropriate amount of water, to equalize volume between samples, and denaturing loading buffer ( $0.0625 \mathrm{M}$ Tris, $\mathrm{pH} 6.8,10 \%(\mathrm{v} / \mathrm{v})$ glycerol, 2\% (w/v) SDS, $0.5 \%$ (v/v) $\beta$-mercaptoethanol, $0.00125 \%$ (w/v) bromophenol blue). 
Immediately prior to sodium dodecyl sulphate-polyacrylamide gel electrophoresis (SDSPAGE), samples were boiled for $10 \mathrm{~min}$, cooled and briefly centrifuged to collect the sample in the bottom of the tube.

Discontinuous gel electrophoresis was carried out with a Mini Protean III (Bio-Rad, Mississauga, $\mathrm{ON})$ and manufacturer's instructions were followed. The separating gel (10\% polyacrylamide gels (10\% (v/v) polyacrylamide, $0.375 \mathrm{M}$ Tris $\mathrm{pH} 8.8,0.1 \%(\mathrm{w} / \mathrm{v}) \mathrm{SDS}$, $0.05 \%(\mathrm{w} / \mathrm{v})$ ammonium persulfate (APS), $0.15 \%(\mathrm{v} / \mathrm{v}) \mathrm{n}, \mathrm{n}, \mathrm{n}$ 'n'-Tetramethylethylenediamine (TEMED)) was poured and fully polymerized (approximately $30 \mathrm{~min}$ ) followed by the stacking gel (4\% (v/v) polyacrylamide, $0.125 \mathrm{M}$ Tris $\mathrm{pH} 6.8,0.1 \%(\mathrm{w} / \mathrm{v})$ SDS, $0.05 \%(\mathrm{w} / \mathrm{v})$ APS, $0.2 \%$ (v/v) TEMED) (approximately $25 \mathrm{~min}$ ). The gels were assembled in the rig, immersed in $1 \mathrm{X}$ TGS (25 mM Tris, $0.2 \mathrm{M}$ glycine, $1 \mathrm{mM} \mathrm{SDS}$ ) and then the protein samples were loaded into the wells and electrophoresed at $90 \mathrm{~V}$. When the loading dye front reached the bottom of the separating gel the voltage was stopped.

If the protein gel was destined for Coomassie staining (checking protein quality, as mentioned earlier), the gel was removed from the apparatus, rinsed in water, and immersed in Coomassie Staining Solution (50\% methanol, 10\% glacial acetic acid, $0.25 \%$ Coomassie Brilliant Blue R-250 (Sigma-Aldrich)). The gel was gently shaken in this solution for $1 \mathrm{~h}$ at RT, and then rinsed overnight in destaining solution (50\% methanol, 10\% glacial acetic acid) to remove background staining.

Gels destined for immunoblot analysis were soaked in transfer buffer (25 mM Tris, 192 $\mathrm{mM}$ glycine, $10 \%(\mathrm{v} / \mathrm{v})$ methanol) for $15 \mathrm{~min}$, while the membranes they were to be 
transferred to were soaked for $30 \mathrm{~min}$. Proteins were transferred to polyvinylidene difluoride (PVDF) membranes (Millipore) at 20V for 20 min using a Trans Blot Semi-dry Transfer Cell (Bio-Rad). Following transfer, membranes were stained immediately in Ponceau-S (SigmaAldrich; 0.19\% (w/v) Ponceau-S, 5\% (v/v) acetic acid)) for $10 \mathrm{~min}$, to verify equal loading of protein and transfer efficiency. The membranes were scanned with a Hewlett Packard ScanJet 3300C. The membranes were then blocked with blocking solution $(5 \%$ (w/v) skim milk powder in wash buffer (TBS-T; 2mM Tris, $\mathrm{pH} 7.5,30 \mathrm{mM} \mathrm{NaCl,} \mathrm{0.1 \%} \mathrm{(v/v)} \mathrm{Tween}$ 20)) for $1 \mathrm{~h}$ at RT with gentle shaking.

The membranes were then incubated in the appropriate polyclonal primary antibody diluted in blocking solution and gently shaken at RT for $1 \mathrm{~h}$ (Table 3). After this, the membranes were washed in TBS-T three times for $10 \mathrm{~min}$.

Table 3. Polyclonal antibodies employed for this study

\begin{tabular}{llll}
\hline Antibody: & Animal raised in: & Dilution used: & Manufacturer: \\
\hline Hsp110-commercial & Rabbit & $1: 2000$ & StressGen, Victoria, BC \\
Hsp110-custom & Rabbit & $1: 850$ & Abgent, San Diego, CA \\
Hsp70-custom & Rabbit & $1: 200$ & Abgent, San Diego, CA \\
Actin-commercial & Mouse & $1: 200$ & Sigma-Aldrich \\
\hline
\end{tabular}

Membranes incubated with the commercial hamster Hsp110 antibody (StressGen, cat. \#SPA1101), were incubated with horseradish peroxidise (HRP)-conjugated goat anti-rabbit IgG secondary antibody (Cedarlane, Hornby, ON) diluted 1:3000 in blocking solution for 1 h. The membranes were again washed three times in TBS-T for $10 \mathrm{~min}$. Finally they were detected using ECL-plus chemiluminescent substrate (Amersham Biosciences, Brockville, 
ON), and imaged using the FluorChem Chemiluminescent imager (Alpha Innotech Corp., San Leandro, CA). Actin blots were incubated with AP-conjugated secondary IgG (Bio-Rad), equilibrated in AP detection buffer, with NBT chloride and BCIP.

Membranes that were incubated with all other primary antibodies were treated in the same way, but the secondary antibody used was AP-conjugated goat anti-rabbit IgG at 1:3000 (Bio-Rad). For these membranes, the washing steps were the same, but for detection they were immersed in AP detection buffer ( $50 \mathrm{mM}$ Tris, $50 \mathrm{mM} \mathrm{NaCl}, 25 \mathrm{mM} \mathrm{MgCl}_{2}$, $\mathrm{pH} 9.5$ ) with $0.33 \%$ NBT and $0.17 \%$ BCIP, and allowed to develop until the band intensity was satisfactory.

\subsection{Laser scanning confocal microscopy (LSCM)}

Cells were prepared for imaging by LSCM on glass coverslips in sterile Petri dishes. It was necessary before growing A6 cells on the coverslips to thoroughly clean the coverslips so that cells could properly attach. Glass coverslips (VWR) were placed in small Coplin jars to ensure full contact with the cleaning solution $(49.5 \%(\mathrm{v} / \mathrm{v})$ ethanol, $0.22 \mathrm{M} \mathrm{NaOH})$ for $30 \mathrm{~min}$ with periodic shaking at RT. The coverslips were then rinsed under running deionized water for $3 \mathrm{~h}$ and dried on Whatman paper. Finally the coverslips were flamed in the laminar flow hood and stored in sterile Petri dishes until used.

To prepare A6 cells for an experiment, coverslips were placed in new sterile Petri dishes and $\mathrm{A} 6$ cell suspension was added to the dish, and allowed to attach to the coverslips at $22^{\circ} \mathrm{C}$ for $24-48 \mathrm{~h}$. A6 cells were then treated directly in the Petri dishes either in the $22^{\circ} \mathrm{C}$ incubator, for chemical treatments, or parafilm-sealed and immersed in a heated water bath 
for heat shocking. Following treatment, the cells were allowed to recover at $22^{\circ} \mathrm{C}$ for $2 \mathrm{~h}$ before preparing for imaging.

After treatment, the L-15 media the cells were grown in was removed and the cells were washed twice in phosphate-buffered saline (PBS; $1.37 \mathrm{M} \mathrm{NaCl}, 67 \mathrm{mM} \mathrm{Na}_{2} \mathrm{HPO}_{4}, 26 \mathrm{mM}$ $\mathrm{KCl}, 14.7 \mathrm{mM} \mathrm{KH}_{2} \mathrm{PO}_{4}, 1 \mathrm{mM} \mathrm{CaCl} 2,0.5 \mathrm{mM} \mathrm{MgCl}_{2}, \mathrm{pH}$ 7.4) and the coverslips were transferred to new small Petri dishes (1 coverslip/dish). The cells were fixed $(3.7 \%(\mathrm{w} / \mathrm{v})$ PFA, pH 7.4 in PBS) for 10 min and then washed 3 times in PBS for 5 min. Next, the cells were permeabilized (0.1\% Triton X-100 (Sigma-Aldrich) in PBS) for 10 min and then washed 3 times in PBS for 5 min. Finally, the cells were blocked (5\% (w/v) BSA Fraction V (Sigma-Aldrich), filter-sterilized using a $0.45 \mu \mathrm{m}$ filter (Pall Filtration Corp.) in PBS) overnight at $4^{\circ} \mathrm{C}$.

The next day the cells were incubated in primary antibody (custom HSP110 at 1:250 in blocking solution) for $1 \mathrm{~h}$. After three, 5-min washes in PBS, the cells were indirectly labeled by incubation in a fluorescent-conjugated secondary antibody (goat-anti rabbit Alexa Fluor 488 (Molecular Probes, Eugene, OR) at 1:2 000 in blocking solution) for 30 min, in the dark, to avoid any chance of photo-bleaching of the fluorescent signal. After this, the cells were immediately probed for actin (rhodamine-tetramethylrhodamine-5-isothiocyanate phalloiden (TRITC (Molecular Probes), 1:60 in PBS) for 20 min, in the dark. The cells were then washed three times for 5 min in PBS. The coverslips were then mounted (cell side down) in one drop of VectaShield (Vector Laboratories Inc, Burlingame, CA) on a glass slide and sealed with clear nail polish. Once dried, the slides were visualized according to 
manufacturer's instructions with a Zeiss Axiovert 200 microscope and LSM 510 META software (Carl Zeiss Canada Ltd., Mississauga, ON). 


\section{Chapter 3: Results}

\subsection{Hsp110 cDNA sequence}

A putative Xenopus hsp 105 cDNA clone was obtained from the ATCC. This expressed sequence tag (EST) clone was unverified by the distributor, and sold as an "hsp105-like" sequence. The insert was cloned into NotI and SalI RE sites in the pCMV-SPORT6 plasmid. After complete sequencing of the insert, it was determined that the 5' portion of the nucleotide sequence was missing, including the initiation codon. A complete cDNA sequence of the hsp 110 open reading frame (Figure 8) was generated after the missing coding sequence, and part of the 5' untranslated region (UTR), was obtained by 5'RACE-PCR (Figure 9).

The amino acid sequence was predicted using the Expasy proteomics server, and aligned, using ClustalW, with several species to confirm its identity. The predicted Xenopus HSP110 amino acid sequence resembled other organisms in length (854 amino acids), molecular mass (96,112 kDa) and $\mathrm{pI}(5.63)$. In comparison to hamster HSP110, the Xenopus HSP110 amino acid sequence displayed $73 \%$ identity with 4 additions and 178 substitutions, 114 of which were conserved (Figure 10). There was one NLS (KKPK) identical to hamster, starting at amino acid 586. Also, there were seven potential N-glycosylation sites, the first 3 of which were identical to hamster (at amino acid 45, 61, 280, 517, 700, 731, and 831, Figure 10). The Xenopus laevis hsp 110 sequence also shared 74\% identity with human and mouse $h s p 105$, $49 \%$ identity with sea urchin egg receptor for sperm and $41 \%$ identity with yeast pss 1 (Table 4). 
Figure 8. Nucleotide sequence and predicted amino acid sequence of the complete Xenopus laevis hsp110 coding region

Nucleotide sequence and predicted amino acid sequence of the complete Xenopus laevis hsp110 coding region (accession number DQ458776). The top line shows the 854 predicted amino acids, and the bottom line shows the nucleotide sequence of the cDNA (2 562 nucleotide bases). The start (ATG, nucleotide position 1) and stop (TAA, nucleotide position 2 559) codons are underlined and shown in bold. The NLS (KKPK) is indicated in bold and underlined, at amino acid position 581. The seven potential N-glycosylation sites (amino acid positions 45, 61, 280, 517, 700, 731, and 831) are also underlined and indicated in bold. 


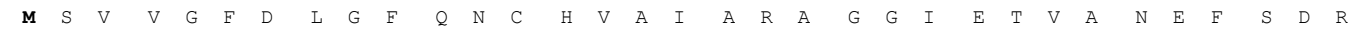

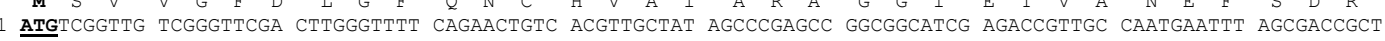

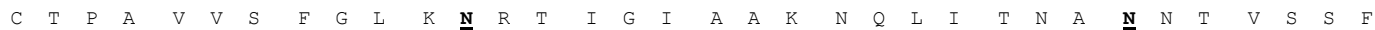

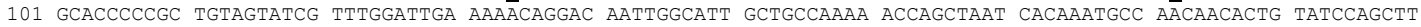

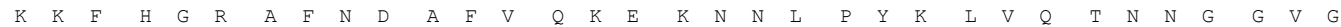

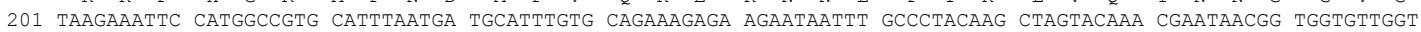

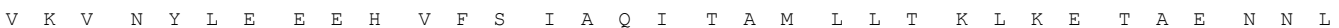

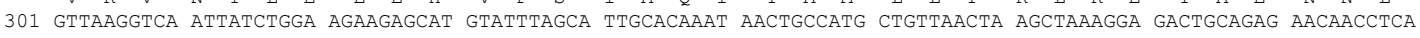

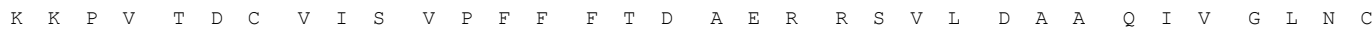

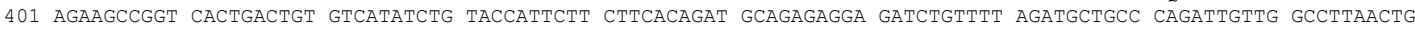

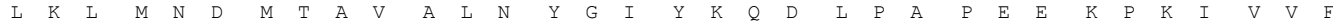

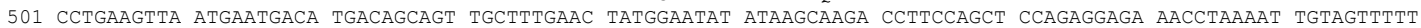

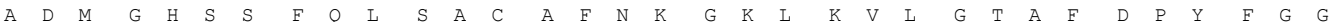
601 GCTGACATGG GACACTCCTC TTTCCAATTA TCTGCCTGTG CCTTCAATAA AgGAAAgCTA AAgGTTCTTG GCACAgCCTT CGACCCATAC TTCGGAGGAA

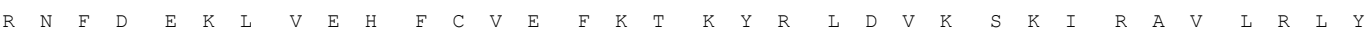

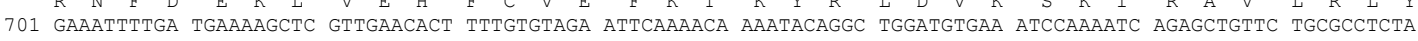

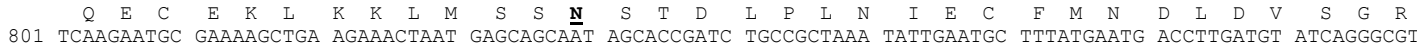

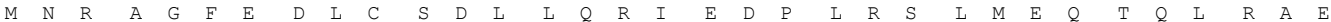

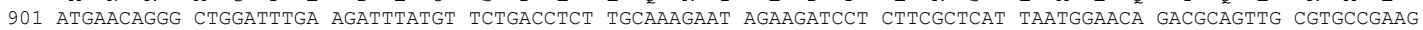

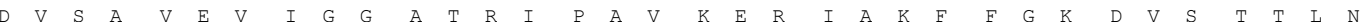

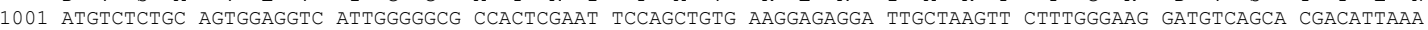

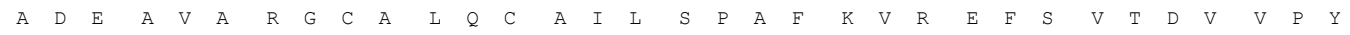

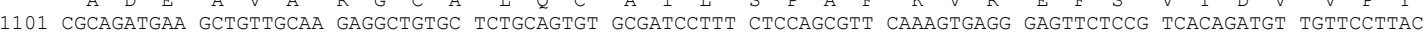

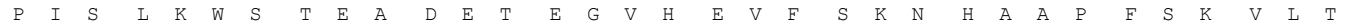

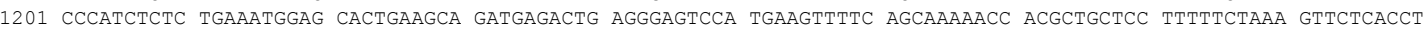

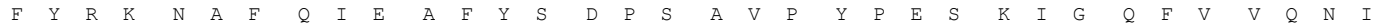

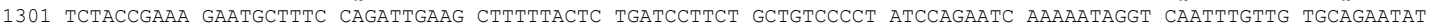

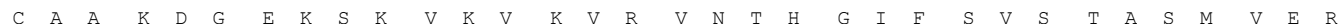

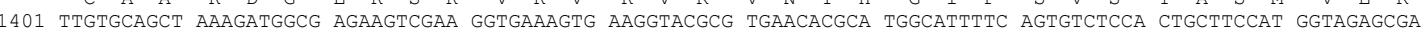

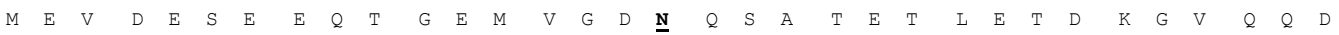

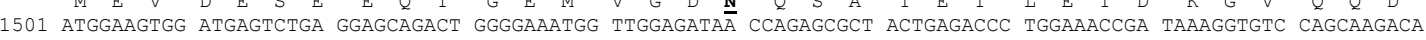

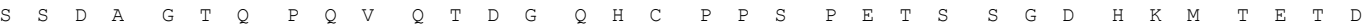
1601 GCAGTGATGC TGGAACACAG CCCCAGGTAC AAACTGATGg GCAGCACTGT CCCCCTTCAC CCGAGACATC CAGTGGGGAT CATAAAATGA CTGAAACTGA

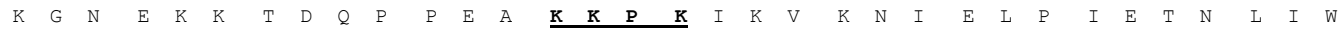

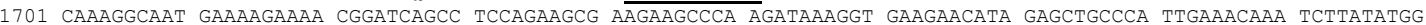

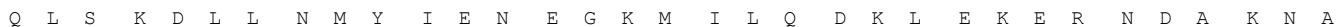

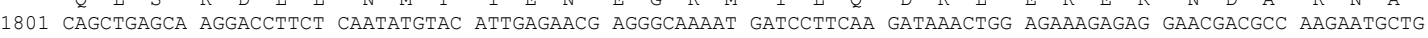

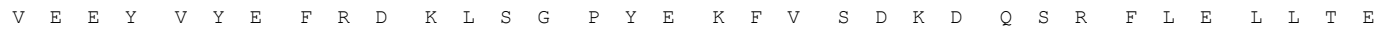

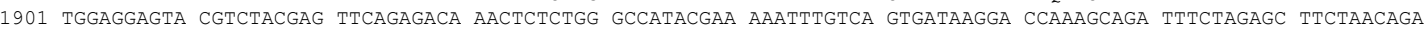
$\begin{array}{lllllllllllllllllllllllllllllllllllllllll}T & E & N & W & L & Y & E & D & G & E & D & Q & R & K & Q & V & Y & I & E & K & L & E & E & L & K & K & R & G & T & P & I & Q & \underline{N}\end{array}$

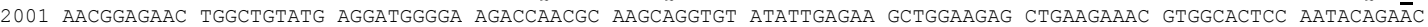

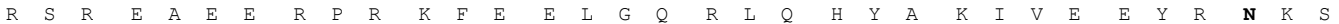

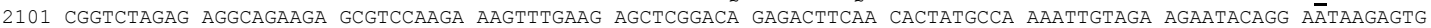

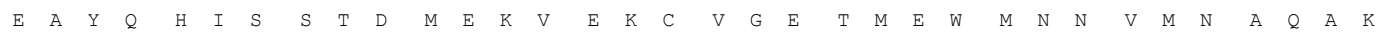

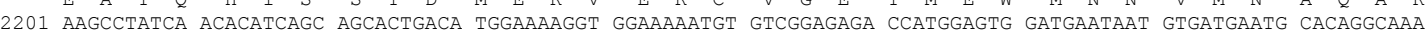

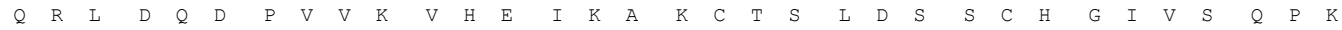

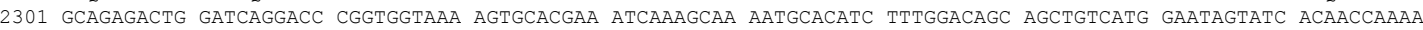

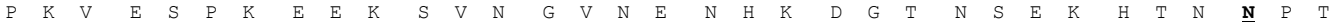

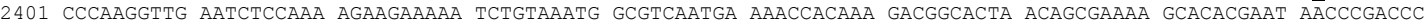

$\begin{array}{llllllllllllllllllllllllllllllllll} & P & Q & Q & N & G & A & C & H & P & N & E & K & S & T & I & D & M & D & F & D & *\end{array}$

2501 AACCGCAGCA GAACGGAGCA TGTCACCCTA ATGAAAAGA CACCATTGAC ATGGACTTTG AT 


\section{Figure 9. Additional hsp110 sequence obtained using 5' RACE-PCR}

The displayed nucleotide sequence was absent from the initially obtained EST clone (ATCC;

IMAGE Clone ID no. 4055839). This additional sequence, which completed the open

reading frame and added to the 5' UTR (underlined), was generated using 5' RACE-PCR.

The start codon is indicated in bold. 
TTACCCAGACTGCGGTTCGAACCGAGGACTTTGCACTGATTACCCAGAGTTCCGCCGCTGCTGCAGGT TGTTATCATGTCGGTTGTCGGGTTCGACTTGGGTTTTCAGAACTGTCACGTTGCTATAGCCCGAGCCG GCGGCATCGAGACCGTTGCCAATGAATTTAGCGACCGCTGCACCCCCGCTGTAGTATCGTTTGGATTG AAAAACAGGACAATTGGCATTGCTGCCAAAAACCAGCTAATCACAAATGCC 
Figure 10. Amino acid sequence comparison of Xenopus laevis HSP110 predicted amino acid sequence and hamster HSP110

Amino acid sequence comparison of Xenopus laevis HSP110 predicted amino acid sequence and hamster HSP110 (accession number CAA87768). Asterisks (*) denote complete amino acid identity between sequences, colons (:) denote conserved substitutions and periods (.) denote semi-conserved substitutions. 
Xenopus Hamster

Xenopus Hamster

Xenopus Hamster

Xenopus Hamster

Xenopus Hamster

Xenopus Hamster

Xenopus Hamster

Xenopus Hamster

Xenopus Hamster

Xenopus Hamster

Xenopus Hamster

Xenopus Hamster

Xenopus Hamster

Xenopus Hamster

Xenopus Hamster
MSVVGFDLGFQNCHVAIARAGGIETVANEFSDRCTPAVVSFGLKNRTIGIAAKNQLITNA 60 MSVVGLDVGSQSCYIAVARAGGIETIANEFSDRCTPSVISFGPKNRTIGVAAKNQQITHA 60

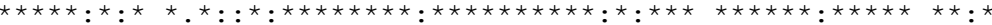

NNTVSSFKKFHGRAFNDAFVQKEKNNLPFKLVQMKNGGVGVKVNYLEEDHVFSIAQITAM 120 NNTVSSFKRFHGRAFSDPFIQKEKESLSYDLVPMKNGGVGIKVMYMDEEHLFSVEQITAM 120

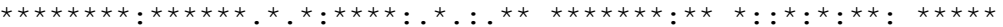

LLTKLKETAENNLKKPVTDCVISVPSFFTDAERRSVLDAAQIVGLNCLKLMNDMTAVALN 180 LLTKLKETAENNLKKPVTDCVISVPSFFTDAERRSVLDAAQIVGLNCLRLMNDMTAVALN 180

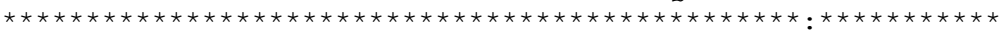

YGIYKQDLPAPEEKPKIVVFADMGHSSFQLSACAFNKGKLKVLGTAFDPYFGGRNFDEKL 240 YGIYKQDLPNADEKPQGSGVCGHGPSSFQVSACAFNKGKLKVLGTAFDPFLGGKNFDEKL 240

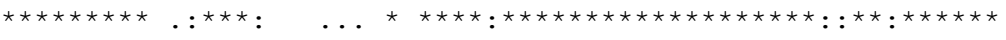

VEHFCVEFKTKYRLDVKSKIRAVLRLYQECEKLKKLMSSNSTDLPLNIECFMNDLDVSGR 300 VEHFCAEFKTKYKLDAKSKIRALLRLHQECEKLKKLMSSNSTDLPLNIECFMNDKDVSAK 300

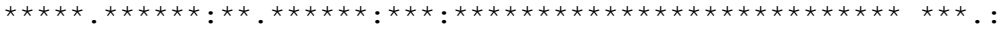

MNRAGFEDLCSDLLQRIEDPLRS LMEQTQLRAEDVSAVEVIGGATRIPAVKERIAKFFGK 360 MNRSQFEELCAELLQKIEVPLHSLMEQTHLKTEDVSAIEIVGGATRIPAVKERIAKFFGK 360

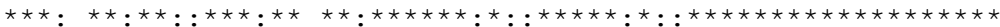

DVSTTLNADEAVARGCALQCAILSPAFKVREFSVTDVVPYPISLKWSTEADETEGVHEVF 420 DVSTTLNADEAVARGCALQCAILSPAFKVREFSVTDAVPFPISLVWNHDSEETEGVHEVF 420

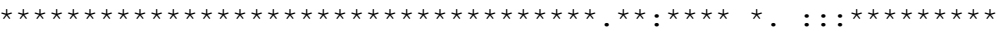

SKNHAAPFSKVLTFYRKNAFQIEAFYSDPSAVPYPESKIGQFVVQNICAAKDGEKSKVKV 480 SRNHAAPFSKVLTFLRRGPFELEAFYSDPQGVPYPEAKIGRFVVQNVSAQKDGEKSKVKV 480

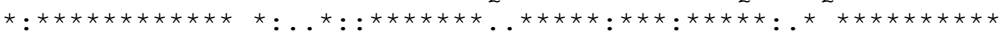

KVRVNTHGIFSVSTASMVERMEVDESEEQ--TGEMVGDNQSATETLETDKGVQQDSSDAG 538 KVRVNTHGIFTISTASMVEKVPTEEDDGSSVEADMECPNQKPAESSDVDKNSQQDNSEAG 540

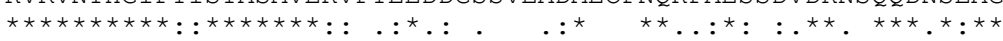

TQPQVQTDGQ---HCPPSPETSSGDHKMTETDKGNEKKTDQPPEAKKPKIKVKNIELPIE 595 TQPQVQTDGQQTSQSPPSPELPSEENKIPDADKANEKKVDQPPEAKKPKIKVVNVELPVE 600

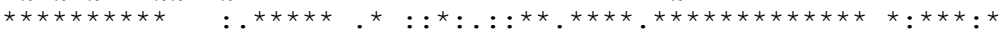

TNLIWQLSKDLLNMYIENEGKMILQDKLEKERNDAKNAVEEYVYEFRDKLSGPYEKFVSD 655 ANLVWQLGRDLLNMYIETEGKMIMQDKLEKERNDAKNAVEECVYEFRDKLCGPYEKFICQ 660

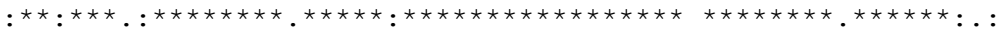

KDQSRFLELLTETENWLYEDGEDQRKQVYIEKLEELKKRGTPIQNRSREAEERPRKFEEL 715 QEHEKFLRLLTETEDWLYEEGEDQAKQAYIDKLEELMKMGNPVKVRFQEAEERPKVLEEL 720

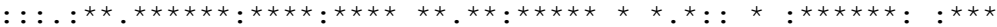

GQRLQHYAKIVEEYRNKSEAYQHISSTDMEKVEKCVGETMEWMNNVMNAQAKQRLDQDPV 775 GQRLQHYAKIAADFRSKDEKYNHIDESEMKKVEKSVNEVMEWMNNVMNAQAKRSLDQDPV 780

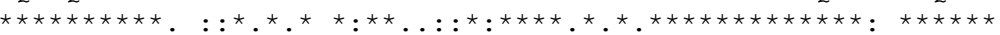

VKVHEIKAKCTSLDSSCHGIVSQPKPKVESPKEEKSVNGVNENHKDGTNSEKHTNNPTQP 835 VRTHEIRAKVKELNNVCEPVVNQPKPKIESPKLERTPNGPNLDKKEDLEG-KDNFGAEAP 839

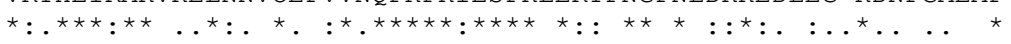

QQNGACHPNEKSTIDMDFD 854 HQNGECHPNEKGSVNMDLD 858

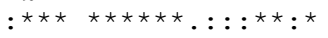


In a preliminary phylogenetic tree, Xenopus groups outside of mammals, in its own subgroup. It is more closely related to the mammals than it is to sea urchin, mold or yeast (Figure 11). The majority of the identity was among the residues in the amino terminus, which has been designated as the ATPase domain based on sequence (Lee-Yoon et al., 1995).

Table 4. Comparison of the amino acid sequence of Xenopus HSP110 with members of the HSP70/DnaK superfamily

\begin{tabular}{cccc}
\hline Organism & Protein & Accession \# & $\begin{array}{c}\text { \% Identity with } \\
\text { Xenopus HSP110 }\end{array}$ \\
\hline Mouse & HSP105 & NP_038587 & 74 \\
Human & HSP105 & Q92598 & 74 \\
Hamster & HSP110 & CAA87768 & 72 \\
Sea Urchin & Egg receptor & NP_999695 & 49 \\
Yeast & PSS1 & O59838 & 41 \\
Xenopus & HSP70 & CAA25576 & 29 \\
Xenopus & HSC70.1 & AAB97092 & 27 \\
Xenopus & HSC70.2 & AAB41583 & 28 \\
Xenopus & BiP & AAB41582 & 28 \\
\hline
\end{tabular}

The percent identity of Xenopus HSP110 with selected member of the HSP70/DnaK superfamily was determined using ClustalW. Genbank accession numbers are shown. 


\section{Figure 11. Preliminary phylogenetic analysis of HSP110}

Sequences were aligned using ClustalW and a phylogenetic tree was generated using the

program MEGA 3.1. The tree was prepared using a neighbor-joining method with pairwise deletion, a bootstrap value of 1000 and Jukes and Cantor (1969) correction. 


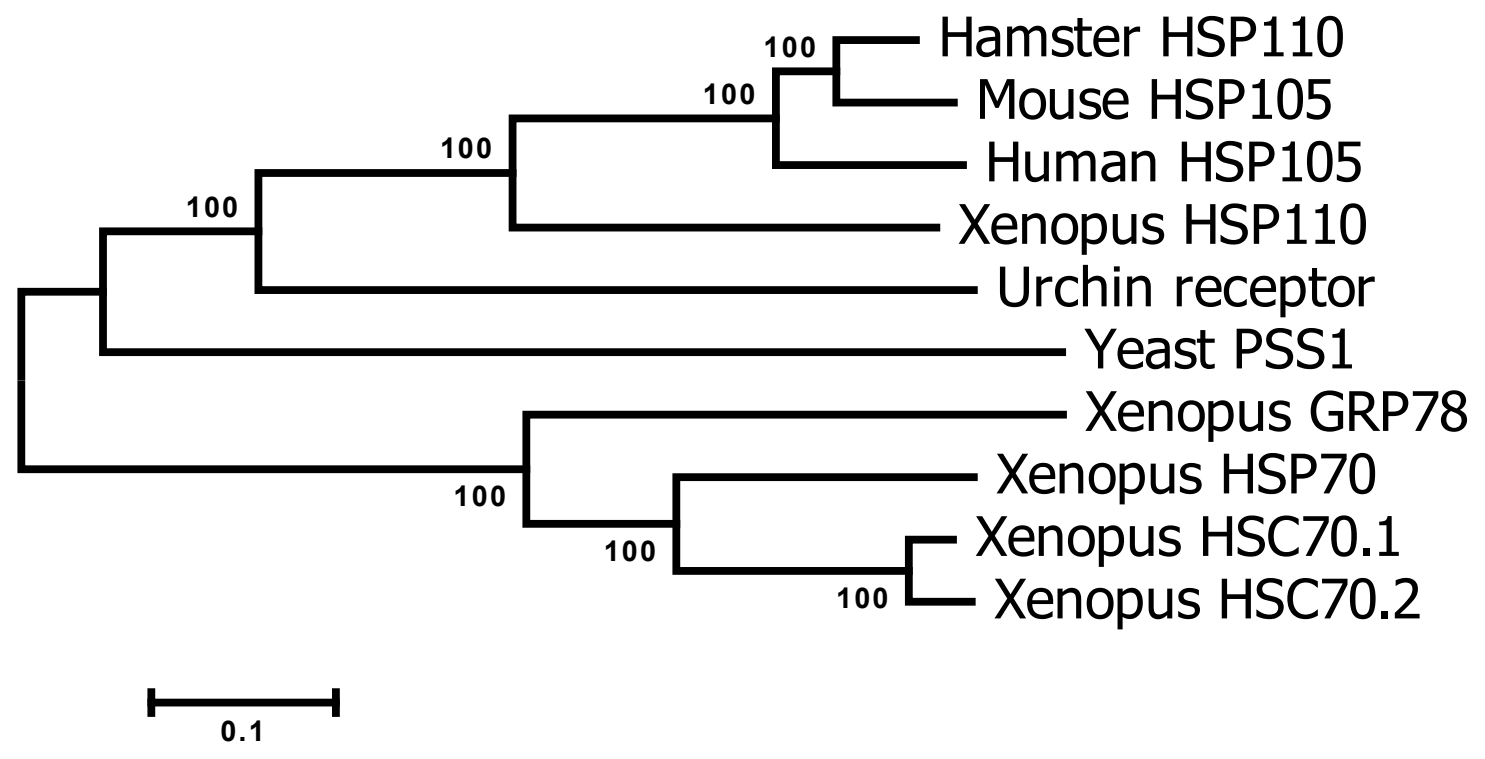




\section{2 hsp110 mRNA accumulation in A6 cells}

Hspl10 mRNA was present constitutively at relatively low levels in A6 cells, as determined by northern blot analysis. Temperature-induced elevation of the $3.4 \mathrm{~kb} h s p 110$ message was detected at $30^{\circ} \mathrm{C}$, peaked at $33-35^{\circ} \mathrm{C}$ and was markedly reduced at $37^{\circ} \mathrm{C}$ (Figure 12). In comparison, $h s p 70$ was not detected constitutively at $22^{\circ} \mathrm{C}$, and was strictly stress inducible. An enhanced accumulation of $h s p 70 \mathrm{mRNA}$ was detected at $30^{\circ} \mathrm{C}$ with peak levels at $35^{\circ} \mathrm{C}$ and a slight reduction at $37^{\circ} \mathrm{C}$.

Temporal characterization of $h s p 110$ mRNA accumulation in A6 cells was carried out at $33^{\circ} \mathrm{C}$ (Figure 13). A slight $h s p 110 \mathrm{mRNA}$ accumulation was detected initially at $0.5 \mathrm{~h}$ with maximal accumulation at $2 \mathrm{~h}$, and then a gradual decrease over time up to $6 \mathrm{~h}$. In comparison, hsp70 mRNA accumulation was easily detectable after only $0.5 \mathrm{~h}$. Maximal induction of $h \operatorname{sp} 70$ was detected at $1 \mathrm{~h}$, and then declined to undetectable levels after $4 \mathrm{~h}$ of heat shock. A temporal characterization of $h s p 110$ and $h s p 70$ mRNA accumulation was also carried out at $35^{\circ} \mathrm{C}$ in A6 cells (Figure 14). A similar pattern was seen at $35^{\circ} \mathrm{C}$ for $h s p 110$. The peak accumulation of $h s p 70$ message at $35^{\circ} \mathrm{C}$ was seen at $2 \mathrm{~h}$, and the message was detectable for the full $6 \mathrm{~h}$ treatment. Actin mRNA levels were relatively unaffected over the $6 \mathrm{~h}$ heat shock period at both temperatures. 
Figure 12. The effect of temperature on $h s p 110$ and $h s p 70$ mRNA accumulation in A6 cells

A6 cells were incubated at $22,30,33,35$, or $37^{\circ} \mathrm{C}$ for $1 \mathrm{~h}$. Total RNA was isolated and the relative levels of $h s p 110$ and $h s p 70$ mRNA were analyzed by northern hybridization using DIG-labeled antisense riboprobes as described in Materials and Methods. Equal loading, transfer efficiency and RNA integrity was demonstrated by staining the membrane prior to northern hybridization with RNA blot stain (bottom panel). Arrows indicate the position of the transcripts. 
$\begin{array}{lllll}22 & 30 & 33 & 35 & 37^{\circ} \mathrm{C}\end{array}$

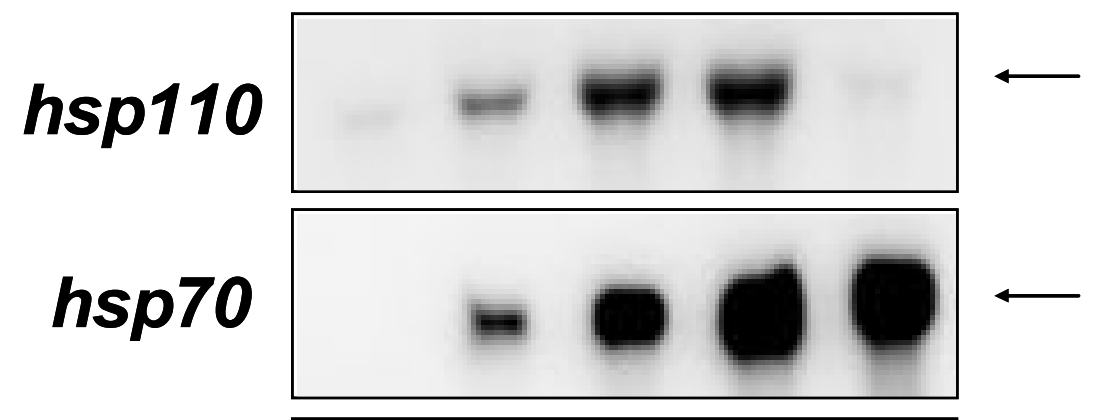

RNA blot stain 
Figure 13. The temporal pattern of $h s p 110, h s p 70$ and actin mRNA accumulation in A6 cells subjected to continuous heat shock

A6 cells were incubated at $33^{\circ} \mathrm{C}$ for $0.5,1,2,4$, or $6 \mathrm{~h}$, or maintained at $22^{\circ} \mathrm{C}(\mathrm{C})$. Total RNA was isolated and the relative levels of $h s p 110$, hsp70 and actin mRNA were analyzed by northern hybridization, using DIG-labeled antisense riboprobes, as described in Materials and Methods. Equal loading, transfer efficiency and RNA integrity was demonstrated by staining the membrane prior to northern hybridization with RNA blot stain (bottom panel). Arrows indicate the position of the transcripts. 


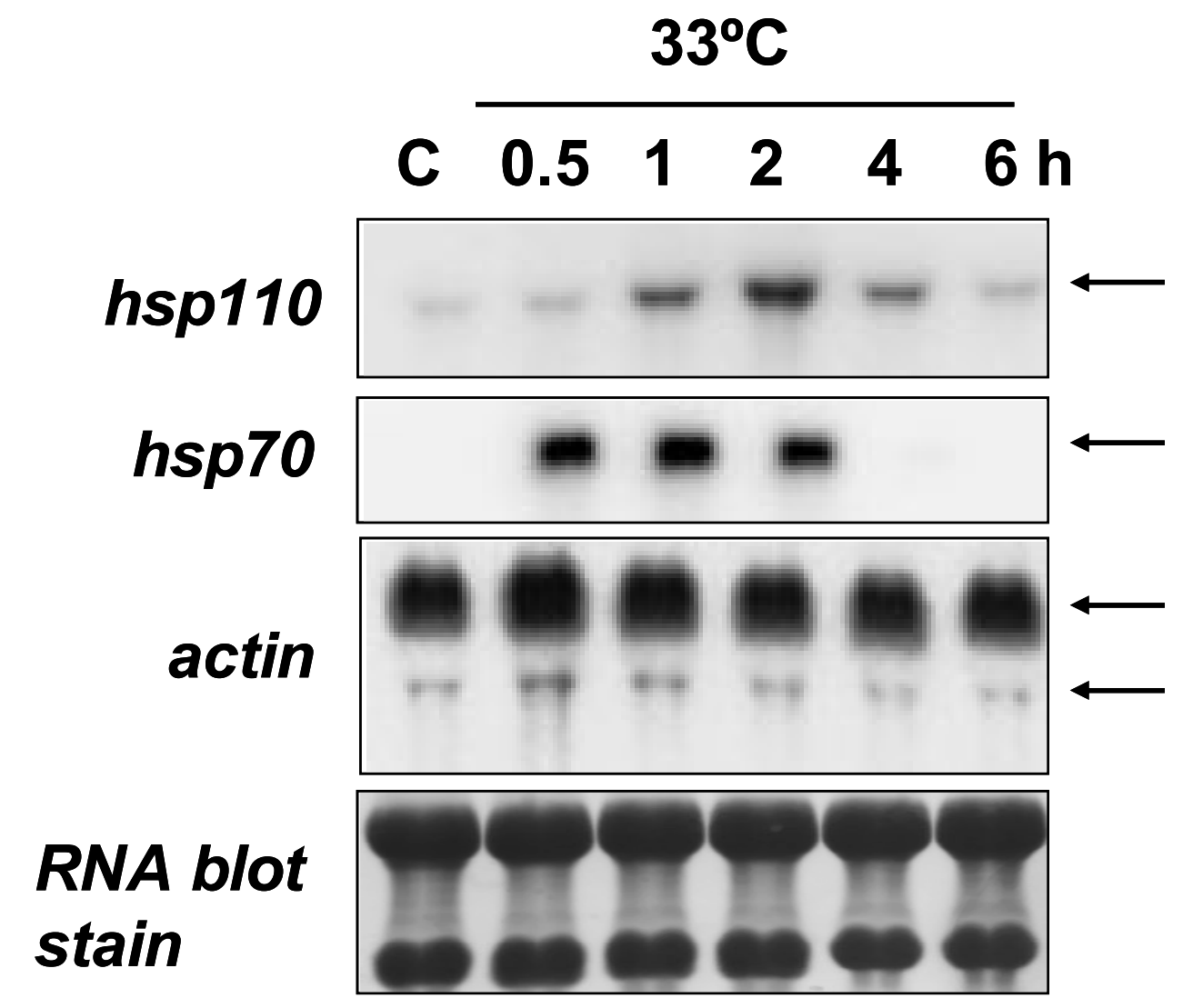


Figure 14. The temporal pattern of $h s p 110, h s p 70$ and actin mRNA accumulation in A6 cells subjected to continuous heat shock

A6 cells were incubated at $35^{\circ} \mathrm{C}$ for $0.5,1,2,4$, or $6 \mathrm{~h}$, or maintained at $22^{\circ} \mathrm{C}(\mathrm{C})$. Total RNA was isolated and the relative levels of $h s p 110$, hsp70 and actin mRNA were analyzed by northern hybridization, using DIG-labeled antisense riboprobes, as described in Materials and Methods. Equal loading, transfer efficiency and RNA integrity was demonstrated by staining the membrane prior to northern hybridization with RNA blot stain (bottom panel). Arrows indicate the position of the transcripts. 


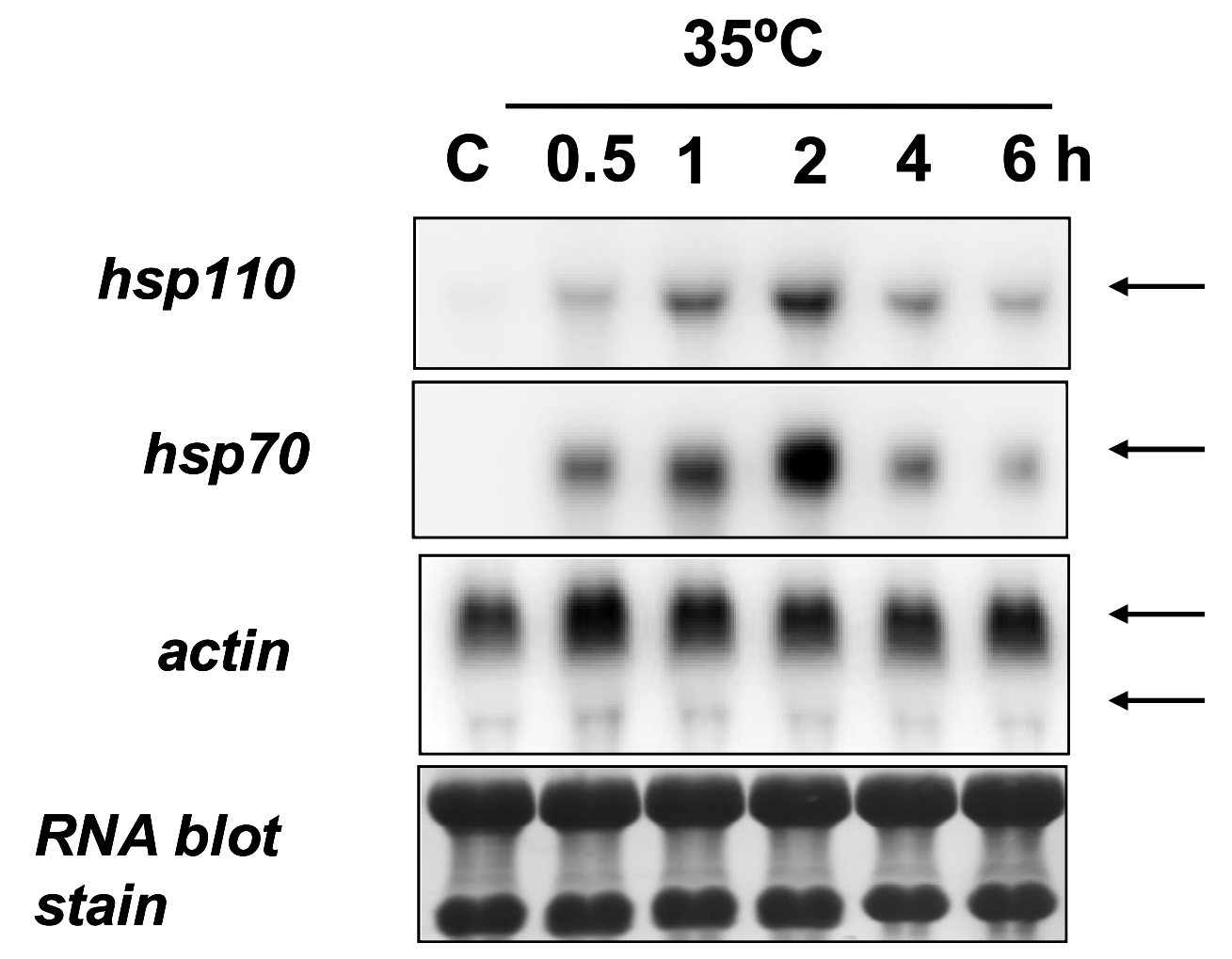


After establishing that hsp110 mRNA accumulated in response to heat shock, A6 cells were exposed to other stressors to further characterize the stress response of Xenopus hsp 110 (Figure 15). After a $5 \mathrm{~h}$ exposure of A6 cells to $6 \%$ ethanol, $h s p 110$ mRNA levels were not altered when compared to control cells, whereas elevated levels of $h s p 70$ mRNA were detected. Neither hsp110, nor hsp70 mRNA accumulated upon exposure to $200 \mu \mathrm{M}$ copper sulphate for $5 \mathrm{~h}$. However, treatment with $200 \mu \mathrm{M}$ cadmium chloride for $5 \mathrm{~h}$ resulted in enhanced accumulation of $h s p 110$ and $h s p 70$ mRNA. Sodium arsenite exposure for $5 \mathrm{~h}$ clearly resulted in a markedly enhanced accumulation of both $h s p 110$ and $h s p 70$ mRNA compared to the control.

It was evident that sodium arsenite treatment of A6 cells elicited a strong accumulation of hsp110 mRNA, so this was explored further. A6 cells were exposed to $50 \mu \mathrm{M}$ sodium arsenite for 1, 2, 3, 4, or $6 \mathrm{~h}$, and the total RNA isolated was analyzed by northern hybridization (Figure 16). An increase in the relative amount of $h s p 110$ mRNA was detectable after $2 \mathrm{~h}$, and reached maximal levels after $6 \mathrm{~h}$ of exposure. A similar trend was noted with $h s p 70$ message, although enhanced accumulation in response to sodium arsenite treatment occurred after only $1 \mathrm{~h}$. Actin mRNA levels were relatively unaffected by continuous sodium arsenite exposure. In other studies elevated levels of $h s p 110 \mathrm{mRNA}$ were detected at $12 \mathrm{~h}$ also, and detected albeit reduced after $24 \mathrm{~h}$ (data not shown). 
Figure 15. The effect of selected non-heat shock stressors on $h s p 110$ and $h s p 70$ mRNA accumulation in $\mathbf{A 6}$ cells

A6 cells were incubated at $22^{\circ} \mathrm{C}(\mathrm{C})$, in the absence or presence of $6 \%$ ethanol (Et), $200 \mu \mathrm{M}$ copper sulfate $(\mathrm{Cu}), 200 \mu \mathrm{M}$ cadmium chloride $(\mathrm{Cd})$ or $100 \mu \mathrm{M}$ sodium arsenite $(\mathrm{Na})$ for $5 \mathrm{~h}$. Total RNA was isolated and the relative levels of $h s p 110$ and $h s p 70$ mRNA were analyzed by northern hybridization, using DIG-labeled antisense riboprobes, as described in Materials and Methods. Equal loading, transfer efficiency and RNA integrity was demonstrated by staining the membrane prior to northern hybridization with RNA blot stain (bottom panel). Arrows indicate the position of the transcripts. 


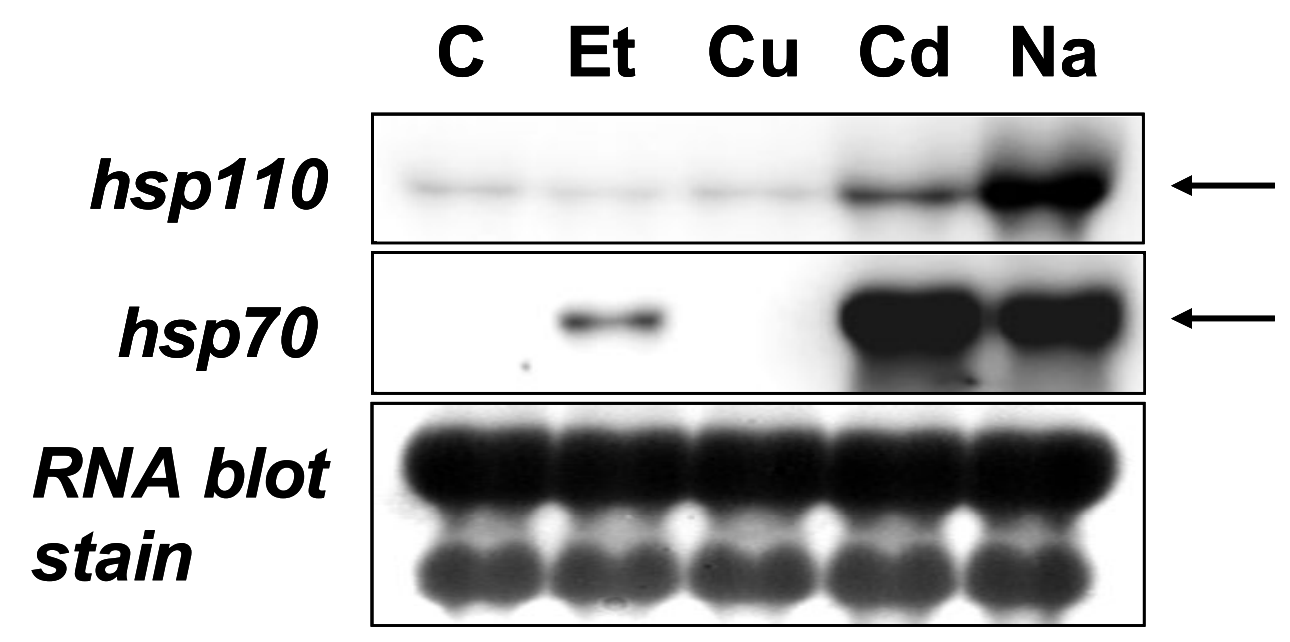


Figure 16. The effect of sodium arsenite on $h s p 110$, hsp 70 and actin mRNA accumulation in A6 cells

A6 cells were incubated at $22^{\circ} \mathrm{C}$ in the absence $(\mathrm{C})$, or presence of $50 \mu \mathrm{M}$ sodium arsenite

(NaAs) for 1, 2, 3, 4 or $6 \mathrm{~h}$. Total RNA was isolated and the relative levels of hsp110, hsp70 and actin mRNA were analyzed by northern hybridization, using DIG-labeled antisense riboprobes, as described in Materials and Methods. Equal loading, transfer efficiency and RNA integrity was demonstrated by staining the membrane prior to northern hybridization with RNA blot stain (bottom panel). Arrows indicate the position of the transcripts. 


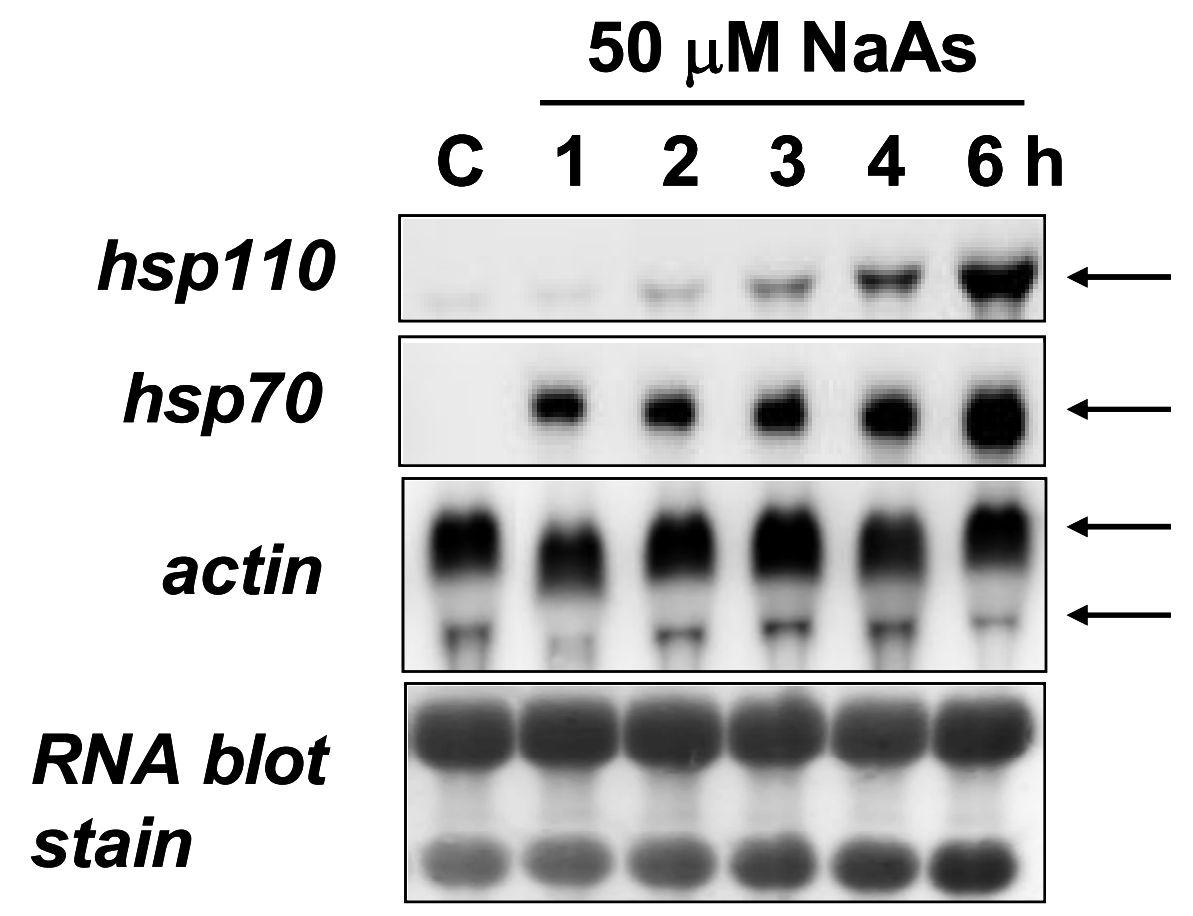




\subsection{Hsp110 mRNA accumulation in Xenopus embryos}

Northern hybridization analysis revealed that $h s p 110$ message was present in unfertilized eggs, and considered a maternal message (Figure 17). The hsp 110 message, unlike $h s p 70$, was present constitutively throughout development, from unfertilized egg to tadpole (Figure 18). Although always present, the relative levels of constitutive $h s p 110$ mRNA differed between developmental stages. Hsp110 mRNA was detected in late blastula embryos, but then declined to very low levels in gastrula, neurula and early tailbud embryos. However, the relative amount of constitutive $h s p 110$ mRNA increased by midtailbud, and then remained elevated until at least tadpole stage (data not shown). Heat shock treatment of embryos resulted in enhanced $h s p 110$ and $h s p 70$ mRNA accumulation at all stages following MBT. The relative amounts of heat-induced $h s p 110$ mRNA accumulation increased with developmental stage from late blastula to midtailbud. Unlike the larger $h s p s, h s p 27$ mRNA accumulation was earliest observed in heat shocked early tailbud stage embryos. Hsp27 message was observed in control embryos and was also heat inducible at mid and late tailbud stages. In contrast to $h s p 110, h s p 70$ and $h s p 27$ mRNA, the relative levels of ef- $1 \alpha$ mRNA did increase slightly throughout development, but the message was unaffected by heat shock. 


\section{Figure 17. hsp110 mRNA is present as a maternal message}

At various stages of development, Xenopus laevis eggs and embryos were maintained at either $22^{\circ} \mathrm{C}(\mathrm{C})$ or exposed to a $33^{\circ} \mathrm{C}$ heat shock $(\mathrm{H})$ for $1 \mathrm{~h}$. Unfertilized eggs (U), fertilized eggs $(\mathrm{F})$, and cleaving embryos $(\mathrm{Cl})$ were harvested and total RNA was isolated (panel A). In comparison, A6 cells were maintained at either $22^{\circ} \mathrm{C}(\mathrm{C})$ or exposed to a $33^{\circ} \mathrm{C}$ heat shock (H) for $2 \mathrm{~h}$ (panel B). Relative levels of $h s p 110$ mRNA was analyzed by northern hybridization, using DIG-labeled antisense riboprobes as described in Materials and Methods. Equal loading, transfer efficiency and RNA integrity are demonstrated by staining the membrane prior to northern hybridization with Blot Stain Blue (bottom panel). Arrows indicate the position of the transcripts. 


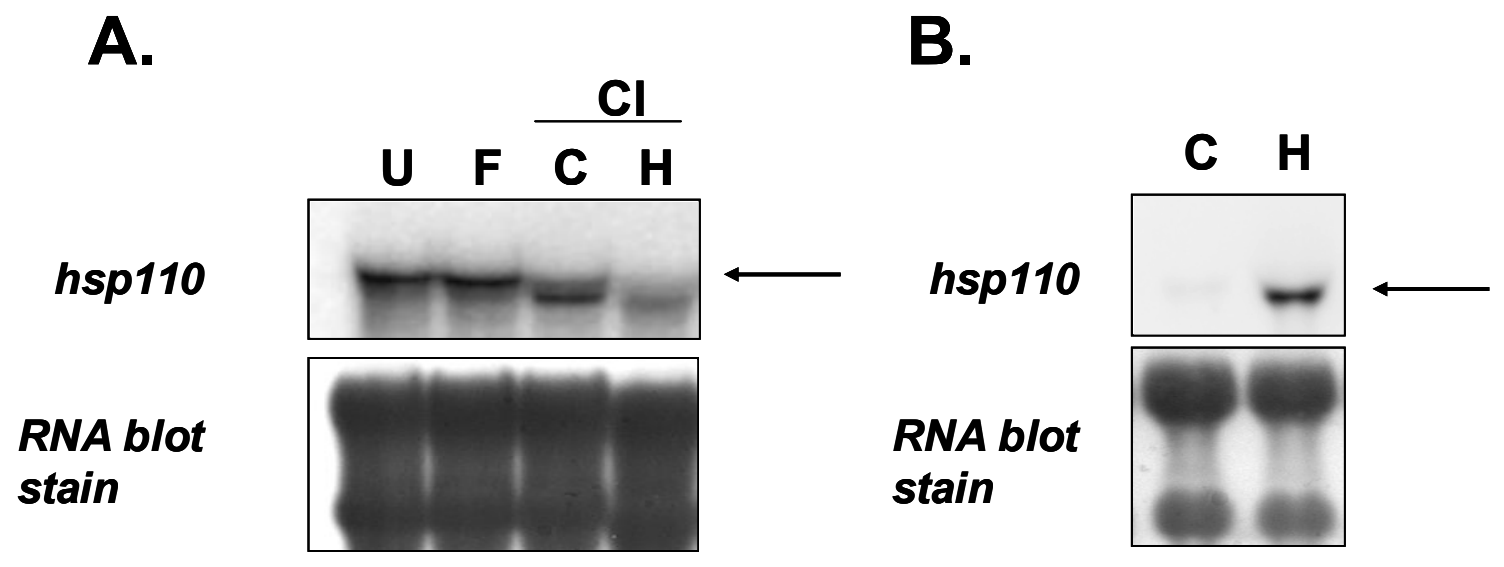




\section{Figure 18. $h s p$ mRNA accumulation during early development}

At various stages of development, Xenopus laevis embryos were maintained at either $22^{\circ} \mathrm{C}$ (C) or exposed to a $33^{\circ} \mathrm{C}$ heat shock $(\mathrm{H})$ for $1 \mathrm{~h}$. Late blastula (B), gastrula $(\mathrm{G})$, neurula $(\mathrm{N})$, early tailbud (etb), mid tailbud (mtb), and late tailbud (ltb) embryos were harvested and total RNA was isolated. Relative levels of $h s p 110, h s p 70, h s p 27$ and elongation factor-1 $\alpha$ (ef-1 $\alpha$ ) mRNA were analyzed by northern hybridization, using DIG-labeled antisense riboprobes as described in Materials and Methods. Equal loading, transfer efficiency and RNA integrity are demonstrated by staining the membrane prior to northern hybridization with Blot Stain Blue (bottom panel). 


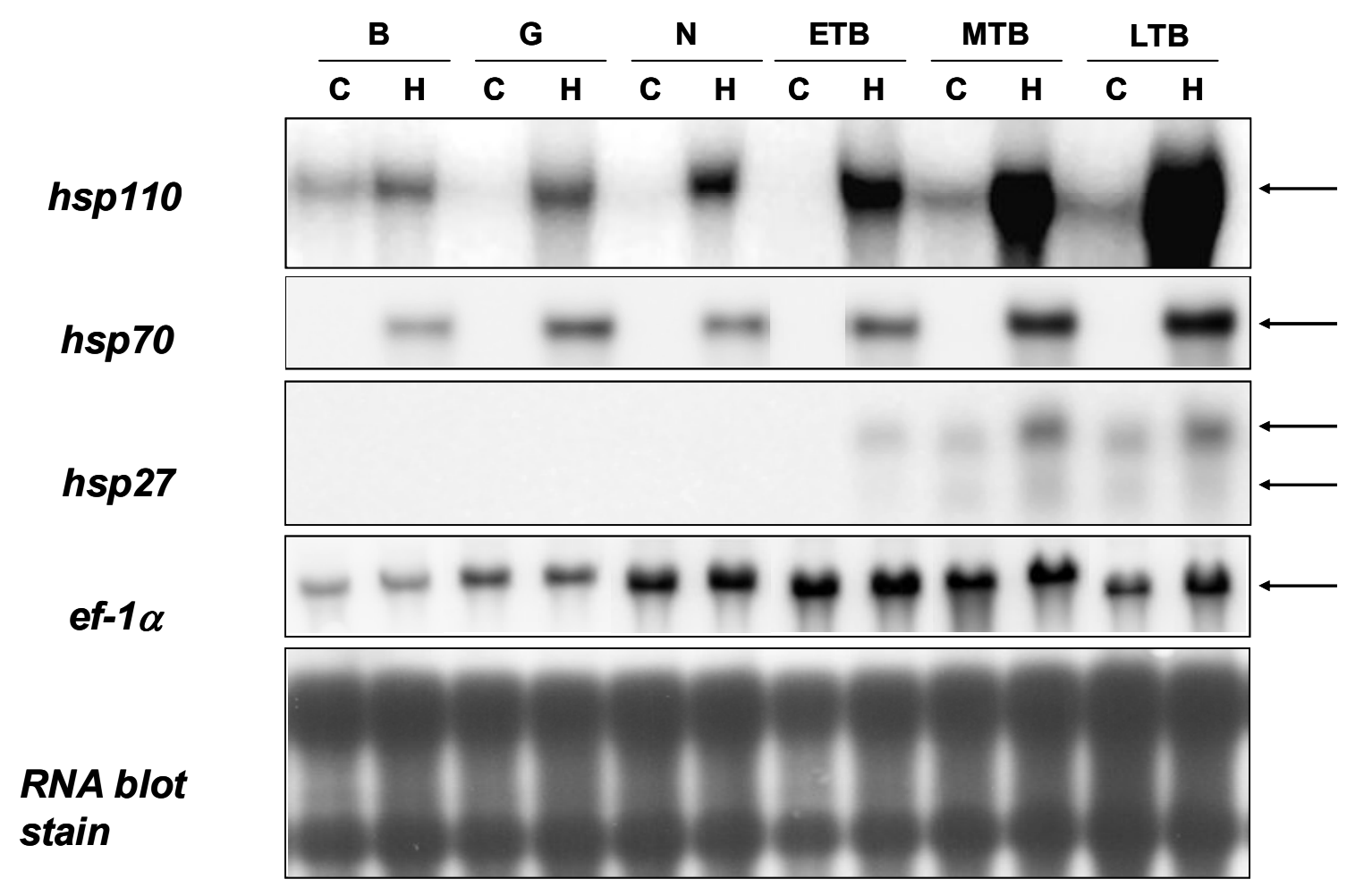


The spatial distribution of $h s p 110, h s p 70$ and $h s p 27$ mRNA in early Xenopus laevis embryos was investigated using whole mount in situ hybridization. Constitutive levels of hsp110 mRNA were detected globally in gastrula embryos (Figure 19). Heat shock treatment enhanced this pattern of message accumulation. In heat shocked neurula embryos, there was an accumulation of $h s p 110$ mRNA along the neural fold. Early tailbud embryos displayed constitutive hsp110 mRNA accumulation in the lens vesicle and head region. Following heat shock, enhanced $h \operatorname{sp} 110$ mRNA accumulation was seen additionally in the notochord, somites and brain region. Control mid and late tailbud stage embryos showed hspl10 mRNA accumulation in the lens vesicle, head and heart region. Embryos that were heat shocked showed an enhancement of this pattern of hsp110 mRNA accumulation, plus enhanced hsp 110 mRNA levels in the brain region, notochord, heart region and somites. In contrast to the above results, in situ hybridization of embryos with a sense $h s p 110$ riboprobe did not produce a detectable DIG signal.

Hsp70 mRNA accumulated in embryos only in response to heat shock (Figure 20). There was no detectable $h s p 70 \mathrm{mRNA}$ accumulation in control embryos as detected by either northern, or in situ, hybridization. Hsp70 mRNA did accumulate in a similar pattern to that of hsp110 in embryos following heat shock, and in general was more widespread. In neurula embryos, $h s p 70$ accumulated along the neural fold. Early tailbud embryos showed accumulation of $h s p 70$ mRNA in the proctodeum, notochord, somites, brain region, heart region and lens vesicle. In mid and late tailbud embryos the same pattern prevailed, but hsp70 mRNA accumulated in the cement gland as well. 


\section{Figure 19. Pattern of $h s p 110$ mRNA accumulation during development}

Albino Xenopus laevis embryos were incubated at $22^{\circ} \mathrm{C}$ (control) and $33^{\circ} \mathrm{C}$ (heat shock) for 1

$\mathrm{h}$ at various stages of development (gastrula (st. 11), neurula (st. 14), early tailbud (st. 25), mid tailbud (st. 27), and late tailbud (st. 38)). Whole mount in situ hybridization analysis was carried out with hsp110 DIG-labeled antisense riboprobes as described in Materials and Methods. NF, neural fold; LV, lens vesicle; BR, brain region; NC, notochord; S, somites; H, heart region. 

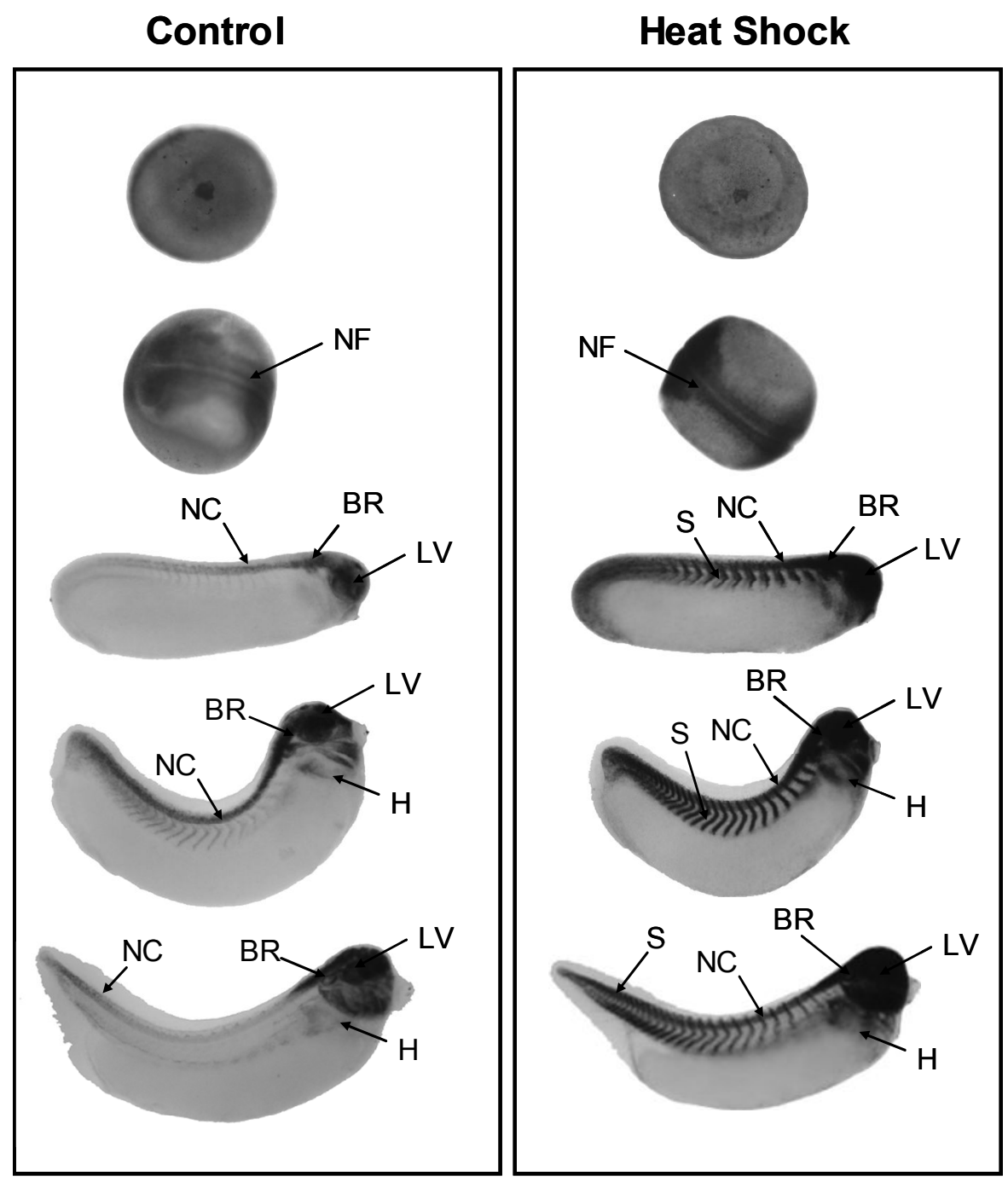

Gastrula

Neurula

Early tailbud

Mid tailbud

Late tailbud 


\section{Figure 20. Spatial pattern of $h s p 70 \mathrm{mRNA}$ accumulation during development}

Albino Xenopus laevis embryos were incubated at $22^{\circ} \mathrm{C}$ (control) and $33^{\circ} \mathrm{C}$ (heat shock) for 1 $\mathrm{h}$ at various stages of development (gastrula (st. 11), neurula (st. 14), early tailbud (st. 25), mid tailbud (st. 27), and late tailbud (st. 38)). Whole mount in situ hybridization analysis was carried out with $h s p 70$ DIG-labeled antisense riboprobes as described in Materials and Methods. NF, neural fold; LV, lens vesicle; BR, brain region; NC, notochord; S, somites; H, heart region; P, proctodeum; CG, cement gland. 

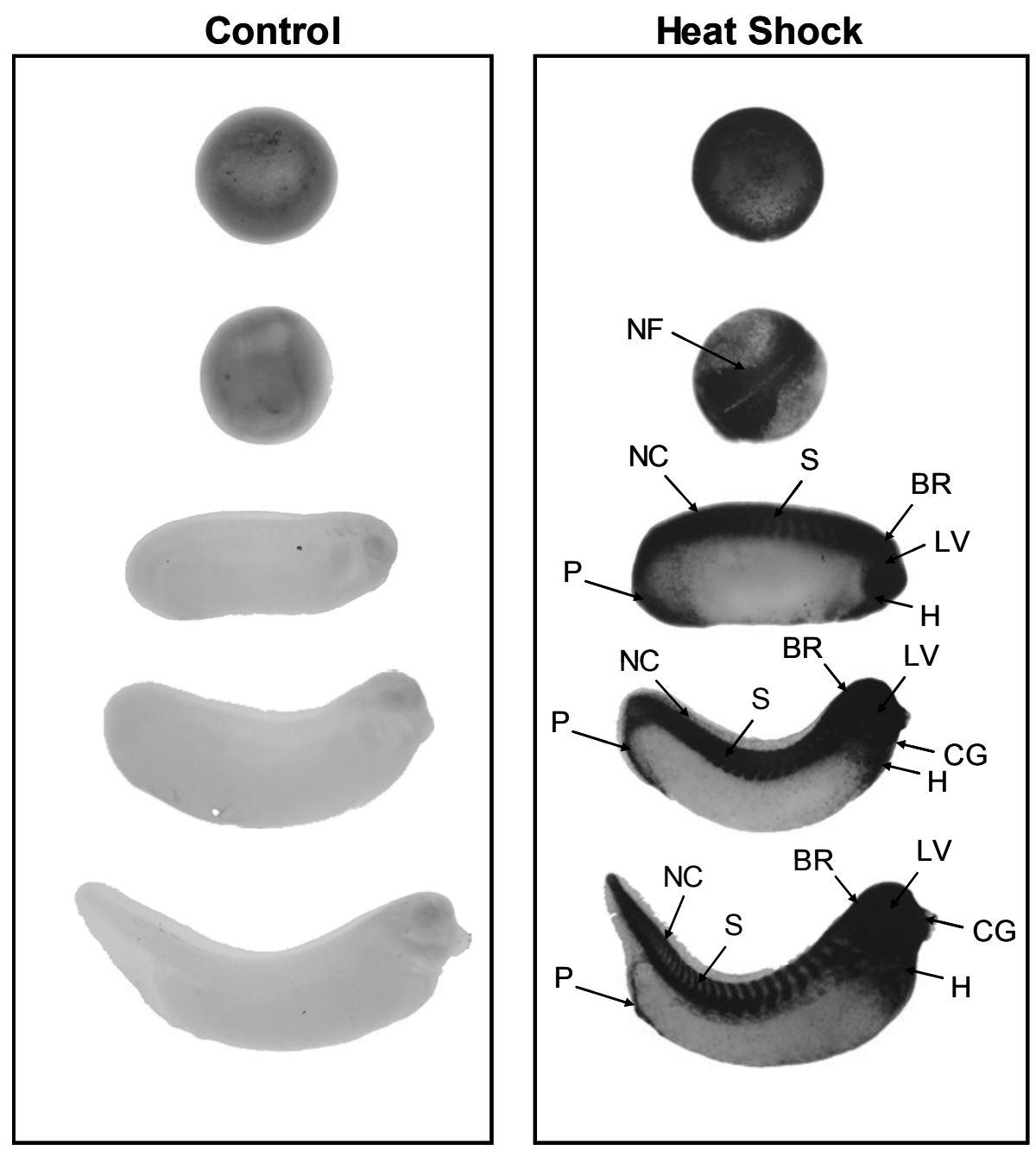

Gastrula

Neurula

Early tailbud

Mid tailbud

Late tailbud 
Hsp27 mRNA accumulated in embryos under both control and heat shock conditions (Figure 21). Control early tailbud embryos displayed an accumulation of $h s p 27$ mRNA in the somites and lens vesicle, and this was enhanced with heat shock. An accumulation of $h s p 27$ mRNA was observed in the somites, lens vesicle and heart of both mid and late tailbud control embryos, and this pattern was enhanced with heat shock.

\subsection{Production of anti-Xenopus HSP70 and HSP110 custom polyclonal antibodies}

An initial examination of the relative level of HSP110 protein by western blot analysis employed a rabbit polyclonal antibody raised against hamster HSP110 since a homologous anti-Xenopus HSP110 antibody was unavailable. This antibody recognized two proteins (under all conditions) of approximately 107 and $110 \mathrm{kDa}$ in size from A6 cells (Figure 22). The relative levels of these putative HSP110 proteins were elevated when cells were incubated at $35^{\circ} \mathrm{C}$ for $2-6 \mathrm{~h}$. Exposure of A6 cells to sodium arsenite for 12 and $24 \mathrm{~h}$ resulted in an elevation of HSP110 protein compared to untreated cells. Actin protein levels remained relatively constant. Due to the detection of several non-specific bands with the commercial antibody, a custom anti-Xenopus HSP110 antibody was obtained. In addition, an antibody specific to HSP70 that did not bind to HSC70, had not been previously available, and a custom antibody was simultaneously produced for HSP70. 
Figure 21. Spatial pattern of $h s p 27$ mRNA accumulation during development Albino Xenopus laevis embryos were incubated at $22^{\circ} \mathrm{C}$ (control) and $33^{\circ} \mathrm{C}$ (heat shock) for 1 $\mathrm{h}$ at various stages of development (early tailbud (st. 23), mid tailbud (st. 27), and late tailbud (st. 38)). Whole mount in situ hybridization analysis was carried out with hsp27 DIG-labeled antisense riboprobes as described in Materials and Methods. LV, lens vesicle; S, somites; H, heart region. 


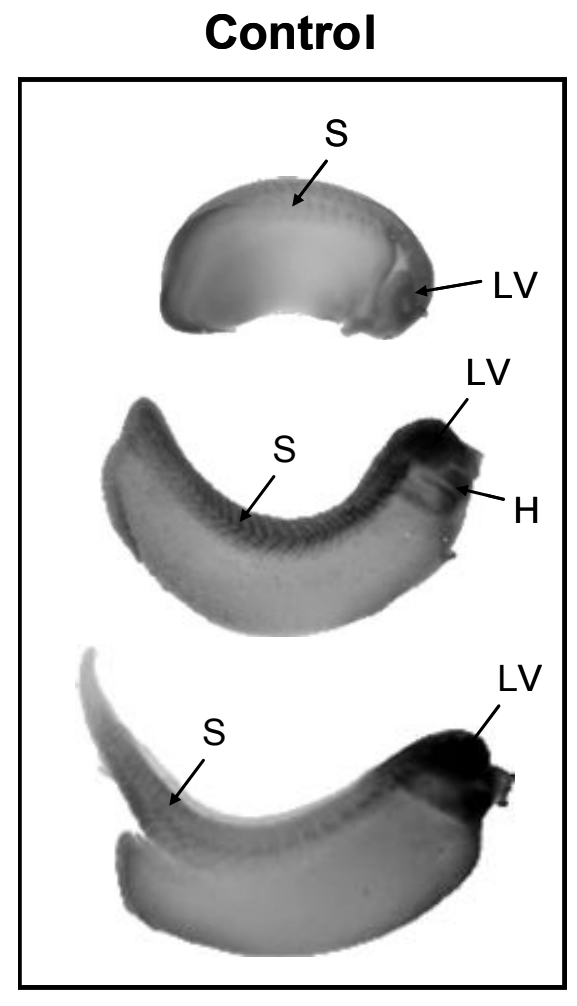

Heat Shock

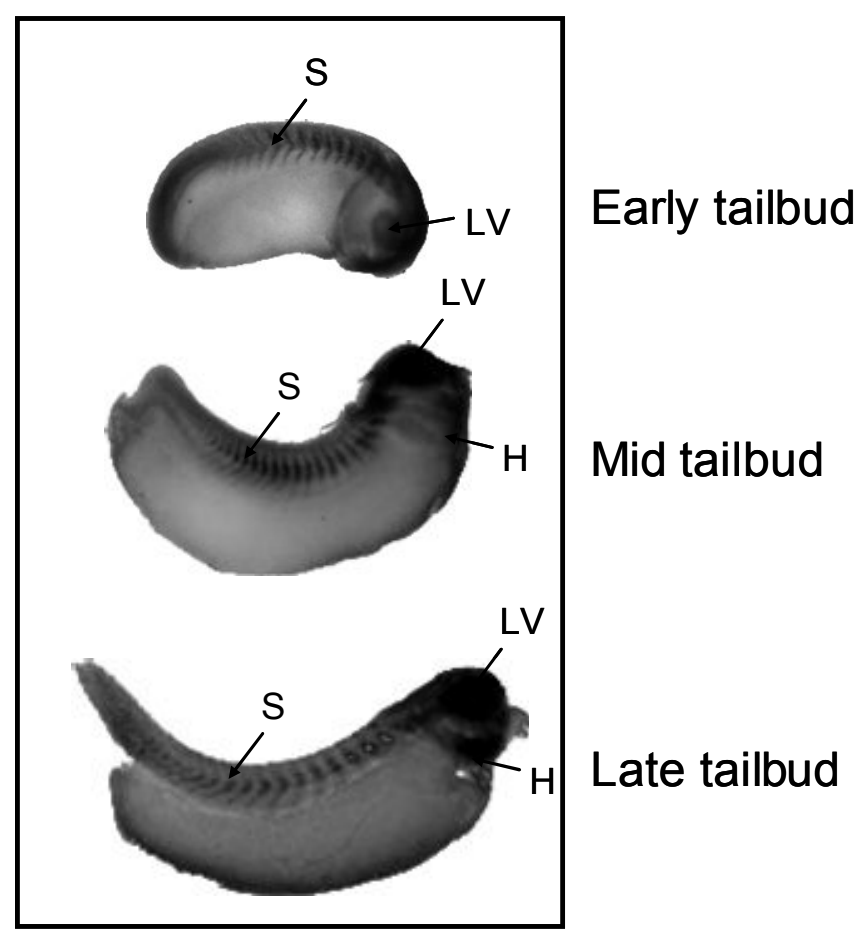


Figure 22. HSP110 protein accumulation in A6 cells measured with a commercially available antibody

In panel A, A6 cells were maintained at $22^{\circ} \mathrm{C}(\mathrm{C})$, or heat-shocked at $35^{\circ} \mathrm{C}$ for 2,4 , or $6 \mathrm{~h}$, and allowed to recover at $22^{\circ} \mathrm{C}$ for $2 \mathrm{~h}$. In panel $\mathrm{B}, \mathrm{A} 6$ cells were exposed to $50 \mu \mathrm{M}$ sodium arsenite $(\mathrm{NaAs})$ for 6,12 , or $24 \mathrm{~h}$, while being maintained at $22^{\circ} \mathrm{C}(\mathrm{C})$. Total protein was isolated and resolved on an 8\% SDS-polyacrylamide gel. Protein was transferred to a PVDF membrane and probed with either a hamster HSP110 polyclonal antibody, or an anti-actin polyclonal antibody as described in Materials and Methods. Ponceau S stained membranes are included to show efficient transfer and equal loading of protein. 


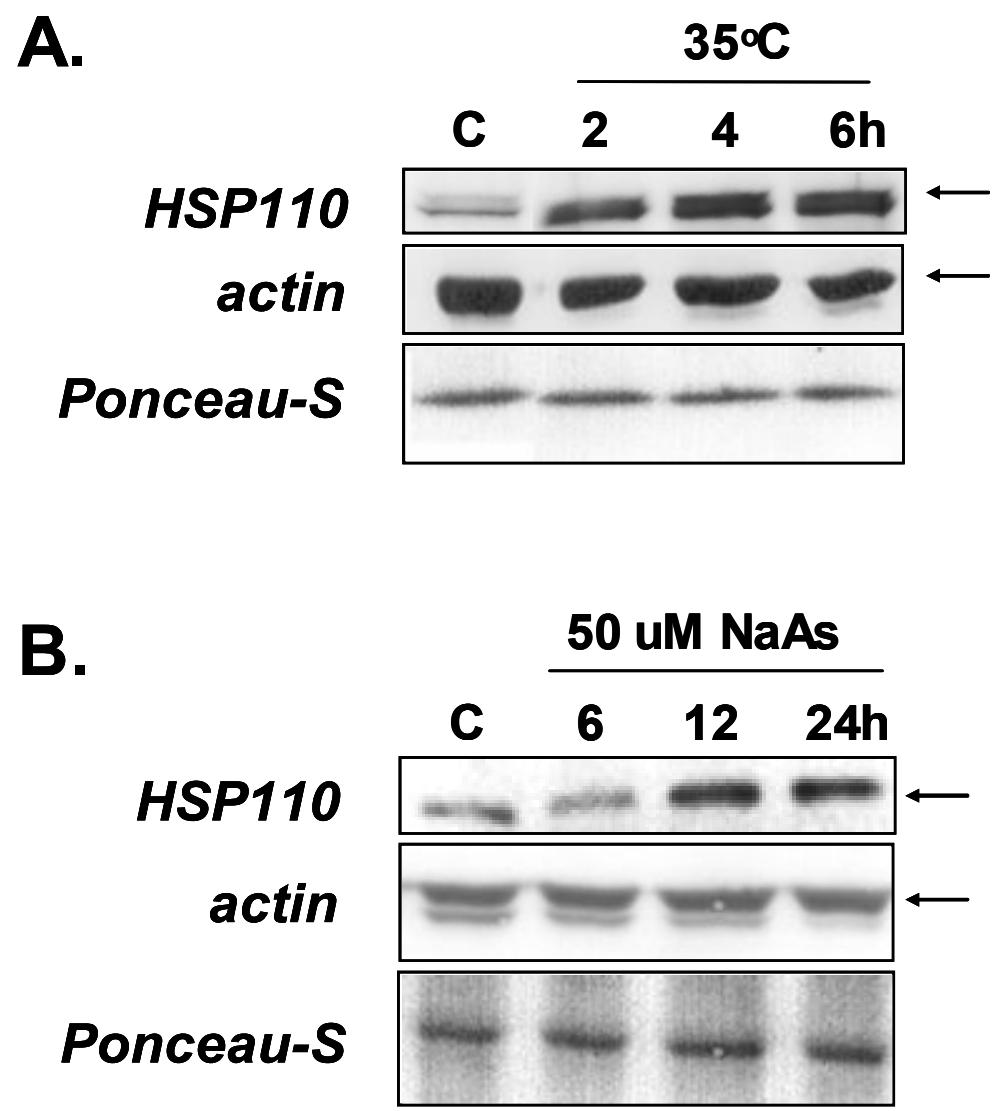


The custom designed polyclonal antibodies were raised in rabbits and the antigens were Xenopus laevis C-terminal peptides coupled to KLH, as described in Materials and Methods. For HSP110 this resulted in a specific antibody that recognized only one protein under most conditions, at approximately $110 \mathrm{kDa}$ (Figure 23). The protein was present constitutively and also accumulated with elevated temperature or elevated concentrations of sodium arsenite. At $35^{\circ} \mathrm{C}$ two bands were detected, one at $110 \mathrm{kDa}$ and an additional band at approximately 97 $\mathrm{kDa}$, which was similar to results found in other species, and will be discussed later. For HSP70 a specific antibody that recognized only one protein, at approximately $70 \mathrm{kDa}$ was produced (Figure 24). HSP70 protein was not present under control conditions but did accumulate in response to elevated temperatures of 33,35 and $37^{\circ} \mathrm{C}$, as well as 12 and $24 \mathrm{~h}$ of exposure to $50 \mu \mathrm{M}$ sodium arsenite.

\subsection{HSP110 protein accumulation in Xenopus A6 cells}

A comparative examination of the relative level of selected heat shock proteins induced by various temperatures was completed by western blot analysis (Figure 25). HSP110 protein was present under control conditions $\left(22^{\circ} \mathrm{C}\right)$, whereas HSP30 and $\mathrm{HSP} 70$ were not, and were strictly stress-inducible. Upon temperature increase, HSP110, HSP70 and HSP30 protein accumulated, reaching a maximum amount of protein at $35^{\circ} \mathrm{C}$ and declined slightly at $37^{\circ} \mathrm{C}$. 


\section{Figure 23. HSP110 protein accumulation in A6 cells}

A6 cells were maintained at $22^{\circ} \mathrm{C}(\mathrm{C})$ or heat shocked for $2 \mathrm{~h}$ at $30,33,35$ or $37^{\circ} \mathrm{C}$, and

allowed to recover at $22^{\circ} \mathrm{C}$ for $2 \mathrm{~h}$. Alternatively, A6 cells were exposed to $50 \mu \mathrm{M}$ sodium arsenite $(\mathrm{NaAs})$ for 6,12 , or $24 \mathrm{~h}$ at $22^{\circ} \mathrm{C}(\mathrm{C})$. Total protein was isolated and resolved on a 10\% SDS-polyacrylamide gel. Protein was transferred to a PVDF membrane and probed with a custom produced anti-Xenopus HSP110 polyclonal antibody as described in Materials and Methods. Ponceau S stained membranes were included to show efficient transfer and equal loading of protein. Arrows indicate the position of the proteins. 


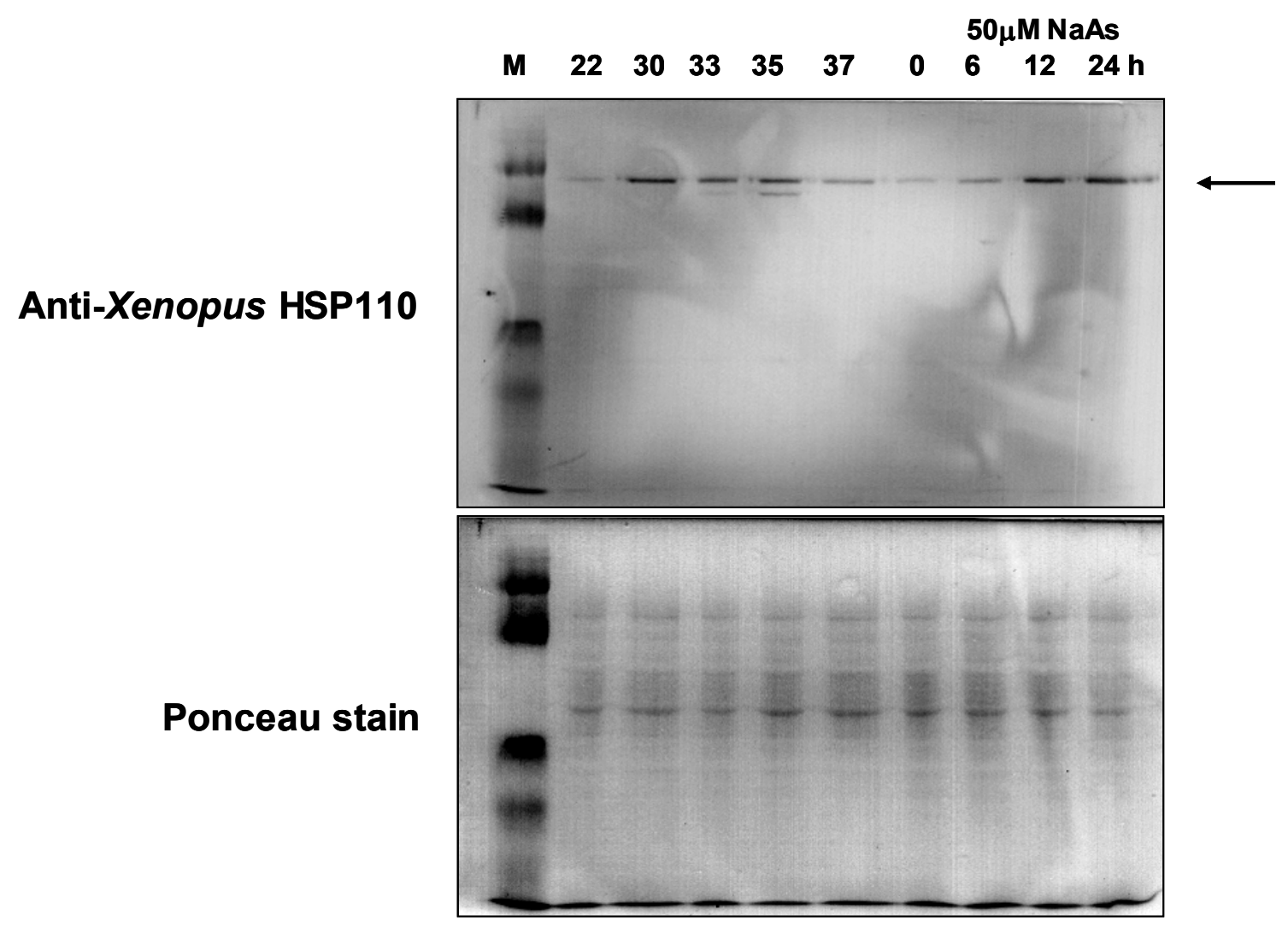


Figure 24. HSP70 protein accumulation in A6 cells

A6 cells were maintained at $22^{\circ} \mathrm{C}(\mathrm{C})$ or heat shocked for $2 \mathrm{~h}$ at $30,33,35$ or $37^{\circ} \mathrm{C}$, and allowed to recover at $22^{\circ} \mathrm{C}$ for $2 \mathrm{~h}$. Alternatively, A6 cells were exposed to $50 \mu \mathrm{M}$ sodium arsenite $(\mathrm{NaAs})$ for 6,12 , or $24 \mathrm{~h}$ at $22^{\circ} \mathrm{C}(\mathrm{C})$. Total protein was isolated and resolved on a 10\% SDS-polyacrylamide gel. Protein was transferred to a PVDF membrane and probed with a custom produced anti-Xenopus HSP70 polyclonal antibody as described in Materials and Methods. Ponceau S stained membranes were included to show efficient transfer and equal loading of protein. Arrows indicate the position of the proteins. 


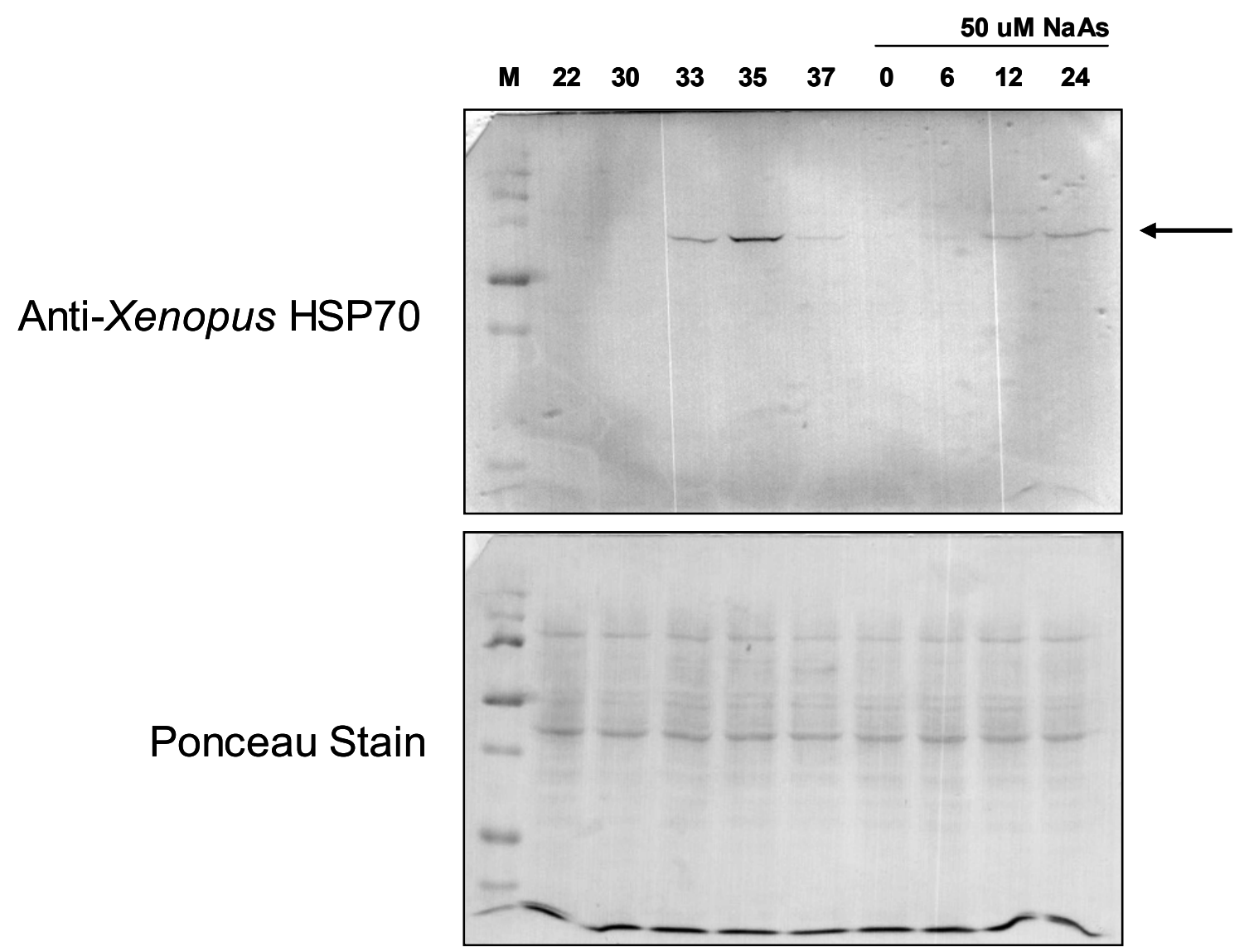


Figure 25. Protein accumulation in response to elevated temperature in A6 cells

A6 cells were maintained at $22^{\circ} \mathrm{C}(\mathrm{C})$, or heat shocked at $30,33,35$ or $37^{\circ} \mathrm{C}$ for $2 \mathrm{~h}$, and allowed to recover at $22^{\circ} \mathrm{C}$ for $2 \mathrm{~h}$. Total protein was isolated and resolved on $10 \% \mathrm{SDS}$ polyacrylamide gels. Protein was transferred to a PVDF membrane and probed with (antiXenopus) HSP110, HSP70, HSP30 or anti-actin polyclonal antibodies as described in Materials and Methods. Ponceau S stained membranes are included to show efficient transfer and equal loading of protein. Arrows indicate the position of the protein. 


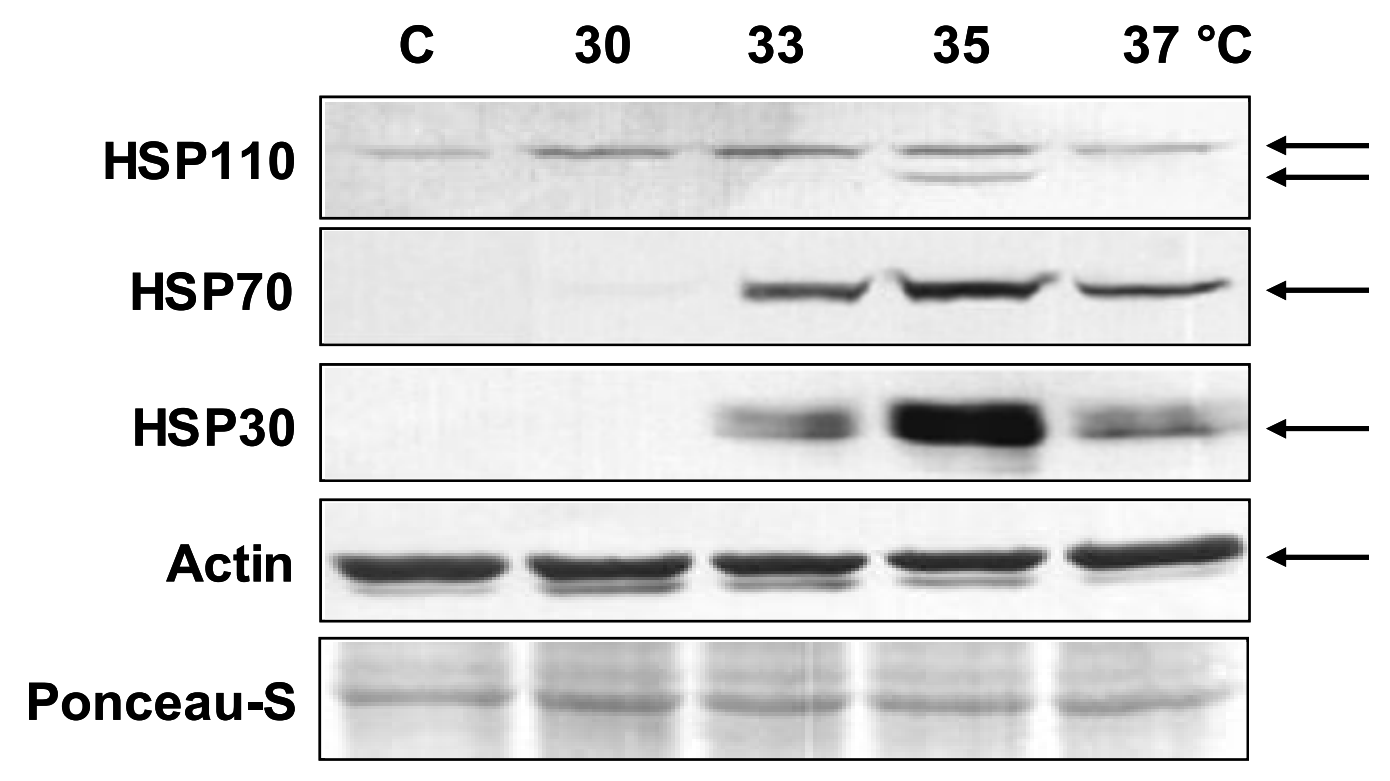


At $35^{\circ} \mathrm{C}$ a band of approximately $97 \mathrm{kDa}$ was detected with the HSP 110 antibody, in addition to the $110 \mathrm{kDa}$ band. This second band was only detected with a $35^{\circ} \mathrm{C}$ heat shock, and under no other conditions. Similarly, HSP30 protein was detected as multiple bands on a western, but this was regardless of treatment. Actin protein levels remained relatively constant.

A temporal investigation of the effects of heat induced stress was carried out on A6 cell extracts using HSP110, HSP70, HSP30 and actin antibodies (Figure 26). Again, HSP110 was present under control conditions, while HSP70 and HSP30 were detected only upon heat shock. Exposure to a constant $33^{\circ} \mathrm{C}$ heat shock resulted in protein accumulation of all three HSPs. Both HSP110 and HSP70 protein were present at elevated levels at $33^{\circ} \mathrm{C}$ and $35^{\circ} \mathrm{C}$ and remained elevated in both cases for up to $6 \mathrm{~h}$. HSP30 was also elevated by a $33^{\circ} \mathrm{C}$ and $35^{\circ} \mathrm{C}$ heat shock, although this protein appeared to be present at the highest levels after $4 \mathrm{~h}$ of $33^{\circ} \mathrm{C}$ and then declined. After $2 \mathrm{~h}$ of $35^{\circ} \mathrm{C}$, HSP30 protein accumulated, increasing further after $4 \mathrm{~h}$, and remaining elevated for at least $6 \mathrm{~h}$. Actin protein levels remained relatively constant.

Sodium arsenite affected the amount of protein present in A6 cells for all HSPs studied (Figure 27). As expected, HSP110 protein was present even in the absence of sodium arsenite treatment, but was elevated with increased concentration reaching a maximum at $50 \mu \mathrm{M}$ (this elevation remains at $100 \mu \mathrm{M}$ also, data not shown). HSP70 protein accumulated with sodium arsenite exposure reaching a maximum at $25 \mu \mathrm{M}$, and declined at $50 \mu \mathrm{M}$. A similar situation was 
Figure 26. Temporal response of heat shock proteins to elevated temperatures in A6 cells

A6 cells were maintained at $22^{\circ} \mathrm{C}(\mathrm{C}), 33^{\circ} \mathrm{C}$ or $35^{\circ} \mathrm{C}$ for 2,4 , or $6 \mathrm{~h}$. Total protein was isolated and resolved on $10 \%$ SDS-polyacrylamide gels. Protein was transferred to a PVDF membrane and probed with (anti-Xenopus) HSP110, HSP70, HSP30 or anti-actin polyclonal antibodies as described in Materials and Methods. Ponceau S stained membranes are included to show efficient transfer and equal loading of protein. Arrows indicate the position of the protein. 


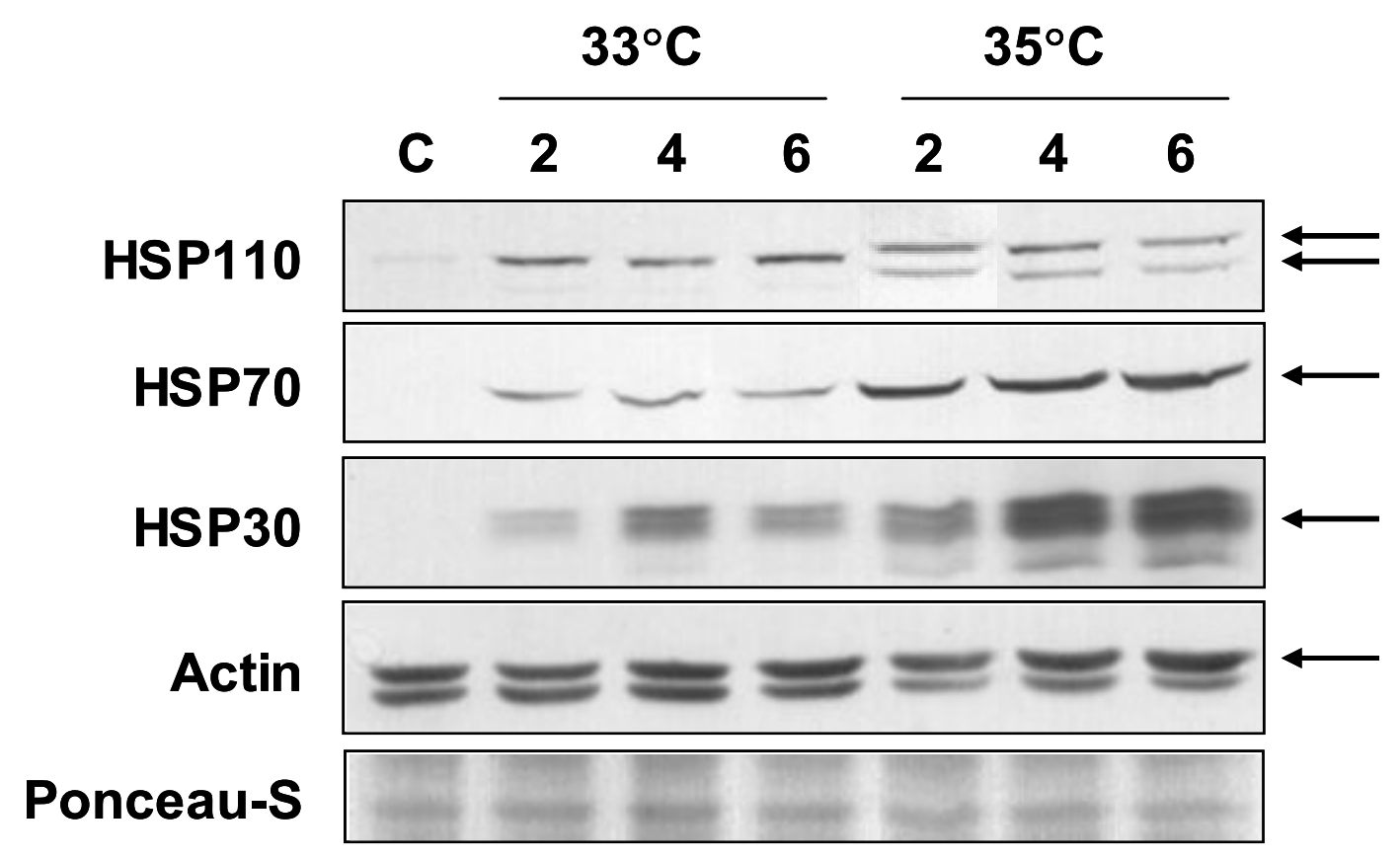


Figure 27. Protein accumulation in response to selected sodium arsenite concentrations in $\mathbf{A 6}$ cells

A6 cells were maintained at $22^{\circ} \mathrm{C}$ in the absence of sodium arsenite $(\mathrm{C})$, or with $5,10,25$ or $50 \mu \mathrm{M}$ sodium arsenite for $12 \mathrm{~h}$. Total protein was isolated and resolved on $10 \% \mathrm{SDS}$ -

polyacrylamide gels. Protein was transferred to a PVDF membrane and probed with (antiXenopus) HSP110, HSP70, HSP30 or anti-actin polyclonal antibodies as described in Materials and Methods. Ponceau S stained membranes are included to show efficient transfer and equal loading of protein. Arrows indicate the position of the protein. 


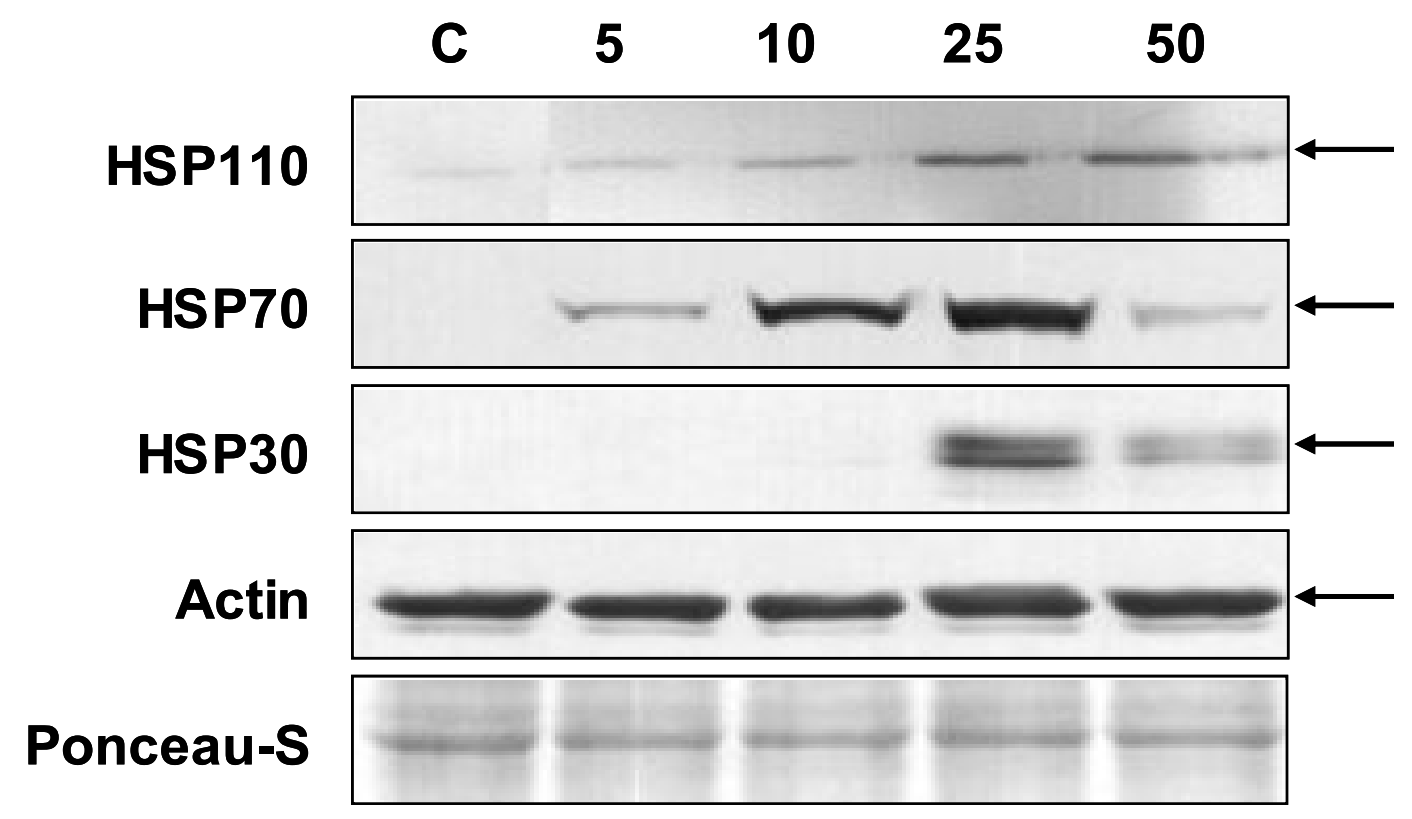


seen with HSP30 protein, which was present maximally at $25 \mu \mathrm{M}$. Actin protein levels remained relatively constant.

\subsection{Intracellular accumulation of HSP110 and HSP30 in Xenopus A6 cells}

\subsubsection{Intracellular accumulation in response to temperature}

Immunofluorescence using confocal laser scanning microscopy (CLSM) revealed that

HSP110 in cells maintained at $22^{\circ} \mathrm{C}$ was localized to both the cytoplasm and nucleus (Figure 28). In contrast, $\mathrm{HSP} 30$ was not detectable in A6 cells maintained at $22^{\circ} \mathrm{C}$. In these control preparations, the phalloidin-stained actin cytoskeleton was clearly visible as red fibers. Heat treatment at $30^{\circ} \mathrm{C}$ elicited a low relative amount of HSP30, whereas HSP110 protein levels were increased compared to control cells. At 33,35 and $37^{\circ} \mathrm{C}$ enhanced levels of both HSPs were clearly detectable. However, the pattern of their intracellular accumulation was very different. For example, HSP110 protein accumulated in very distinct, punctate areas within the cell, especially surrounding the nucleus, whereas HSP30 protein was homogeneously expressed in the cytoplasm. Also, while temperature stress resulted in HSP110 protein increases in the cytoplasm and nucleus, HSP30 was primarily enriched in the cytoplasm.

A6 cells continuously incubated at $33^{\circ} \mathrm{C}$ displayed an accumulation of HSP110 primarily in the cytoplasm (Figure 29). HSP110 was routinely observed surrounding the nucleus in long, spindle-shaped structures at the cell periphery. HSP110 protein accumulation compared to the control did not increase substantially from 2 to $6 \mathrm{~h}$ at $33^{\circ} \mathrm{C}$. 
Figure 28. Cellular localization of HSP110 and HSP30 proteins in A6 cells in response to elevated temperatures

A6 cells were maintained at $22^{\circ} \mathrm{C}$ (control; A1-A4), or heat-treated for $2 \mathrm{~h}$ at $30^{\circ} \mathrm{C}(\mathrm{B} 1-\mathrm{B} 4)$, $33^{\circ} \mathrm{C}(\mathrm{C} 1-\mathrm{C} 4), 35^{\circ} \mathrm{C}(\mathrm{D} 1-\mathrm{D} 4)$ or $37^{\circ} \mathrm{C}(\mathrm{E} 1-\mathrm{E} 4)$, followed by a $2 \mathrm{~h}$ recovery period at $22^{\circ} \mathrm{C}$. Cells were then labeled for HSP110 (columns 1-2), HSP30 (columns 3-4) and F-actin (columns 2 and 4) expression using Alexa Fluor 488 (green; for HSPs), TRITC (red; for Factin) and DAPI (blue; for the nucleus) as outlined in Materials and Methods. Cells were visualized using a Zeiss LSM 510 Meta laser confocal microscope. 

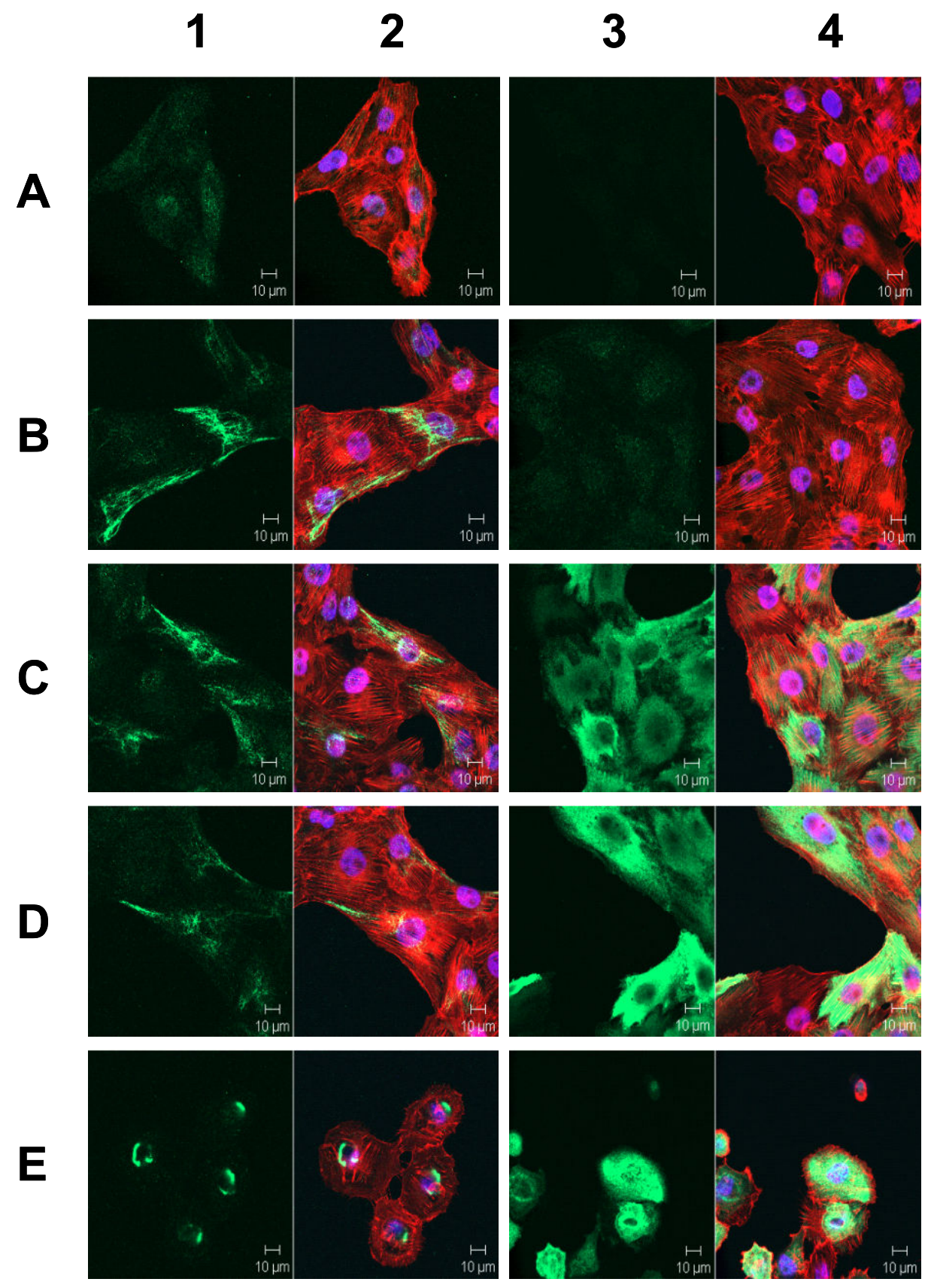
Figure 29. Cellular localization of HSP110 and HSP30 protein in A6 cells in response to extended temperature elevation at $33^{\circ} \mathrm{C}$

A6 cells were maintained at $22^{\circ} \mathrm{C}$ (control; A1-A4), or exposed to $33^{\circ} \mathrm{C}$ for $2 \mathrm{~h}(\mathrm{~B} 1-\mathrm{B} 4), 4 \mathrm{~h}$ (C1-C4) or $6 \mathrm{~h}$ (D1-D4). Cells were then labeled for HSP110 (columns 1-2), HSP30

(columns 3-4) and F-actin (columns 2 and 4) expression using Alexa Fluor 488 (green; for HSPs), TRITC (red; for F-actin) and DAPI (blue; for the nucleus) as outlined in Materials and Methods. Cells were visualized using a Zeiss LSM 510 Meta laser confocal microscope. 


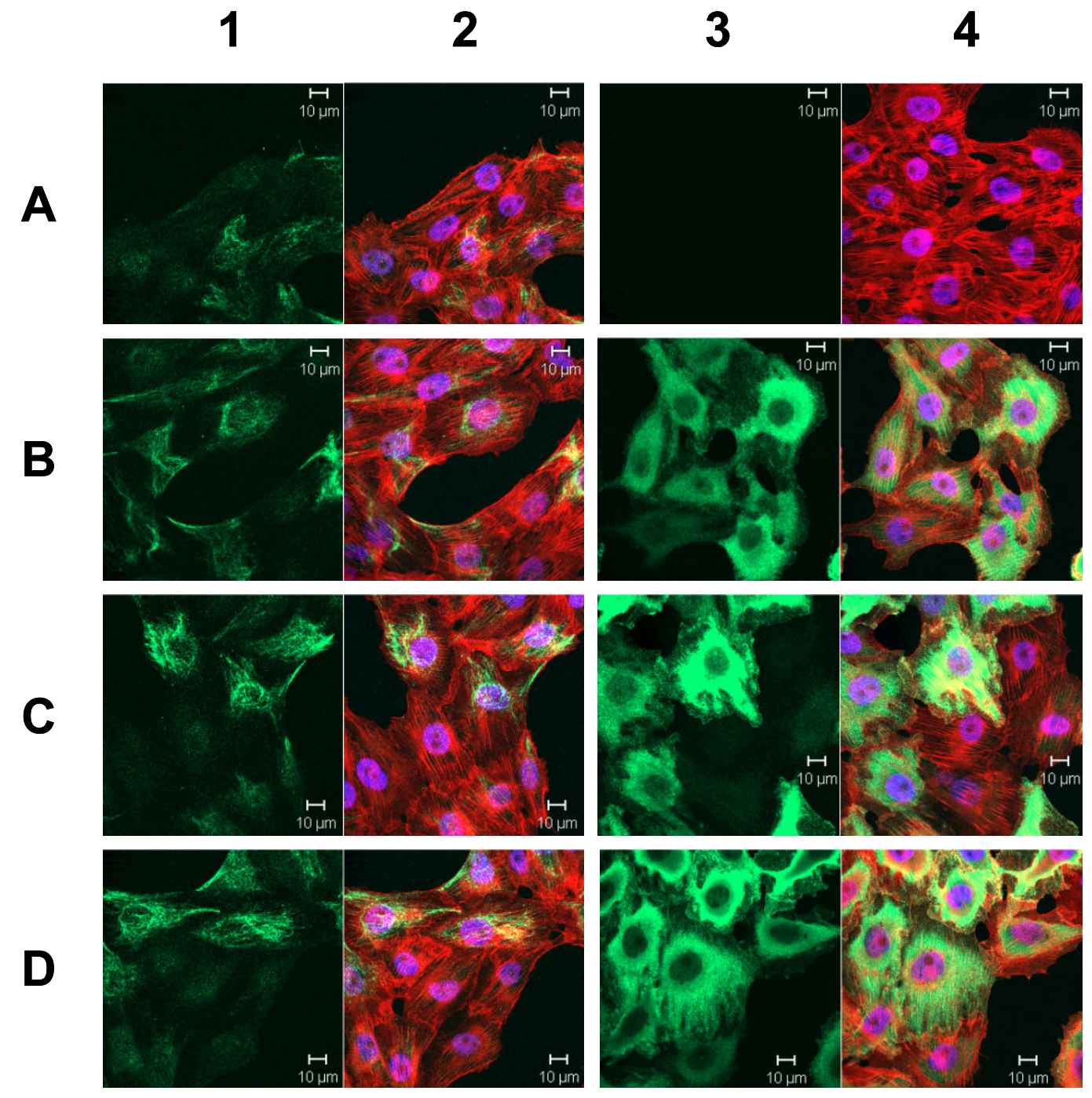


However, relative levels of $\mathrm{HSP} 30$ increased markedly at $33^{\circ} \mathrm{C}(2$ to $6 \mathrm{~h})$ compared to control. In A6 cells continuously incubated at $35^{\circ} \mathrm{C}$, HSP110 accumulation was observed in the cytoplasm with enrichment around the nucleus (Figure 30). After $6 \mathrm{~h}$ at $35^{\circ} \mathrm{C}$, there was less HSP110 accumulation than observed at $4 \mathrm{~h}$. In comparison, the relative levels of HSP30 were markedly increased with time at $35^{\circ} \mathrm{C}$ showing maximal levels from 4 to $6 \mathrm{~h}$. After $2 \mathrm{~h}$ at $35^{\circ} \mathrm{C}$ HSP 30 was localized diffusely in the cytoplasm. By $4 \mathrm{~h}, \mathrm{HSP} 30$ was focused on the edges of the cytoplasm, and by $6 \mathrm{~h}$, relatively high levels of HSP30 were homogeneously localized throughout the cytoplasm. Interestingly, in some cells, this treatment caused an increased accumulation of HSP30 protein at the periphery of the nucleus.

\subsubsection{Intracellular accumulation in response to sodium arsenite}

The effect of varying concentrations of sodium arsenite on A6 cell HSP110 and HSP30 localization is shown in Figure 31. Exposure of A6 cells to $10 \mu \mathrm{M}$ was the minimum concentration resulting in differences in HSP110 or HSP30 accumulation compared to control cells. At this concentration, HSP110 accumulation was visualized as scattered cytoplasmic spindle-shaped structures whereas HSP30 accumulated in a diffuse pattern in the cytoplasm. Exposure of A6 cells to $25 \mu \mathrm{M}$ sodium arsenite resulted in the localization of HSP110 protein at opposite ends of several nuclei, while HSP30 remained diffuse throughout the cytoplasm. A similar pattern of HSP110 and HSP30 accumulation and localization was observed at $50 \mu \mathrm{M}$ sodium arsenite. Also exposure of A6 cells to $10 \mu \mathrm{M}$ or $50 \mu \mathrm{M}$ sodium arsenite for extended periods of time resulted in few differences in HSP110 accumulation (Figure 32 and Figure 33). Finally, co-localization of HSP110 or HSP30 with actin or tubulin 
Figure 30. Cellular localization of HSP110 and HSP30 protein in A6 cells in response to extended temperature elevation at $35^{\circ} \mathrm{C}$

A6 cells were maintained at $22^{\circ} \mathrm{C}$ (control; A1-A4), or exposed to $35^{\circ} \mathrm{C}$ for $2 \mathrm{~h}(\mathrm{~B} 1-\mathrm{B} 4), 4 \mathrm{~h}$ (C1-C4) or $6 \mathrm{~h}$ (D1-D4). Cells were then labeled for HSP110 (columns 1-2), HSP30

(columns 3-4) and F-actin (columns 2 and 4) expression using Alexa Fluor 488 (green; for HSPs), TRITC (red; for F-actin) and DAPI (blue; for the nucleus) as outlined in Materials and Methods. Cells were visualized using a Zeiss LSM 510 Meta laser confocal microscope. 

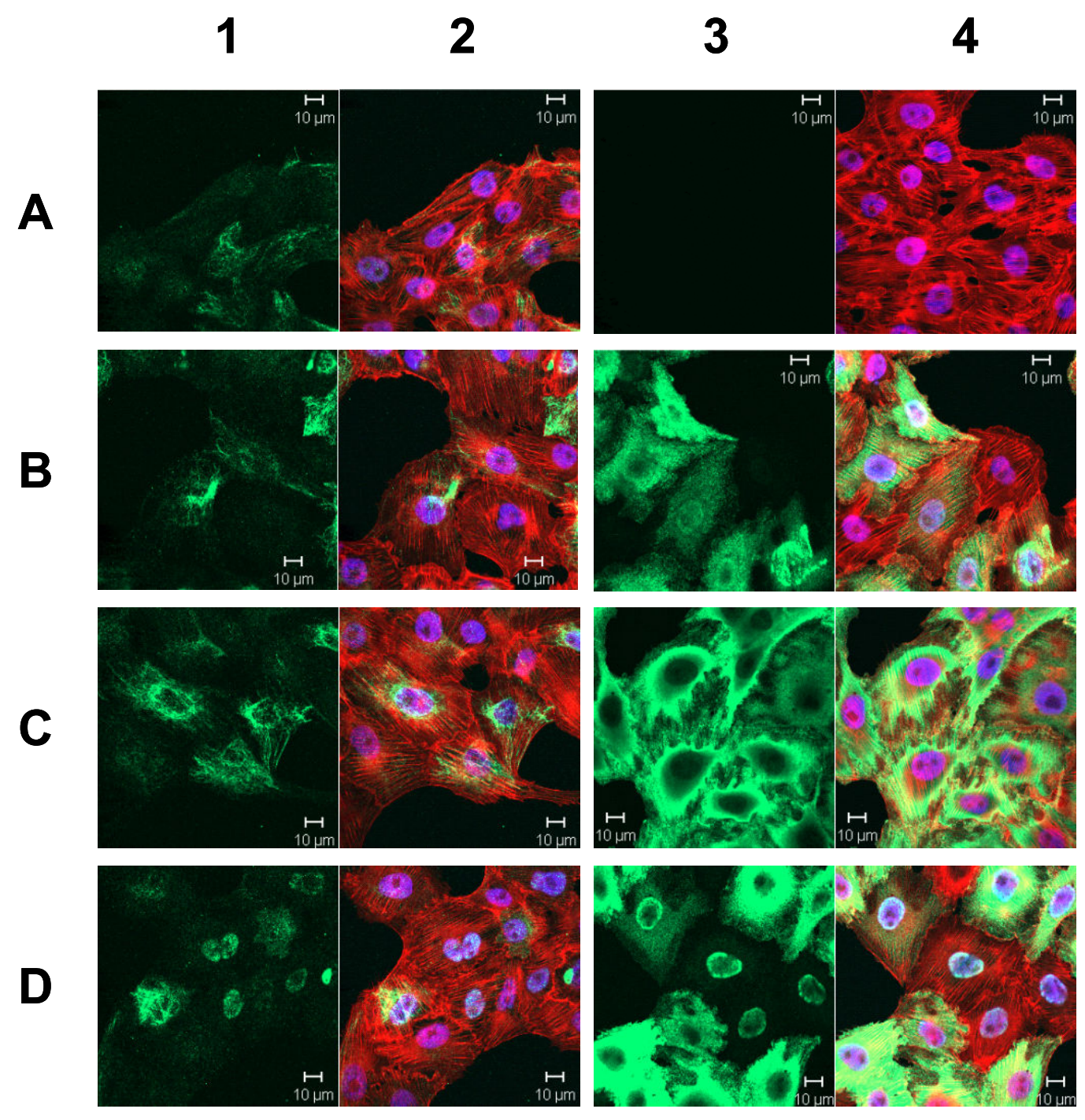
Figure 31. Cellular localization of HSP110 and HSP30 proteins in A6 cells in response to sodium arsenite

A6 cells were maintained at $22^{\circ} \mathrm{C}$ (control; A1-A4), or exposed to sodium arsenite for $12 \mathrm{~h}$ at $5 \mu \mathrm{M}$ (B1-B4), $10 \mu \mathrm{M}$ (C1-C4), $25 \mu \mathrm{M}$ (D1-D4) or $50 \mu \mathrm{M}$ (E1-E4). Cells were then labeled for HSP110 (columns 1-2), HSP30 (columns 3-4) and F-actin (columns 2 and 4) expression using Alexa Fluor 488 (green; for HSPs), TRITC (red; for F-actin) and DAPI (blue; for the nucleus) as outlined in Materials and Methods. Cells were visualized using a Zeiss LSM 510 Meta laser confocal microscope. 

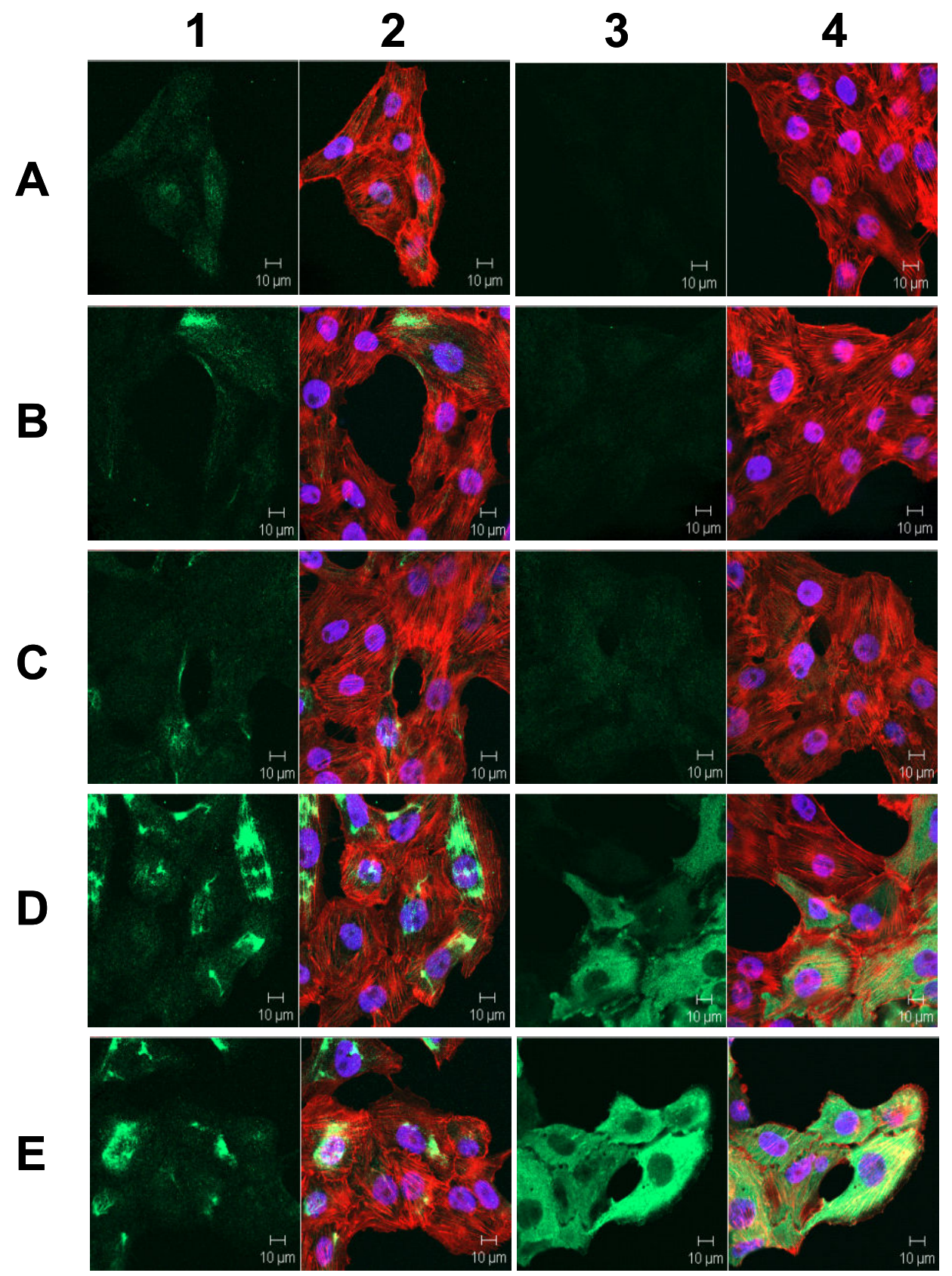
Figure 32. Cellular localization of HSP110 protein in A6 cells in response to extended sodium arsenite exposure at $10 \mu \mathrm{M}$

A6 cells were maintained at $22^{\circ} \mathrm{C}$ (control; A1-A2), or exposed to $10 \mu \mathrm{M}$ sodium arsenite for $5 \mathrm{~h}$ (B1-B2), $12 \mathrm{~h}(\mathrm{C} 1-\mathrm{C} 2)$ or $24 \mathrm{~h}$ (D1-D2). Cells were then labeled for HSP110 and F-actin expression using Alexa Fluor 488 (green; for HSP110), TRITC (red; for F-actin) and DAPI (blue; for the nucleus) as outlined in Materials and Methods. Cells were visualized using a Zeiss LSM 510 Meta laser confocal microscope. 

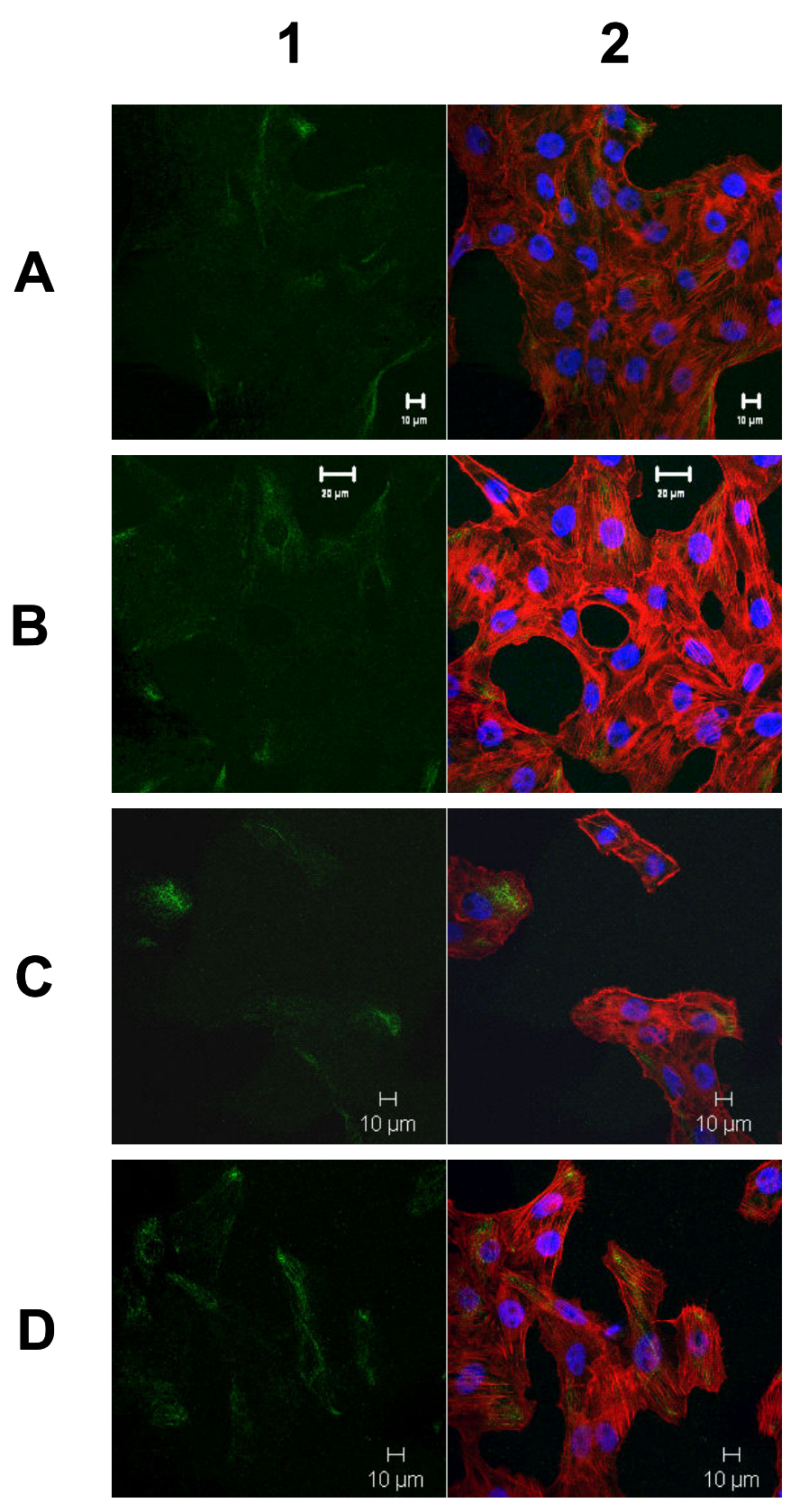
Figure 33. Cellular localization of HSP110 protein in A6 cells in response to extended sodium arsenite exposure at $50 \mu \mathrm{M}$

A6 cells were maintained at $22^{\circ} \mathrm{C}$ (control; A1-A2), or exposed to $50 \mu \mathrm{M}$ sodium arsenite for $5 \mathrm{~h}$ (B1-B2), $12 \mathrm{~h}$ (C1-C2) or $24 \mathrm{~h}$ (D1-D2). Cells were then labeled for HSP110 and F-actin expression using Alexa Fluor 488 (green; for HSP110), TRITC (red; for F-actin) and DAPI (blue; for the nucleus) as outlined in Materials and Methods. Cells were visualized using a Zeiss LSM 510 Meta laser confocal microscope. 

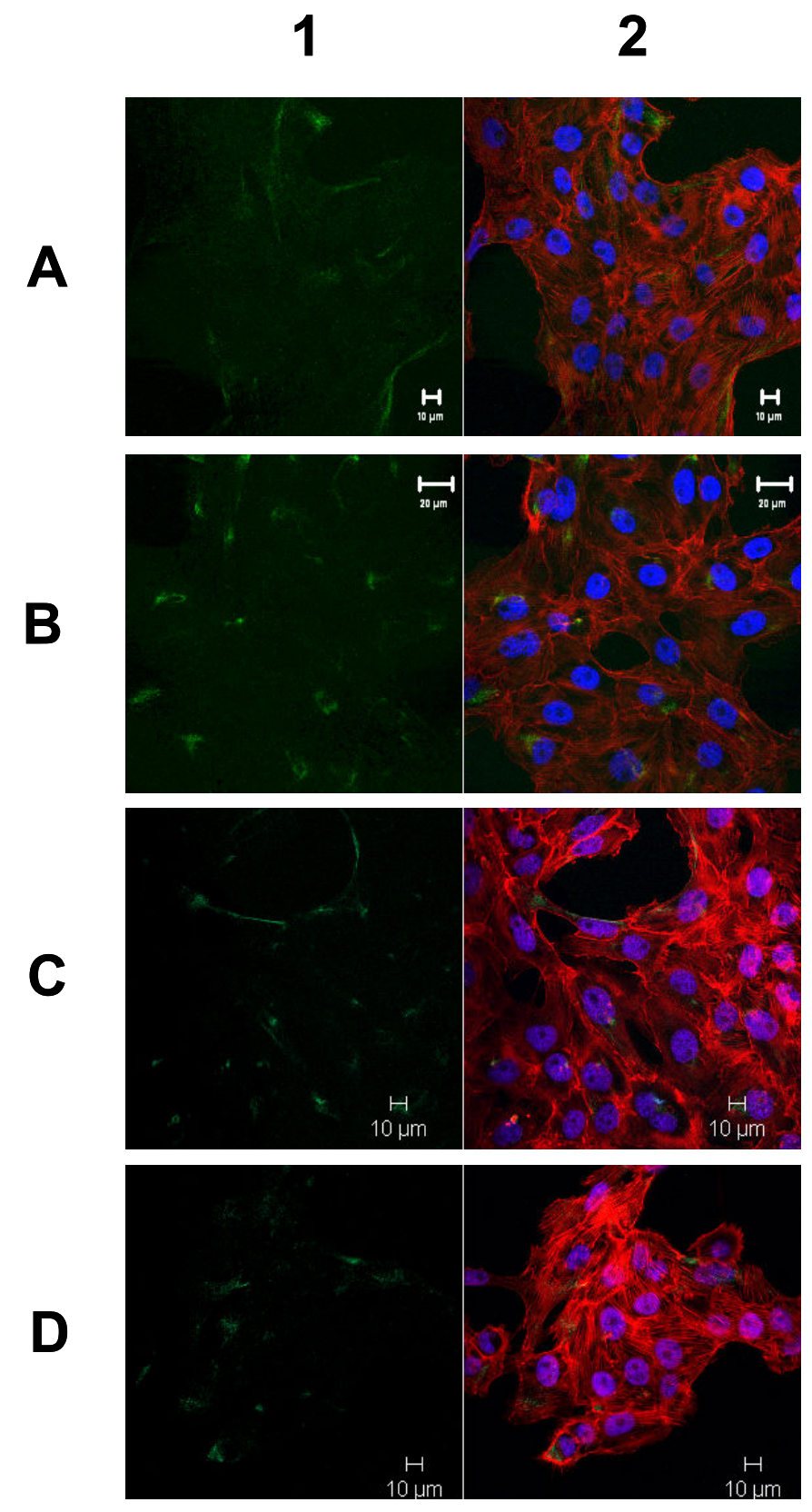
was not directly observed in any of the aforementioned treatments. This would have been indicated by a yellow merged signal. Although in some images a yellow signal is visible, suggesting colocalization of HSP30 and actin, this may be due to a coincidental overlap of protein, rather than direct protein interaction. Further experiments would be necessary to confirm such interactions. 


\section{Chapter 4: Discussion}

In this study, we characterized for the first time, a Xenopus hsp110 cDNA sequence and the expression of this gene in Xenopus cultured cells and embryos. Xenopus HSP110 shared identity with HSP110-like proteins from other organisms including mouse, human, and sea urchin (Hatayama et al., 1994; Ishihara et al., 1999; Foltz et al., 1993). For example, amino acid sequence comparison of the coding region of Xenopus HSP110 with HSP110/105 proteins from mammalian species revealed an identity of $72-74 \%$ while members of the Xenopus $h s p 70$ family ( $h s p 70, h s c 70.1, h s c 70.2$ and BiP) only shared an identity of 27-29\%. Most of the identity within the superfamily resided in the ATP-binding domain in the Nterminus. The Xenopus HSP110 NLS (KKPK) was identical in sequence and position to hamster as were three of seven potential N-glycosylation sites. Phylogenetic analysis indicated that Xenopus HSP110 grouped outside of mammals. A comprehensive phylogenetic analysis of the entire HSP70/DnaK superfamily has been presented previously (Lee-Yoon et al., 1995; Easton et al., 2000).

Analysis of hsp110 mRNA levels in Xenopus A6 kidney epithelial cells revealed that this message was constitutive as reported previously for mammalian cultured cells (Yasuda et al., 1995; Ishihara et al., 1999; Hatayama et al., 2001; Yamagishi et al., 2002). The pattern of heat shock-induced hsp 110 mRNA accumulation in A6 cells incubated at different temperatures and during continuous treatment at $33^{\circ} \mathrm{C}$ and $35^{\circ} \mathrm{C}$ was similar to the pattern observed with hsp70 mRNA. Heat shock treatment also enhanced the relative level of HSP110 protein as determined by immunoblot analysis. While the Xenopus hsp 110 gene has 
not been isolated it is likely that heat shock-induced expression was the result of HSF-HSE interaction as determined for other $h s p$ genes in Xenopus and other organisms (Heikkila, 2004; Morimoto, 1998). Genomic cloning of murine hsp 105 revealed 2 HSEs in the 5' UTR (Yasuda, et al., 1999). In contrast to Xenopus hsp70 mRNA, the relative levels of hsp110 mRNA were quite low when $\mathrm{A} 6$ cells were incubated at $37^{\circ} \mathrm{C}$. If the Xenopus hsp 110 gene has introns, as determined for mammalian hsp110 (Feige et al., 1996; Yasuda et al., 1999), then it is possible that the low level of Xenopus hsp $110 \mathrm{mRNA}$ accumulation at $37^{\circ} \mathrm{C}$ was due to an inhibition of RNA splicing as found with $h s p 90$ primary transcripts (Yost and Lindquist, 1986; Kay et al., 1987; Bond, 1988). This is a viable possibility since introns are present in the hspl10 gene of Xenopus tropicalis as revealed by the genome project for that organism (U.S. Department of Energy Joint Genome Institute; http://genome.jgipsf.org/Xentr4/Xentr4.home.html). Since Xenopus laevis is tetraploid it is possible that multiple copies of the hspl10 gene exist. Therefore, the results presented with A6 cells and embryos in the present study may reflect the overall response of the different $h s p 110$ genes to the various stressors.

In contrast to heat shock, treatment of A6 cells with sodium arsenite produced a gradual increase in $h s p 110$ and $h s p 70$ mRNA accumulation for at least 12-24 h. A gradual increase in hsp105 mRNA levels after sodium arsenite exposure was reported in both HeLa cells and FM3A cells (Ishihara et al., 1999; Yasuda et al., 1995). Cadmium chloride also enhanced Xenopus hsp110 and hsp70 mRNA accumulation in A6 cells while treatment with copper sulfate had no detectable effect on either message. However, treatment of A6 cells with ethanol resulted in an accumulation of $h s p 70$ mRNA but with no accompanying increase in 
hspl10 mRNA levels compared to control. This latter finding suggests the presence of regulatory mechanisms that lead to a stressor-specific accumulation of different $h s p$ mRNAs. In support of this possibility, stressor-specific activation of $h s p$ genes has been observed in rat hepatoma cells (Wiegant et al., 1994; Ovelgonne et al., 1995).

This study investigated $h s p 110$ mRNA accumulation in developing Xenopus embryos. The detection of constitutive levels of hsp 110 mRNA in unfertilized eggs, cleavage and early blastula stage embryos suggested that these transcripts were maternally inherited since the zygotic genome was not activated until after the midblastula stage (Kimmelman et al., 1987; Hair et al., 1998). The relative levels of constitutive $h s p 110$ message declined in gastrula, neurula and early tailbud embryos and then increased in midtailbud and later stage embryos. The reasons for this decline are not known although it is possible that this phenomenon reflects the decay in maternal $h s p 110$ mRNA followed by enhanced zygotic constitutive hsp1 10 mRNA accumulation in midtailbud. Similar findings were observed with maternal transcripts encoding insulin receptor and S-adenosylmethionine decarboxylase during Xenopus early development (Groigno et al. 1999; Shinga et al., 1996). In comparison to hspl $10 \mathrm{mRNA}$, hsp70 was detected only in response to stress and the magnitude of the response increased with development. Unlike $h s p 70$ and $h s p 110$ messages, which accumulated in blastula embryos, $h s p 27$ message was differentially expressed in a heatinducible fashion beginning in early tailbud embryos, similar to Xenopus hsp30 (Krone and Heikkila, 1988).

In the present study, whole mount in situ hybridization revealed an enhanced accumulation of hsp110 mRNA in lens vesicle, notochord, brain, and heart region of Xenopus late tailbud 
embryos. We found a similar result for $h s p 70 \mathrm{mRNA}$, $s p 27 \mathrm{mRNA}$ and previously for the mRNA encoding collagen-binding hsp47 (Hamilton and Heikkila, 2006). This pattern of mRNA enrichment was similar to that of fish, avian and mammalian embryos for $h s p 27$ (Mao and Shelden, 2006; Kawazoe et al., 1999; Armstrong et al., 2001), mouse embryos for hsp105 (Hatayama et al., 1997), and fish and Drosophila embryos for hsp70 (Lele et al., 1997; Wang and Lindquist, 1998). Tissue-specific enrichment of mouse hsp105 mRNA was also reported in brain, lung, liver, heart, intestine and limb at gestational days 11 and 14 (Hatayama et al., 1997; Satoh et al., 1998). While the mechanism for tissue-specific enrichment of hspl10 mRNA is not known, the presence of this mRNA in selected tissues of early Xenopus embryos suggests that $h s p 110$ may have a role during organogenesis. A possible role in apoptosis was suggested for mouse HSP105 during early development since this protein was observed specifically in cells undergoing programmed cell death in the interdigital regions of the limb tissue (Hatayama et al., 1997). This proposed apoptotic role was supported by recent data linking HSP110 expression to caspase-3 expression during mouse development (Evrard et al., 1999; 2000; Gashegu et al., 2007).

Whole mount in situ hybridization analysis revealed that heat shock enhanced $h s p 110$ mRNA accumulation in selected tissues including the notochord, somites, lens vesicle, heart region and brain region of late tailbud embryos. The mechanism for preferential enrichment of hsp110 message in selected tissues of normal and heat shocked Xenopus embryos is not known. There are a number of possibilities for this finding including preferential mRNA stability or tissue-specific transcription. Unfortunately, very little is known about either possibility. In fact, the mouse $h s p 105$ gene promoter sequence has been the only one 
analyzed for its constitutive and heat-inducible expression in transfected cultured cells (Yasuda et al., 1999). While heat shock-induced activation of $h s p$ genes by HSF-HSE interaction is well documented, the mechanism responsible for preferential accumulation of hsp110 mRNA in selected tissues is unclear. Previous studies with heat shocked Xenopus embryos have suggested that a reduced temperature set point for HSF activation in selected tissues may be a possible mechanism for the tissue-specific enrichment of $h s p 30$ and $h s p 70$ mRNA (Lang et al., 1999; 2000). Also HSF activation at a reduced temperature compared to other cells or tissues has been reported in mouse pachytene spermatocytes and adult Xenopus laevis heart (Sarge, 1995; Ali et al., 1997). Given these findings, it is possible that under heat shock conditions the interaction between HSF and HSE of the hsp 110 promoter may be superimposed on the mechanisms associated with tissue-specific expression. Future analysis of the Xenopus hspl10 gene may aid in elucidating the mechanisms associated with the pattern of hspl10 gene expression during early embryogenesis. Finally, it is possible that the preferential accumulation of $h s p 110$ mRNA in selected tissues during heat shock may indicate a protective role for HSP110. Previous experiments have documented the ability of HSP110 to confer heat resistance and/or act as a molecular chaperone (Oh et al., 1997; 1999; Hatayama et al., 2001).

In order to investigate HSP110 protein accumulation, a polyclonal rabbit-anti hamster HSP110 commercial antibody was initially employed. While this antibody detected HSP110, it also detected several non-specific proteins, which prevented us from examining cellular localization using CLSM. A custom polyclonal rabbit-anti Xenopus HSP110 antibody was prepared using a KLH-coupled C-terminal peptide. This preparation provided much greater 
specificity and enabled us to investigate both protein accumulation via western blot analysis, and cellular localization of HSP110 with confidence. This antibody produced a single band of approximately $110 \mathrm{kDa}$ via western blot analysis, and detected HSP110 protein under both control and stressed conditions, which was expected based on the preliminary results obtained from the commercial preparation. Also, the production of an antibody specific to Xenopus HSP70 was particularly helpful. Previously, an antibody that would detect HSP70 exclusively, and not HSC70, was not available.

Western blot analyses indicated HSP110 protein accumulation in response to both elevations in temperature and increasing sodium arsenite concentrations. Similar patterns of protein accumulation were found for HSP70 and HSP30, although these two proteins were only detected in response to stress. Interestingly, HSP70 and HSP30 protein levels declined in response to $50 \mu \mathrm{M}$ sodium arsenite, while HSP110 protein remained elevated. It is possible that HSP110 protein, or $h s p 110$ mRNA have longer half-lives than HSP70, HSP30 or their messages. This may be feasible given that $h s p 70$ and $h s p 30$ gene expression is primarily stress-inducible whereas $h s p 110$ is a constitutively expressed gene.

Two HSP1 10 protein bands were detected at $33-35^{\circ} \mathrm{C}$ with western blot analysis. One possibility that may account for this finding is alternative splicing. A similar finding was also reported in mouse and human, which express two HSP105 isoforms $\alpha$ and $\beta$, the latter alternatively spliced from the former (Yasuda et al., 1995; Ishihara et al., 1999). Mammalian HSP $105 \beta$ protein, a $90 \mathrm{kDa}$ band, was detected only at heat shock temperatures of $42^{\circ} \mathrm{C}$ and not under any other conditions. In the present study, the $97 \mathrm{kDa}$ Xenopus HSP110 band was 
detected only at $33-35^{\circ} \mathrm{C}$, and not under the other heat shock or sodium arsenite treatments employed. Given the similarity between the patterns of mouse and Xenopus HSP110 accumulation, it is possible that alternative splicing may be the mechanism for the appearance of the $97 \mathrm{kDa}$ HSP110 band. However, since a genomic analysis of Xenopus HSP110 has not been completed we are unable to confirm this hypothesis. It is also possible that the additional Xenopus HSP110 band may be the result of post-translational modifications, especially given the number of putative glycosylation sites in the HSP110 protein. Finally, multiple $h s p 110$ genes are also a possibility since Xenopus laevis is tetraploid. Alterations in the coding regions of hspl10 genes during evolution could have given rise to HSP110 isoforms with different sizes.

In this study, Xenopus HSP110 localized primarily in the cytoplasm, showing enrichment near, and in some cases was present in, the nucleus. Immunofluorescent detection showed that Xenopus HSP110 was present under control conditions and accumulated in response to heat shock and sodium arsenite, which was in agreement with western blot analysis results. This general pattern of HSP110/HSP105 localization was shared with mouse (Hatayama et al., 1994; Yasuda et al., 1995) and human cultured cells (Ishihara et al., 1999). Hamster cells also shared this pattern of intracellular distribution, but additionally accumulated in the nucleolus (Subjeck et al., 1983; Lee-Yoon et al., 1995). Under control conditions, Xenopus HSP110 demonstrated diffuse staining in the cytoplasm and in the nucleus in some cases, but was never documented in the nucleolus. This is similar to what has been reported in mouse cultured cells (Hatayama et al., 1994). In A6 cells, long spindle-shaped HSP110 structures close to the cell periphery were frequently noted. Increases in temperature $\left(30,33\right.$ and $\left.35^{\circ} \mathrm{C}\right)$, 
as well as prolonged high temperature exposure resulted in a general increase in HSP110 cytoplasmic staining, and also an increase in the frequency of the spindle-shaped structures, which have not thus far been reported in the literature. It is possible, based on the morphology, that perhaps this localization is related to microtubules or the cytoskeleton. This possibility is supported well by findings in other organisms. For example, HSP105, which was shown to co-localize with $\alpha$-tubulin in HeLa and COS-7 cells, was suggested as having a stabilizing role in microtubular structure (Saito et al., 2003). It was suggested that this relationship between HSP105 $\alpha$ and $\alpha$-tubulin would be protective for the cell, through binding to denaturing microtubules and preventing their aggregation and disorganization, and also possibly preventing apoptosis. In the present study, a monoclonal mouse anti- $\alpha$-tubulin antibody was employed with Xenopus A6 cells to investigate a possible co-localization of HSP110 with $\alpha$-tubulin. While no co-localization of these two proteins was observed (data not shown) it was possible that this phenomenon could be explained by co-localization of HSP110 with a different cytoskeletal protein other than F-actin or $\alpha$-tubulin. Additionally, HSP110 immunofluorescence was observed not just as thread or spindle-shaped fibers (which may parallel stress fibers), but also in the nucleus, as aggregates at the periphery of the nucleus, and amorphously in the cytoplasm. It is possible given its role as a molecular chaperone that HSP110 may function in different subcellular locations with selective client proteins during stress.

In contrast to HSP110 localization, HSP30 was strictly stress-inducible and displayed a granular, or punctate, cytoplasmic localization, that was ameliorated in response to increasing temperature and sodium arsenite exposure. This pattern has been suggested to be due to the 
formation of super-aggregated HSP30 structures (Gellalchew and Heikkila, 2005; Ohan et al., 1998). Also, upon exposure to higher temperatures, F-actin is prone to cytoplasmic disorganization, and HSP30 was observed to co-localize to these areas. It is possible that HSP30 was involved in cytoskeletal protection since it has been shown to bind actin by coimmunoprecipitation (Fernando et al., 2003) and it co-localized with actin in areas of disorganization (Gellalchew and Heikkila, 2005). Unlike HSP110, very little nuclear or perinuclear localization of HSP30 was observed in this study, but did increase slightly at high temperatures. HSP30 does not possess a NLS, but has been reported in the nucleus at very low levels in response to high temperature exposure (Gellalchew and Heikkila, 2005; Manwell and Heikkila, 2007). Additionally, in response to prolonged exposure to high temperatures, HSP30 was initially enriched at the cell periphery, and longer treatments resulted in enrichment at the nuclear periphery. Although, few similarities were noted between the localization of HSP30 and HSP110, this is not surprising given these two HSPs belong to different HSP families entirely.

HSP110 was also routinely observed surrounding the nucleus following stress, especially concentrated at opposite ends of the nucleus. This localization pattern of HSP110 was found in response to both elevated temperature and sodium arsenite treatment. Although treatment of A6 cells at $37^{\circ} \mathrm{C}$ resulted in detachment of cells from the substrate, and the death of many cells, in cells that did survive this stress, HSP110 localized in distinct intensely stained areas at opposite ends of the nucleus. It is unclear what caused this distinctive pattern of HSP110 localization. Furthermore, in A6 cells subjected to prolonged heat shock, HSP110 was detected in the nucleus. Nuclear localization in response to prolonged heat shock was 
previously observed with HSP30 in Rana catesbeiana FT cells, human HSP27, mouse HSP25 (Mulligan-Tuttle and Heikkila, 2007; Van de Klundert et al., 1998; Adhikari et al., 2004).

Recently Saito et al. (2007) produced antibodies that were able to distinguish between mouse HSP $105 \alpha$ and HSP $105 \beta$. This study revealed that HSP105 $\alpha$ and HSP $105 \beta$ localized in different cellular compartments, with HSP105 $\beta$ specifically in the nucleus of mammalian COS-7 cells. While the antibody prepared in the present study was not able to distinguish between putative HSP $110 \alpha$ and HSP110 $\beta$, it is tempting to speculate that Xenopus HSP110 would behave in a similar manner. Although the antibody employed is unable to differentiate HSP $110 \alpha$ from HSP110 $\beta$, one would expect to observe HSP110 in the nucleus at $35^{\circ} \mathrm{C}$ to a greater extent than other treatments. However, the Xenopus HSP110 intracellular localization data presented in this study do not support this hypothesis. An increased amount of HSP110 protein was observed in the nucleus, but only when $\mathrm{A} 6$ cells were treated at $35^{\circ} \mathrm{C}$ for $6 \mathrm{~h}$. While it is clear that western blot analysis supports the presence of a putative HSP110 $\beta$, more extensive localization investigation would be required to conclude the presence of a similarly functioning HSP110 $\alpha$ and HSP110 in Xenopus laevis.

The presence of HSP110 in control A6 cells and embryos suggests that HSP110 may play a role in unstressed cells. Oh et al. (1997) implied that HSP110 likely serves an important function under control conditions simply due to the levels that are present constitutively, which have been reported to be $0.7 \%$ of total cell protein in the mouse brain (Subjeck et al., 1982c). The developmental regulation of $h s p 110 \mathrm{mRNA}$ accumulation in embryos also 
suggests a role for this protein during embryogenesis. A pattern of mRNA accumulation similar to Xenopus was observed in mouse embryos (Hatayama et al., 1997), and those authors proposed that HSP105 played a role in organogenesis. Moreover, the localization of HSP105 to apoptotic bodies during development may indicate additional roles in metamorphosis, neural tube closure, parietal plate closure, or mesonephros degeneration. It remains to be determined whether Xenopus HSP110 is directly involved in any of these processes, and the possibility should not be ruled out. In mouse FM3A cells, HSP105 was shown to interact with HSP70 family proteins, forming large complexes (of heterodimers and heterotetramers) of HSP105 and HSC70/HSP70 under unstressed conditions (Hatayama et al., 1998). The authors proposed that either HSP 105 was regulating the function of HSC70, or that $\mathrm{HSC} 70$ was regulating the function of HSP105, or that HSP105 was functioning cooperatively with HSC70/HSP70. A new role as a "nucleic acid chaperone" was put forward, in which the hamster N-terminal ATP-binding domain of HSP110 was shown to bind directly to RNA under control conditions, possibly for the unwinding of complex secondary RNA structures to expose cis-acting sequences critical for recognition and binding by other protein factors (Henics et al., 1999). In summary, a role for HSP110 under normal cellular conditions has been well-documented in several animal systems. Although HSP110 mRNA and protein are clearly present constitutively, a role in Xenopus is yet to be determined.

This study has presented for the first time a characterization of Xenopus laevis HSP110, including the full-length sequence, mRNA accumulation data, spatial patterning of mRNA, the production of polyclonal antibody, characterization of protein accumulation and cellular 
localization data. This work has opened the door to many potential studies regarding Xenopus HSP110. For example, a thorough high magnification analysis, possibly including immunoelectron microscopy, would shed light on the interesting and unique localization patterns exhibited by Xenopus HSP110. Similarly, a localization study using CLSM in embryos might yield interesting results and would nicely complement the whole mount in situ hybridization study presented here. Furthermore, a determination of potential client proteins of HSP110 might help to elucidate its function. This could be accomplished with immunoprecipitation studies, or a yeast two hybrid analysis. Additionally, given that HSP110 displays documented chaperone activity in hamster (Oh et al., 1999), it would be interesting to determine whether Xenopus HSP110 functions as a chaperone. Another function that has been well-documented for HSP105 is an involvement in apoptosis (Hatayama et al., 1997; Hatayama et al., 2001; Yamagishi et al., 2002; Yamagishi et al., 2006). The Xenopus laevis system would lend itself well to such a project given the availability of the A6 and XTC cell lines, as well as an excellent developmental system. A last approach to function of this protein could be inhibitory in nature. Antisense morpholino oligonucleotides have enjoyed much success in the Xenopus laevis embryo system, allowing a simple way to 'knockdown' a gene, in order to determine a function in its absence (Heasman, 2002). 


\section{References}

Abdulle, R., Mohindra, A., Fernando, P. and Heikkila, J. J. 2002. Xenopus small heat shock proteins, Hsp30C and Hsp30D, maintain heat- and chemically denatured luciferase in a folding-competent state. Cell Stress and Chaperones 7: 6-16.

Adhikari, A. D., Sridhar Rao, K., Rangaraj, N., Parnaik, V. K. and Mohan Rao, C. 2004. Heat stress-induced localization of small heat shock proteins in mouse myoblasts: intracellular lamin $\mathrm{A} / \mathrm{C}$ speckles as target for alphaB-crystallin and Hsp25. Experimental Cell Research 299: 393-403.

Ali, A., Fernando, P., Smith, W.L., Ovsenek, N., Lepock, J.R. and Heikkila, J.J. 1997. Preferential activation of HSP-binding activity and hsp70 gene expression in Xenopus heart after mild hyperthermia. Cell Stress Chaperones 2, 229-237.

Ali, A., Salter-Cid, L., Flajnik, M. F. and Heikkila, J. J. 1996a. Isolation and characterization of a cDNA encoding a Xenopus 70-kDa heat shock cognate protein, hsc70.1. Comparative Biochemistry and Physiology. Part B, Biochemistry \& Molecular Biology 113: 681-687.

Ali, A., Krone, P. H., Pearson, D. and Heikkila, J. J. 1996b. Evaluation of stress-inducible hsp90 gene expression as a potential molecular biomarker in Xenopus laevis. Cell Stress and Chaperones 1: 62-69.

Anderson, R L. 1998. Stress proteins and apoptosis in prenatal development, cancer and medicine. Cell Stress and Chaperones 3: 209-212.

Armstrong, C. L., Krueger-Naug, A. M, Currie, R. W. and Hawkes R. 2001. Constitutive expression of heat shock protein HSP25 in the central nervous system of the developing adult mouse. Journal of Comparative Neurology 434: 262-274.

Arrigo, A-P. 1998. Small stress proteins: chaperones that act as regulators of intracellular redox state and programmed cell death. Journal of Biological Chemistry 379: 19-26.

Arrigo, A-P. and Landry, J. 1994. Expression and function of the low-molecular weight heat shock proteins. In: R.I. Morimoto, A. Tissieres, and C. Georgopoulos (Eds.), The Biology of Heat Shock Proteins and Molecular Chaperones. Cold Spring Harbor Laboratory Press. Cold Spring Harbor, N.Y, pp. 335-373.

Arrigo, A.-P., Paul, C., Ducasse, C., Manero, F., Kretz-Remy, C., Virot, S., Javouhey, E., Mounier, N. and Diaz-Latoud, C. 2002. Small stress proteins: novel negative modulators of apoptosis induced independently of reactive oxygen species. Progress in Molecular and Subcellular Biology 28: 185-204.

Arrigo, A.-P., Virot, S., Chaufour, S., Firdaus, W., Kretz-Remy, C. and Diz-Latoud, C. 2005. Hsp27 consolidates intracellular redox homeostasis by upholding glutathione in its reduced form and by decreasing iron intracellular levels. Antioxidant Redox Signal 7: 414-422. 
Baker, C. V. and Bronner-Fraser, M. 1997. The origins of the neural crest. Part I: Embryonic Induction. Mechanisms of Development 69: 3-11.

Beere, H. M. 2001. Stressed to death: regulation of apoptotic signaling pathways by the heat shock proteins. Science STKE 93: RE1.

Bernstam, L. and Nriagu, J. 2000. Molecular aspects of arsenic stress. Journal of Toxicology and Environmental Health 3: 293-322.

Bienz, M. 1984a. Developmental control of the heat shock response in Xenopus. Proceedings of the National Academy of Science 81: 3138-3142.

Bienz, M. 1984b. Xenopus hsp70 genes are constitutively expressed in injected oocytes. EMBO Journal 3: 2477-2483.

Bharadwaj, S., Ali, A. and Ovsenek, N. 1999. Multiple components of the HSP90 chaperone complex function in regulation of heat shock factor 1 in vivo. Molecular and Cellular Biology 19: 8033-8041.

Bond, U. 1988. Heat shock but not other stress inducers leads to the disruption of a sub-set of snRNPs and inhibition of in vitro splicing in HeLa cells. EMBO Journal 7: 3509-3518.

Boorstein, W. R., Ziegelhoffer, T. and Craig, E. A. 1994. Molecular evolution of the HSP70 multigene family. Journal of Molecular Evolution 38:1-17.

Brown, D. D. and Littna, E. 1964. RNA synthesis during the development of Xenopus laevis, the South African clawed toad. Journal of Molecular Biology 8: 669-687.

Chirgwin, J., Przbyla, A., MacDonald, R. and Rutter, W. 1979. Isolation of biologically active ribonucleic acid from sources enriched in ribonuclease. Biochemistry 18: 5294-5299.

Chung, K. S., Hoe, K. L., Kim, K. W., and Yoo, H. S. 1998. Isolation of a novel heat shock protein 70-like gene, pss1+ of Schizosaccharomyces pombe homologous to hsp110/SSE subfamily. Gene 210: 143-150.

Ciocca, D. R., Oesterreich, S., Chamness, G. C., McGuire, W. L. and Fuqua, S. A. W. 1993. Biological and clinical implications of heat shock protein 27000 (Hsp27): a review. Journal of the National Cancer Institute 85: 1558-1570.

Cotto, J. J. and Morimoto, R. I. 1999. Stress-induced activation of the heat-shock response: cell and molecular biology of heat-shock factors. In "Cellular responses to stress" (Downes, C. P., Wolf, C. R., and Lane, D. P., Eds.), pp. 105-118, Princeton University Press, London.

Craig, E. A., Ignolia, T. D. and Mansequ, L. J. 1983. Expression of Drosophila heat-shock cognate genes during heat shock and development. Developmental Biology 99: 418-426. 
Daugaard, M., Rohde, M. and Jäättelä. 2007. The heat shock protein 70 family: Highly homologous proteins with overlapping and distinct functions. FEBS Letters 581: 3702-3710.

Davidson, E. H. 1986. "Gene activity in early development," Academic Press, New York.

Deuchar, E. M. 1975. "Xenopus: The South African Clawed Frog," John Wiley \& Sons, Ltd., London.

Dragovic, Z., Broadley, S. A., Shomura, Y., Bracher, A. and Hartl, F. U. 2006. Molecular chaperones of the Hsp110 family act as nucleotide exchange factors of Hsp70s. EMBO Journal 25: 2519-2528.

Easton, D. P., Kaneko, Y. and Subjeck, J. R. 2000. The Hsp110 and Grp170 stress proteins: newly recognized relatives of the Hsp70s. Cell Stress \& Chaperones 5:276-290.

Edgar, B. A. and Schlubiger, G. 1986. Parameters controlling transcriptional activation during early Drosophila development. Cell 44: 871-877.

Ehrnsperger, M., Graber, S., Gaestel, M. and Buchner, J. 1997. Binding of non-native protein to hsp25 during heat shock creates a reservoir of folding intermediates for reactivation. EMBO Journal 16: 221-229.

Evrard, L., Vanmuylder, N., Dourov, N., Glineur, R. and Louryan, S. 1999. Cytochemical identification of HSP110 during early mouse facial development. Journal of Craniofacial Genetics and Developmental Biology 19: 24-32.

Evrard, L., Vanmuylder, N., Dourov, N., Hermans, C., Biermans, J., Werry-Huet, A., Rooze, M. and Louryan, S. 2000. Correlation of HSP110 expression with all-trans retinoic acid-induced apoptosis. Journal of Craniofacial Genetics and Developmental Biology 20: 183-192.

Fathallah, D. M., Cherif, D., Dellagi, K. and Arnaout, M. A. 1993. Molecular cloning of a novel human hsp70 from a B cell line and its assignment to chromosome 5 [published erratum appears in J Immunol 1993 Dec 1;151 (11):6616]. Journal of Immunology 151: 810-813.

Feige, U., Morimoto, R. I., Yahara, I. and Polla, B. S. 1996. “Stress-inducible cellular responses,” Birkhauser Verlag., Basel, Switzerland.

Feige, U. and Polla, B. S. 1994. Hsp70 - a multi-gene, multi-structure, multi-function family with potential clinical applications. Experientia 50: 979-986.

Fernandes, M., O'Brien, T. and Lis, J. T. 1994. Structure and regulation of heat shock gene promoters. In "The biology of heat shock proteins and molecular chaperones" (Morimoto, R. I., Tissières, A., and Georgopoulos, C., Eds.), pp. 375-393, Cold Spring Harbor Laboratory Press, New York.

Fernando, P. and Heikkila, J. J. 2000. Functional characterization of Xenopus small heat shock protein, Hsp30C: the carboxyl end is required for stability and chaperone activity. Cell Stress and Chaperones 5: 148-159. 
Fernando, P., Megeney, L. A. and Heikkila, J. J. 2003. Phosphorylation-dependent structural alterations in the small hsp30 chaperone are associated with cellular recovery. Experimental Cell Research 286: 175-185.

Foltz, K. R., Partin, J. S. and Lennarz, W. J. 1993. Sea urchin egg receptor for sperm: sequence similarity of binding domain and hsp70. Science 259: 1421-1425.

Freeman, B. C. and Morimoto, R. I. 1996. The human cytosolic molecular chaperones, hsp90, hsp70 (hsc70) and hdj-1 have distinct roles in the recognition of a non-native protein and protein refolding. EMBO Journal 15: $2969-2979$.

Garrido, C., Brunet, M., Didelot, C., Zermati, Y., Schmitt, E. and Kroemer, G. 2006. Heat shock proteins 27 and 70: anti-apoptotic proteins with tumorigenic properties. Cell Cycle 5: 2592-2601.

Gashegu, J., Ladha, R., Vanmuylder, N., Philippson, C., Bremer, F., Rooze, M. and Louryan, S. 2007. HSP110, caspase-3 and -9 expression in physiological apoptosis and apoptosis induced by in vivo embryonic exposition to all-trans retinoic acid or irradiation during early mouse eye development. Journal of Anatomy 210: $532-541$.

Gellalchew, M. and Heikkila, J. J. 2005. Intracellular localization of Xenopus small heat shock protein, hsp30, in A6 kidney epithelial cells. Cell Biology International 29: 221-227.

Gething, M. J. and Sambrook, J. F. 1992. Protein folding in the cell. Nature 355: 33-45.

Gilbert, S. F. 1994. Transcriptional regulation of gene expression. In: "Developmental biology," $6{ }^{\text {th }}$ edition. Sinauer associates, Inc., Massachusetts.

Gorlich, D., Kostka, S., Kraft, R., Dingwall, C., Laskey, R. A., Hartmann, E. and Prenn, S. 1995. Two different subunits of importin cooperate to recognize nuclear localization signals and bind them to the nuclear envelope. Current Biology 5: 383-392.

Gotoh, K., Nonoguchi, K., Higashitsuji, H., Kaneko, Y., Sakurai, T., Sumitomo, Y., Itoh, K., Subjeck, J. R. and Fujita, J. 2004. Apg-2 has a chaperone-like activity similar to Hsp110 and is overexpressed in hepatocellular carcinomas. FEBS Letters 560: 19-24.

Graf, J. and Kobel, H. R. 1991. Genetics of Xenopus laevis. In "Methods in cell biology" 36: pp. 19-34, Academic Press, Inc., England.

Groigno, L., Richard-Parpaillon, L. and Boujard, D. 1999. Expression pattern of insulin receptor mRNA during Xenopus laevis embryogenesis. Mechanisms of Development 86: 151-154.

Hair, A., Prioleau, M. Vassetzky, Y. and Mechali, M. 1998. Control of gene expression in Xenopus early development. Developmental Genetics 22: 122-131. 
Hamilton, A. M. and Heikkila, J. J. 2006. Examination of the stress-induced expression of the collagen binding heat shock protein, hsp 47, in Xenopus laevis cultured cells and embryos. Comparative Biochemistry and Physiology, Part A 143: 133-141.

Harland, R. M. 1991. In situ hybridization: an improved whole mount method for Xenopus embryos. In: Kay, B. K., Peng, H. B. (Eds), Methods in Cell Biology 36: 685-694. Academic Press, Toronto.

Hartl, F.-U., Hlodan, R. and Langer, T. 1994. Molecular chaperones in protein folding: the art of avoiding sticky situations. Trends in Biochemical Sciences 19: 20-25.

Haslbeck, M. and Buchner, J. 2002. Chaperone function of sHSPs. Progress in Molecular and Subcellular Biology 28: 37-59.

Hatayama, T., Nishiyama, E. and Yasuda, K. 1994. Cellular localization of high-molecular-mass heat shock proteins in murine cells. Biochemical and Biophysical Research Communications 200: 1367-1373.

Hatayama, T., Takigawa, T., Takeuchi, S. and Shiota, K. 1997. Characteristic expression of high molecular mass heat shock protein HSP105 during mouse embryo development. Cell Structure and Function 22: $517-$ 525 .

Hatayama, T., Yamagishi, N., Minobe, E. and Sakai, K. 2001. Role of hsp105 in protection against stressinduced apoptosis in neuronal PC12 cells. Biochemical and Biophysical Research Communications 288: 528-534.

Hatayama, T., Yasuda, K. and Yasuda, K. 1998. Association of HSP105 with HSC70 in high molecular mass complexes in mouse FM3A cells. Biochemical and Biophysical Research Communications 248: 395-401.

Heasman, J. 2002. Morpholino oligos: making sense of antisense? Developmental Biology 243: 209-214.

Heikkila, J. J. 2003. Expression and function of small heat shock protein genes during Xenopus development. Seminars in Cell \& Developmental Biology 14: 259-266.

Heikkila, J. J. 2004. Regulation and function of small amphibian genes during amphibian development. Journal of Cellular Biochemistry 93: 672-680.

Heikkila, J. J., Darasch, S. P., Mosser, D. D. and Bols, N. C. 1987. Heat and sodium arsenite act synergistically on the induction of heat shock gene expression in Xenopus laevis A6 cells. Biochemistry and Cell Biology 65: 310-316.

Heikkila, J. J., Kloc, M., Bury, J., Schultz, G. A. and Browder, L. W. 1985. Acquisition of the heat-shock response and thermotolerance during early development of Xenopus laevis. Developmental Biology 107: 483-489. 
Heikkila, J. J., Ohan, N., Tam, Y. and Ali, A. 1997. Heat shock protein gene expression during Xenopus development. Cellular and Molecular Life Sciences 53: 114-121.

Henics, T., Nagy, E., Oh, H. J., Csermely, P., von Gabain, A. and Subjeck, J. R. 1999. Mammalian Hsp70 and Hsp110 proteins bind to RNA motifs involved in mRNA stability. Journal of Biological Chemistry 274: 17318-17324.

Hilgarth, R. S., Murphy, L. A., O’Connor, C. M., Clark, J. A., Park-Sarge, O. and Sarge, K. D. 2004. Identification of Xenopus heat shock transcription factor-2: conserved role of sumoylation in regulating deoxyribonucleic acid-binding activity of heat shock transcription factor-2 proteins. Cell Stress and Chaperones 9: 214-220.

Ishihara, K., Yasuda, K. and Hatayama, T. 1999. Molecular cloning, expression and localization of human 105 $\mathrm{kDa}$ heat shock protein, hsp105. Biochimica et Biophysica Acta 1444: 138-142.

Jukes, T. H. and Cantor, C. R. 1969. Evolution of protein molecules. In: Munro, H. N. (Ed.), Mammalian Protein Metabolism. Academic Press, New York. pp. 21-132.

Katschinski, D. M. 2004. On heat and cells and proteins. News in physiological sciences 19: 11-15.

Kaneko, Y., Nishiyama, H., Nonoguchi, K., Higashitsuji, H., Kishishita, M. and Fujita, J. 1997. A novel hsp110-related gene, apg-1, that is abundantly expressed in the testis responds to a low temperature heat shock rather than the traditional elevated temperatures. Journal of Biological Chemistry 272: 2640-2645.

Kawazoe, Y., Tanabe, M. and Nakai, A. 1999. Ubiquitous and cell-specific members of the avian small heat shock protein family. FEBS Letters 455: 271-275.

Kay, R. J., Russnak, R .H., Jones, D., Mathias, C. and Candido, P. M. 1987. Expression of intron-containing C. elegans heat shock genes in mouse cells demonstrates divergence of 3 ' splice site recognition sequences between nematodes and vertebrates, and an inhibitory effect of heat shock on the mammalian splicing apparatus. Nucleic Acids Research 15: 3723-3741.

Keller, R. 1991. Early embryonic development of Xenopus laevis. In: Methods in cell biology, 36: pp. 61-113, Academic Press, Inc., England.

Kimelman, D., Kirschner, M. and Scherson, T. 1987. The events of the midblastula transition in Xenopus are regulated by changes in the cell cycle. Cell 48: 399-407.

Kohler, M., Speck, C., Christiansen, M., Bischoff, F. R., Prehn, S., Haller, H., Gorlich, D. and Hartmann, E. 1999. Evidence for distinct substrate specificities of importin $\alpha$ family members in nuclear protein import. Molecular and Cellular Biology 19: 7782-7791. 
Kojima, R., Randall, J., Brenner, B. M. and Gullans, S. R. 1996. Osmotic stress protein 94 (Osp94). Journal of Biological Chemistry 271: 12327-12332.

Krone, P. H. and Heikkila, J. J. 1988. Analysis of hsp30, hsp70, and ubiquitin gene expression in Xenopus laevis tadpoles. Development 103: 59-67.

Krone, P. H. and Heikkila, J. J. 1989. Expression of microinjected hsp70/CAT and hsp30/CAT chimeric genes in developing Xenopus laevis embryos. Development 106: 271-281.

Krone, P. H., Snow, A., Ali, A., Pasternak, J. J. and Heikkila, J. J. 1992. Comparison of the regulatory regions of the Xenopus laevis small heat-shock protein encoding gene family. Gene 110: 159-166.

Kumar, S., Tamura, K. and Nei, M. 2004. MEGA3: Integrated software for molecular evolutionary genetics analysis and sequence alignment. Briefings in Bioinformatics 5: 150-163.

Landry, J., Bernier, D., Chretien, P., Nicole, L.M., Tanguay, R. M. and Marceau, N. 1982. Synthesis and degradation of heat shock proteins during development and decay of thermotolerance. Cancer Research $\mathbf{4 2}$ : 2457-2461.

Lang, L., Miskovic, D., Fernando, P. and Heikkila, J. J. 1999. Spatial pattern of constitutive and heat shockinduced expression of the small heat shock protein gene family, Hsp30, in Xenopus laevis tailbud embryos. Developmental Genetics 25: 365-374.

Lang, L., Miskovic, D., Lo, M. and Heikkila, J. J. 2000. Stress-induced, tissue-specific enrichment of hsp70 mRNA accumulation in Xenopus laevis embryos. Cell Stress \& Chaperones 5: 36-44.

Lee-Yoon, D., Easton, D., Murawski, M., Burd, R. and Subjeck, J. R. 1995. Identification of a major subfamily of large hsp70-like proteins through the cloning of the mammalian 110-kDa heat shock protein. Journal of Biological Chemistry 270: 15725-15733.

Lele, Z., Engel, S. and Krone, P. H. 1997. Hsp47 and $h s p 70$ gene expression is differentially regulated in a stress- and tissue-specific manner in zebrafish embryos. Developmental Genetics 21: 123-133.

Leroux, M. R., Melki, R., Gordon, B., Batelier, G. and Candido, E. P. 1997. Structure-function studies on small heat shock protein oligomeric assembly and interaction with unfolded polypeptides. Journal of Biological Chemistry 272: 24646-24656.

Liang, P. and MacRae, T. H. 1997. Molecular chaperones and the cytoskeleton. Journal of Cell Science 110: 1431-1440.

Lin, B., Wang, J., Liu, H., Chen, R., Meyer, Y., Barakat, A. and Delseny, M. 2001. Genomic analysis of the Hsp70 superfamily in Arabidopsis thaliana. Cell Stress and Chaperones 6: 201-208.

Lindquist, S. and Craig, E. A. 1988. The heat-shock proteins. Annual Review of Genetics 22: 631-677. 
MacRae, T. H. 2000. Structure and function of small heat shock/ $\alpha$-crystallin proteins: established concepts and emerging ideas. Celular and Molecular Life Sciences 57: 899-913.

Manwell, L. A. and Heikkila, J. J. 2007. Examination of KNK437- and quercetin-mediated inhibition of heat shock-induced heat shock protein gene expression in Xenopus laevis cultured cells. Comparative Biochemistry and Physiology, Part A. 148: 521-530.

Mao, L. and Sheldon, E. A. 2006. Developmentally regulated gene expression of the small heat shock protein Hsp27 in zebrafish embryos. Gene Expression Patterns 6: 127-133.

Masui, Y. and Markert, C. L. 1971. Cytoplasmic control of nuclear behavior during meiotic maturation of frog oocytes. Journal of Experimental Zoology 177: 129-146.

Mauk, R., Jaworski, D., Kamei, N. and Glabe, C. G. 1997. Identification of a 97-kDa heat shock protein from S. franciscanus ovaries with $94 \%$ amino acid identity to the S. purpuratus egg surface receptor for sperm. Developmental Biology 184: 31-37.

Miskovic, D. and Heikkila, J. J. 1999. Constitutive and stress-inducible expression of the endoplasmic reticulum heat shock protein 70 gene family member, immunoglobulin-binding protein (BiP), during Xenopus laevis early development. Developmental Genetics 25: 31-39.

Miskovic, D., Salter-Cid, L., Ohan, N., Flajnik, M. and Heikkila, J. J. 1997. Isolation and characterization of a cDNA encoding a Xenopus immunoglobulin binding protein, BiP (Grp78). Comparative Biochemistry and Physiology 116B: 227-234.

Mohun, T. J., Brennan, S., Dathanm, N., Fairman, S. and Gordon, J. B. 1983. Cell type-specific activation of actin genes in the early amphibian embryo. Nature 311: 716-721.

Morimoto, R. I. 1998. Regulation of heat shock transcriptional response: cross talk between a family of heat shock factors, molecular chaperones, and negative regulators. Genes \& Development 12: 3788-3796.

Morimoto, R. I. and Milarski, K. L. 1990. Expression and function of vertebrate hsp70 genes. In: Stress proteins in biology and medicine. R. Morimoto, A Tissieres and C. Georgopoulos (Eds). Cold Spring Harbor Press, Cold Spring Harbor.

Morimoto, R. I., Jurivich, D. A., Kroeger, P. E., Mathur, S. K., Murphy, S. P., Nakai, A., Sarge, K., Abravaya, K. and Sistonen, L. T. 1994a. Regulation of heat shock gene transcription by a family of heat shock factors. In "The biology of heat shock proteins and molecular chaperones" (Morimoto, R. I., Tissières, A., and Georgopoulos, C., Eds.), pp. 417-455, Cold Spring Harbor Laboratory Press, New York.

Morimoto, R. I., Tissières, A. and Georgopoulos, C. 1994b. Progress and perspectives on the biology of heat shock proteins and molecular chaperones. In "The biology of heat shock proteins and molecular chaperones" 
(Morimoto, R. I., Tissières, A., and Georgopoulos, C., Eds.), pp. 1-30, Cold Spring Harbor Laboratory Press, New York.

Morrow, G., Heikkila, J. J. and Tanguay, R. M. 2006. Differences in the chaperone-like activities of the four main small heat shock proteins of Drosophila melanogaster. Cell Stress and Chaperones 11: 51-60.

Mosser, D. D., Caron, A. W., Bourget, L., Meriin, A. B., Sherman, M. Y., Morimoto, R. I. and Massie, B. 2000. The chaperone function of hsp70 is required for protection against stress-induced apoptosis. Molecular and Cellular Biology 20: 7146-7159.

Mosser, D. D., Theodorakis, N. G. and Morimoto, R. I. 1988. Coordinate changes in heat shock elementbinding activity and hsp70 gene transcription rates in human cells. Molecular and Cellular Biology 8: 47364744.

Mosser, D. D., Kotzbauer, P. T., Sarge, K. D. and Morimoto, R. I. 1990. In vitro activation of heat shock transcription factor DNA-binding by calcium and biochemical conditions that affect protein conformation. Proceedings of the National Academy of Sciences 87: 3748-3752.

Mulligan-Tuttle, A. and Heikkila, J. J. 2007. Expression of the small heat shock protein gene, hsp30, in Rana catesbiana fibroblasts. Comparative Biochemistry and Physiology, Part A 148: 308-316.

Mukai, H., Kuno, T., Tanaka, H., Hirata, D., Miyakawa, T. and Tanaka, C. 1993. Isolation and characterization of SSE1 and SSE2, new members of the yeast Hsp70 multigene family. Gene 132: 57-66.

Nakai, A., Tanabe, M., Kawazoe, Y., Inazawa, J., Morimoto, R. and Nagata, K. 1997. HSF4, a new member of the human heat shock factor family which lacks properties of a transcriptional activator. Molecular and Cellular Biology 17: 469-481.

Newport, J. W. and Kirschner, M. W. 1982a. A major developmental transition in early Xenopus embryos. I. Characterization and timing of cellular changes at the midblastula stage. Cell 30: 675-686.

Newport, J. W. and Kirschner, M. W. 1982b. A major developmental transition in early Xenopus embryos. II. Control of the onset of transcription. Cell 30: 687-696.

Nieuwkoop, P. D. and Faber, J. 1994. "Normal table of Xenopus laevis," Garland Publishing, New York.

Nonoguchi, K., Itoh, K., Xue, J. H., Tokuchi, H., Nishiyama, H., Kaneko, Y., Tatsumi, K., Okuno, H., Tomiwa, K. and Fujita, J. 1999. Cloning of human cDNAs for Apg-1 and Apg-2, members of the Hsp110 family, and chromosomal assignment of their genes. Gene 237: 21-28.

Norris, C. E., Brown, M. A., Hickey, E., Weber, L. A. and Hightower, L. E. 1997. Low-molecular-weight heat shock proteins in a desert fish (Poeciliopsis lucida): homologs of human Hsp27 and Xenopus Hsp30.

Molecular Biology and Evolution 14: 115-129. 
Nover, L. 1991. Inducers of HSP synthesis: heat shock and chemical stressors. In "Heat shock response" pp. 540, CRC Press, Inc., Boca Raton.

Oh, H. J., Chen, X. and Subjeck, J. R. 1997. hsp110 protects heat-denatured proteins and confers cellular thermoresistance. Journal of Biological Chemistry 272: 31636-31640.

Oh, H. J., Easton, D., Murawski, M., Kaneko, Y. and Subjeck, J. R. 1999. The chaperoning activity of hsp110. Journal of Biological Chemistry 274: 15712-15718.

Ohan, N. and Heikkila, J. J. 1995. Involvement of differential gene expression and mRNA stability in the developmental regulation of the Hsp 30 gene family in heat-shocked Xenopus laevis embryos.

Developmental Genetics 17: 176-184.

Ohan, N. W., Tam, Y., Fernando, P. and Heikkila, J. J. 1998. Characterization of a novel group of basic small heat shock proteins in Xenopus laevis A6 kidney epithelial cells. Biochemistry and Cell Biology 76: 665671.

Ovakim, D. H. and Heikkila, J. J. 2003. Effect of histone deacetylase inhibitors on heat shock protein gene expression during Xenopus development. Genesis 36: 88-96.

Ovelgonne, H., Bitorina, M. and Van Wijk, R. 1995. Stressor-specific activation of heat shock genes in H35 rat hepatoma cells. Toxicology and Applied Pharmacology 135: 100-109.

Parcellier, A., Gurbuxani, S., Schmitt, E., Solary, E. and Garrido, C. 2003. Heat shock proteins, cellular chaperones that modulate mitochondrial cell death pathways. Biochemical and Biophysical Research Communications 304: 505-512.

Parsell, D. A. and Lindquist, S. 1993. The function of heat shock proteins in stress tolerance: degradation and reactivation of damaged proteins. Annual Review of Genetics 27:437-496.

Pirkkala, L., Nykänen, P. and Sistonen, L. 2001. Roles of the heat shock transcription factors in regulation of the heat shock response and beyond. FASEB Journal 15: 1118-1131.

Plesofsky-Vig, N. and Brambl, R. 1998. Characterization of an 88-kDa heat shock protein of Neurospora crassa that interacts with hsp30. Journal of Biological Chemistry 273: 11335-11341.

Rafferty, K. A. 1965. Mass culture of amphibian cells: Methods and observations concerning stability of cell type. In "Biology of amphibian tumors" pp. 52-81, Springer-Verlag, Berlin.

Raviol, H., Bukau, B. and Mayer, M. P. 2006. Human and yeast Hsp110 chaperones exhibit functional differences. FEBS Letters 580: 168-174.

Ritossa, F. 1962. A new puffing pattern induced by heat shock and DNP in Drosophila. Experentia 18: 571573. 
Saito, Y., Yamagishi, N., Ishihara, K. and Hatayama, T. 2003. Identification of $\alpha$-tubulin as an Hsp105 $\alpha-$ binding protein by the yeast two-hybrid system. Experimental Cell Research 286: 233-240.

Saito, Y., Yamagishi, N. and Hatayama, T. 2007. Different localization of Hsp105 family proteins in mammalian cells. Experimental Cell Research 313: 3707-3717.

Sambrook, J. and Russell, D. W. 2001. "Molecular Cloning," Cold Spring Harbor Laboratory Press, New York.

Sarge, K.D. 1995. Male germ cell-specific alteration in temperature set point of the cellular stress response. Journal of Biological Chemistry 270: 18745-18748.

Satoh, J., Yukitake, M. and Kuroda, Y. 1998. Constitutive and heat-inducible expression of HSP105 in neurons and glial cells in culture. NeuroReport 9: 2977-2983.

Shaner, L., Trott, A., Goeckeler, J. L., Brodsky, J. L. and Morano, K. A. 2004. The function of the yeast molecular chaperone Sse1 is mechanistically distinct from the closely related Hsp70 family. Journal of Biological Chemistry 279: 21992-22001.

Shi, Y. and Thomas, J. O. 1992. The transport of proteins into the nucleus requires the 70-kilodalton heat shock protein or its cytosolic cognate. Molecular and Cellular Biology 12: 2186-2192.

Shinga, J., Kashiwagi, K., Tashiro, K., Igarashi, K. and Shiokawa, K. 1996. Maternal and zygotic expression of mRNA for $S$-adenosylmethionine decarboxylase and its relevance to the unique polyamine composition in Xenopus oocytes and embryos. Biochimica et Biophysica Acta 1308: 31-40.

Shiokawa, K. 1991. Gene expression from endogenous and exogenously-introduced DNAs in early embryogenesis of Xenopus laevis. Development, Growth \& Differentiation 33: 1-8.

Sive, H. L., Grainger, R. M. and Harland, R. M. 2000. "Early development of Xenopus laevis," Cold Spring Harbor Laboratory Press, New York.

Smith, J. C. and Tata, J. R. 1991. Xenopus cell lines. In "Methods in cell biology" 36, pp. 635-654, Academic Press, Inc., England.

Sõti, C., Nagy, E., Giricz, Z., Vigh, L., Csermely, P. and Ferdinandy, P. 2005. Heat shock proteins as emerging therapeutic targets. British Journal of Pharmacology 146: 769-780.

Sreedhar, A. S. and Csermely, P. 2004. Heat shock proteins in the regulation of apoptosis: new strategies in tumor therapy: a comprehensive review. Pharmacology \& Therapeutics 101: 227-257.

Stump, D. G., Landsberger, N. and Wolffe A. P. 1995. The cDNA encoding Xenopus laevis heat-shock factor 1 (XHSF1): nucleotide and deduced amino-acid sequences, and properties of the encoded protein. Gene 160: 207-211. 
Subjeck, J. R., Sciandra, J. J., Chao, C. F. and Johnson, R. J. 1982a. Coexpression of thermotolerance and heat shock proteins in mammalian cells. In "Heat shock: from bacteria to man" (Schlesinger, M., Ashburner, M., and Tissières, A., Eds.), pp. 405-411, Cold Spring Harbor Laboratory Press, New York.

Subjeck, J. R., Sciandra, J. J., Chao, C. F. and Johnson, R. J. 1982b. Heat shock proteins and biological response to hyperthermia. British Journal of Cancer 45: 127-131.

Subjeck, J. R., Sciandra, J. J. and Johnson, R. J. 1982c. Heat shock proteins and thermotolerance: a comparison of induction kinetics. British Journal of Radiology 55: 579-584

Subjeck, J. R., Shyy, T., Shen, J. and Johnson, R. J. 1983. Association between the mammalian 110,000-dalton heat-shock protein and nucleoli. Journal of Cell Biology 97: 1389-395.

Thériault, J. R., Lambert, H., Chavez-Zobel, A. T., Charest, G., Lavigne, P. and Landry, J. 2004. Essential role of the NH1-terminal WD/EPF motif in the phosphorylation-activated protective function of mammalian Hsp27. Journal of Biological Chemistry 279: 23463-23471.

Thompson, J. D., Higgins, J. G. and Gibson, T. J. 1994. CLUSTAL W: improving the sensitivity of progressive multiple sequence alignment through sequence weighting, position-specific gap penalties and weight matrix choice. Nucleic Acids Research 22: 4673-4680.

Tomosovic, S. P., Steck, P. A. and Heitzman, D. 1983. Heat stress proteins and thermal resistance in rat mammary tumor cells. Radiation Research 95: 399-413.

Van de Klundert, F. A., Gijsen, M. L., van den Ijssel, P. R., Snoeckx, L. H. and de Jong, W. W. 1998. alpha Bcrystallin and hsp25 in neonatal cardiac cells - differences in cellular localization under stress conditions. European Journal of Cell Biology 75: 38-45.

van Montfort, R., Slingsby, C. and Vierling, E. 2002. Structure and function of the small heat shock protein $\alpha$ crystallin family of molecular chaperones. Advances in Protein Chemistry 59: 105-156.

Voellmy, R. 2004. On mechanisms that control heat shock transcription factor activity in metazoan cells. Cell Stress and Chaperones 9: 122-133.

Wang, Z. and Lindquist, S. 1998. Developmentally regulated nuclear transport of transcription factors in Drosophila embryos enable the heat shock response. Development 125: 4841-4850.

Weigant, F. A., Souren, J. E., van Rijn, J. and van Wijk, R. 1994. Stressor-specific induction of heat shock proteins in rat hepatoma cells. Toxicology 94: 143-159.

Westwood, J. T., Clos, J. and Wu, C. 1991. Stress-induced oligomerization and chromosomal relocalization of heat-shock factor. Nature 353: 822-827. 
Wieske, M., Benndorf, R., Behlke, J., Dölling, R., Grelle, G., Bielka, G. and Lutsch, G. 2001. Defined sequence segments of the small heat shock proteins HSP25 and $\alpha \beta$-crystallin inhibit actin polymerization. European Journal of Biochemistry 268: 2083-2090.

Yagita, Y., Kitagawa, K., Taguchi, A., Ohtsuki, T., Kuwabara, K., Mabuchi, T., Matsumoto, M., Yanagihara, T. and Hori, M. 1999. Molecular cloning of a novel member of the HSP110 family of genes, ischemiaresponsive protein $94 \mathrm{kDa}$ (irp94), expressed in rat brain after transient forebrain ischemia. Journal of Neurochemistry 72: 1544-1551.

Yamagishi, N., Ishihara, K., Saito, Y. and Hatayama, T. 2006. Hsp105 family proteins suppress staurosporineinduced apoptosis by inhibiting the translocation of Bax to mitochondria in HeLa cells. Experimental Cell Research 312: 3215-3223.

Yamagishi, N., Saito, Y., Ishihara, K. and Hatayama, T. 2002. Enhancement of oxidative stress-induced apoptosis by Hsp105 $\alpha$ in mouse embryonal F9 cells. European Journal of Biochemistry 269: 4143-4151.

Yasuda, K., Ishihara, K., Nakashima, K. and Hatayama, T. 1999. Genomic cloning and promoter analysis of the mouse 105-kDa heat shock protein (HSP105) gene. Biochemical and Biophysical Research Communications 256: $75-80$.

Yasuda, K., Nakai, A., Hatayama, T. and Nagata, K. 1995. Cloning and expression of murine high molecular mass heat shock proteins, HSP105. Journal of Biological Chemistry 270: 29718-29723.

Yost, H. J. and Lindquist, S. 1986. RNA splicing is interrupted by heat shock and is rescued by heat shock protein synthesis. Cell 45: 185-193. 